\title{
The dominant Anopheles vectors of human malaria in the Asia-Pacific region: occurrence data, distribution maps and bionomic précis
}

\author{
Marianne E Sinka ${ }^{{ }^{*}}$, Michael J Bangs ${ }^{2}$, Sylvie Manguin ${ }^{3}$, Theeraphap Chareonviriyaphap ${ }^{4}$, Anand P Patil ${ }^{1}$, \\ William H Temperley ${ }^{1}$, Peter W Gething ${ }^{1}$, Iqbal RF Elyazar ${ }^{5}$, Caroline W Kabaria ${ }^{6}$, Ralph E Harbach ${ }^{7}$ and \\ Simon I Hay ${ }^{1,6^{*}}$
}

\begin{abstract}
Background: The final article in a series of three publications examining the global distribution of 41 dominant vector species (DVS) of malaria is presented here. The first publication examined the DVS from the Americas, with the second covering those species present in Africa, Europe and the Middle East. Here we discuss the 19 DVS of the Asian-Pacific region. This region experiences a high diversity of vector species, many occurring sympatrically, which, combined with the occurrence of a high number of species complexes and suspected species complexes, and behavioural plasticity of many of these major vectors, adds a level of entomological complexity not comparable elsewhere globally. To try and untangle the intricacy of the vectors of this region and to increase the effectiveness of vector control interventions, an understanding of the contemporary distribution of each species, combined with a synthesis of the current knowledge of their behaviour and ecology is needed.
\end{abstract}

Results: Expert opinion (EO) range maps, created with the most up-to-date expert knowledge of each DVS distribution, were combined with a contemporary database of occurrence data and a suite of open access, environmental and climatic variables. Using the Boosted Regression Tree (BRT) modelling method, distribution maps of each DVS were produced. The occurrence data were abstracted from the formal, published literature, plus other relevant sources, resulting in the collation of DVS occurrence at 10116 locations across 31 countries, of which 8853 were successfully geo-referenced and 7430 were resolved to spatial areas that could be included in the BRT model. A detailed summary of the information on the bionomics of each species and species complex is also presented.

Conclusions: This article concludes a project aimed to establish the contemporary global distribution of the DVS of malaria. The three articles produced are intended as a detailed reference for scientists continuing research into the aspects of taxonomy, biology and ecology relevant to species-specific vector control. This research is particularly relevant to help unravel the complicated taxonomic status, ecology and epidemiology of the vectors of the Asia-Pacific region. All the occurrence data, predictive maps and EO-shape files generated during the production of these publications will be made available in the public domain. We hope that this will encourage data sharing to improve future iterations of the distribution maps.

\footnotetext{
* Correspondence: marianne.sinka@gmail.com; simon.hay@zoo.ox.ac.uk ${ }^{1}$ Spatial Ecology and Epidemiology Group, Tinbergen Building, Department of Zoology, University of Oxford, South Parks Road, Oxford OX1 3PS, UK Full list of author information is available at the end of the article
} 


\section{Background}

The Asian-Pacific region experiences a notably high diversity of vector species, species complexes and suspected species complexes, many occurring sympatrically and exhibiting a high level of behavioural plasticity [1]. This complexity, and the taxonomic ambiguity of many of the dominant vector species (DVS) of the region, is a major contributing factor to the continuing impact of malaria in this area.

Second only to Africa, central and southeastern Asia suffers with $39 \%$ of the global malaria burden (estimated clinical cases of P. falciparum malaria only) [2], with pockets of medium to high endemicity found in Orissa State (eastern India), western Myanmar and the lowlands of New Guinea [3]. The impact of Plasmodium vivax is also considerable, with an estimated $41.9 \%$ of the global population at risk (PAR) of $P$. vivax transmission occurring in India alone. Seven other Asian nations (China, Indonesia, Pakistan, Vietnam, the Philippines, Myanmar and Thailand) are also listed within the top 10 countries with the highest $P$. vivax PAR estimates [4].

Of 41 DVS recognised globally [5], 19 occur in the Asian-Pacific region and of these, at least ten are now considered as species complexes [6] (Table 1). A species complex tends to encompass a group of closely related, morphologically indistinguishable species, which may occur in sympatry (but not interbreeding), yet still display behavioural differences that could confound any control efforts that ignore their bionomics and epidemiological importance $[7,8]$. Moreover, even amongst those species that are not members of a complex, behavioural differences are common depending upon location, such that a species can be considered a primary vector in one area, but of secondary or no importance elsewhere [8].

The correct identification of any vector implicated in malaria transmission is key to successful control. For example, in central Vietnam, where members of both the An. dirus and An. minimus species complexes were considered primary vectors, control was targeted twice a year to precede the period of malaria transmission attributed to each species complex. However, Van Bortel et al. [9], discovered that the mosquitoes previously identified as An. minimus were actually An. varuna (a member of the Funestus Group that also includes the Minimus Complex). Anopheles varuna is highly zoophilic in the study area and therefore a non-vector. This misidentification resulted in the misdirection of valuable and limited resources and highlights common difficulties in vector control in the Asian-Pacific region where the close relationship and sympatric distributions of many of the species can result in the application of

Table 1 Defining the dominant Anopheles vector species and species complexes of human malaria in the Asia-Pacific region.

\begin{tabular}{|c|c|c|c|c|c|c|}
\hline $\begin{array}{l}\text { Anopheline species or species } \\
\text { complex }\end{array}$ & $\begin{array}{l}\text { White } \\
\text { [32] }\end{array}$ & $\begin{array}{c}\text { Service } \\
{[522,523]}\end{array}$ & $\begin{array}{l}\text { Kiszewski } \\
{[524]}\end{array}$ & $\begin{array}{l}\text { Mouchet } \\
\text { [525] }\end{array}$ & $\begin{array}{c}\text { Malaria } \\
\text { epidemiology zone } \\
\text { (Bangs, unpub obs) }\end{array}$ & EO source \\
\hline An. aconitus & $y$ & $y$ & & $y$ & $8,9,10$ & {$[32]+$ TAG } \\
\hline An. annularis & & & y & & $8,9,10$ & TAG \\
\hline An. balabacensis & y & y & & y & 10 & {$[28,32]+\mathrm{TAG}$} \\
\hline An. barbirostris* & & & y & & $8,9,10$ & {$[29,32]+\mathrm{TAG}$} \\
\hline An. culicifacies* & y & y & y & y & $6(?), 7,8,9,10(?)$ & {$[8,32]+$ TAG } \\
\hline An. dirus* & y & y & y & y & 9,10 & {$[8,29,32]+$ TAG } \\
\hline An. farauti* & y & y & & y & 12 & {$[32]+\mathrm{TAG}$} \\
\hline An. flavirostris & & y & y & y & 10 & {$[32]+\mathrm{TAG}$} \\
\hline An. fluviatilis* & $y$ & y & y & y & 8,9 & {$[8,32]+\mathrm{TAG}$} \\
\hline An. koliensis & & y & & y & 12 & {$[32]+\mathrm{TAG}$} \\
\hline An. lesteri & & y & y & y & $9(?), 10$ & Harbach (unpub obs) + TAG \\
\hline An. leucosphyrus \& An. latens & y & y & & & 10 & {$[8,28,32]+\mathrm{TAG}$} \\
\hline An. maculatus group & y & y & y & y & $8,9,10$ & {$[8,32]+\mathrm{TAG}$} \\
\hline An. minimus* & y & y & y & y & $8,9,10$ & {$[8,32]+\mathrm{TAG}$} \\
\hline An. punctulatus* & & y & y & y & 12 & {$[32]+\mathrm{TAG}$} \\
\hline An. sinensis* & y & y & y & y & $4(?), 8(?), 9,10,11$ & {$[32]+\mathrm{TAG}$} \\
\hline An. stephensi & & & y & y & $6(?), 8,9$ & {$[32]+\mathrm{TAG}$} \\
\hline An. subpictus* & $y$ & $y$ & & & $8,9,10,12$ & TAG \\
\hline An. sundaicus* & y & y & y & y & 9(?), 10 & {$[8,25]+\mathrm{TAG}$} \\
\hline
\end{tabular}

An asterisk $\left({ }^{*}\right)$ denotes that a "species" is now recognised as a species complex. Macdonald's malaria epidemiology zones [521] 6, Desert; 7, Ethiopian; 8, IndoPersian; 9, Indo-Chinese Hills; 10, Malaysian; 11, Chinese 12, Australasian. A question mark (?) indicates uncertainty of presence in the listed zone. The final DVS species listed were defined during two separate Technical Advisory Group (TAG) meetings. 
unnecessary or unsuitable intervention methods. Moreover, in an increasingly changing environment, deforestation, the implementation of new irrigation programmes and expanding agricultural development can rapidly alter the composition of the local mosquito fauna [10-14], and subsequently influence the control methods required.

Nonetheless, vector control has proved highly successful in areas of the Asian-Pacific region with the WHO reporting a greater than $50 \%$ decrease in the number of malaria cases in Bhutan, the Democratic People's Republic of Korea, Sri Lanka and Thailand since 2000 [15]. This reduction is associated with intensive malaria intervention programmes, including indoor residual spraying (IRS) of insecticides and the distribution of insecticide-treated bednets (ITNs). Successful control has also been implemented to take advantage of speciesspecific behaviour, for example the introduction of small larvivorous fish into the intra-domestic water containers that served as larval habitats for the 'urban vector' $A n$. stephensi [16].

The DVS of the Asian-Pacific region have been the subject of a number of comprehensive reviews (e.g. [7,8,17-26]) and attempts to establish their distribution ranging from simple maps identifying sampling locations (e.g. [18,27-31]), expert opinion maps (e.g. $[8,25,32,33])$, GIS overlays (e.g. [18,34-38]) and those employing methods to predict species distributions (e.g. [39-42]). Surprisingly few attempts have been made with the application of more sophisticated modelling methods to the DVS of Asia, essentially only those of Foley et al. $[39,41,42]$.

This current work presents predicted distribution maps for the 19 DVS of the Asian-Pacific region, created using the Boosted Regression Tree (BRT) methodology and applied to a comprehensive database of contemporary (post 31 December 1984) occurrence data. The modelling method also benefits from the inclusion of updated expert opinion (EO) ranges for each species or species complex, specifically useful for those species with limited occurrence records. The predictive maps are presented alongside a bionomics summary of each species/species complex, highlighting the complexity of many of the species that occur in this region.

\section{Methods}

An introduction to the MAP DVS project, including details on DVS selection, is given in Hay et al. [5]. A full description of the DVS bionomics and occurrence data assembly, modelling and mapping protocols, and climatic and environmental variable grid pre- and post-processing, is provided in Sinka et al. [43].
From a list of 41 DVS recognised globally, 19 species or species complexes are found within the Asian-Pacific region (Table 1). These species range from the Arabian Peninsula (e.g. An. stephensi and the An. culicifacies complex) across the Indian subcontinent, north into China and Korea (e.g. An. lesteri) and as far west as the Solomon Islands and Vanuatu (e.g. the An. farauti complex) and south into Queensland and the Northern Territory of Australia (e.g. the An. farauti complex).

\section{Data assembly, data checks and expert opinion maps}

A systematic search of the published, peer-reviewed scientific and medical literature, using online bibliographic databases $[44,45]$, was conducted and augmented with a range of focussed searches of other relevant data sources [46-49]. Searches were concluded on 31 October 2009, and all literature containing data meeting our search criteria [43] were reviewed. Following the protocol described in Hay et al. [5], data were extracted and processed through a series of rigorous checking procedures before migration into a web-based PostgreSQL database, where a final series of checks were conducted [43].

A total of 3857 publications and reports were amalgamated for review. Of these, 2276 fulfilled the inclusion criteria $[5,43]$, culminating in the assembly of DVS occurrence data for 147 countries. The 19 Asian-Pacific species and species complexes were distributed across 31 countries from data abstracted from 875 sources.

Preliminary maps were produced by overlaying occurrence data points over expert opinion (EO, see Table 1) species distribution ranges (Additional file 1: Expert opinion distribution maps for the 19 DVS of the AsianPacific region (Raster prediction files are available on request)). These maps were examined and refined by a technical advisory group (TAG, see acknowledgments) of Anopheles experts, and any data points that had fallen outside of the known EO ranges were checked and, where necessary, the EO ranges were adjusted to incorporate any confirmed areas of species presence.

\section{Boosted Regression Trees, climatic/environmental variables and model protocol}

The Boosted Regression Tree method uses open access, reliable and well-supported $\mathrm{R}$ code and benefits from a flexibility that allows it to utilise both categorical and continuous data [50-52]. The maps produced are easy to interpret and are accompanied by a clear ranking of each environmental or climatic predictor variable identified by the model as relevant to the distribution of the species being mapped (see below). Moreover, in a review that rigorously tested 16 species modelling methods, BRTs were shown to consistently perform well [53]. The 
BRT method is described in detail in Elith et al. [50] and summarised in Sinka et al. [43] with specific reference to its implementation in DVS mapping. The evaluation statistics produced using this method (Deviance, Correlation, Discrimination (Area Under the operating characteristic Curve: AUC) and Kappa $(\kappa))$ were used to guide the assessment of the predictive performance of the models.

A suite of open access, environmental and climatic variable $5 \times 5 \mathrm{~km}$ resolution grids, relevant to the ecology and biology of the DVS, were assembled. These included a digital elevation model (DEM) [54-56], precipitation $[57,58]$, land surface temperature (LST), middle infra-red radiation (MIR) and the Normalized Difference Vegetation Index (NDVI) (Advanced Very High Resolution Radiometer (AVHRR) [59-62]) plus 22 individual categories of land cover including three grouped classes: flooded areas, forested areas and dry areas (Globcover [63] (A full list of the variables applied is given in Additional file 2: Summary tables showing evaluation statistics for all mapping trials and final BRT environmental and climatic variable selections for the final, optimal predictive maps). Each grid underwent a series of processing steps to ensure all land and sea pixels exactly corresponded. Nearest-neighbour interpolation was used to fill in any small gaps in the data, for example, those areas obscured by cloud cover. Temporal Fourier analysis was applied to all multi-temporal data to generate seven products: the overall mean, maximum and minimum of the data cycles, the amplitude (maximum variation of the cycle around the mean) and the phase (timing of the cycle) of the annual and bi-annual cycles [64].

A detailed protocol describing the modelling procedures followed to attain the 'optimal' mapping outputs are given in Sinka et al. [43]. Briefly, these included running a series of model iterations to assess the effects of incorporating half-weighted pseudo-presence data (randomly allocated from within the known EO range of each DVS), the number of pseudo-absences required and the extent of buffer from which they should be drawn. The buffer was established by extending the range limit of the EO maps to provide an area of terrain next to the known range of each DVS, and therefore close to the feasible range of conditions for the species to exist. Pseudo-absences were assigned within the buffer area at random. The evaluation metrics provided by the BRT could only be used as a guide to the predictive performance of each series of maps, as each iteration was created using different data inputs. Thus the 'optimal' settings chosen should be considered as subjective, as they were based on a combination of visual assessment guided by, but not relying on, the evaluation metrics.

\section{Bionomics}

A bionomics summary of each of the Asian-Pacific DVS is provided to accompany the predictive maps. The large geographic ranges, presence of a relatively high proportion of identified and suspected species complexes and a level of behavioural plasticity amongst many of the DVS across this region, adds a level of complexity to summarising each of the species' behaviour. However, understanding their bionomics is crucial to the success of any interventions applied to control these malaria vectors. The review provided here does address some of the complexities, but is a general summary provided with the caveat that local expertise should always be additionally consulted when evaluating the possible vector control methods to be applied in specific locations.

The bionomics summaries do not include a detailed assessment of insecticide resistance amongst the DVS of the Asian-Pacific region. Whilst resistance appears widespread in many of the species, and is therefore an important aspect that must be considered before the application of any chemical-based control intervention, it was not possible to do full justice to this area of vector biology within the confines of this current work. However, insecticide resistance is being addressed by a number of other research groups and projects (e.g. MALVECASIA $[65,66])$ and a number of recent publications (e.g. [23,67-77]) provide detailed information that should be considered alongside this current work.

The full protocol applied to extracting bionomics data from the available literature (Table 2) is provided in the supplemental information accompanying Sinka et al. [43]. Due to the large number of studies available for some of the DVS in this region, an additional filtering step was necessary to maintain a reasonable sized data source for summary. Where the number of citations remained significantly high (>100) after following the steps outlined in Sinka et al. [43], which included filtering the literature using the terms 'behaviour', 'larva', 'biting' etc., the remaining citations were manually searched to provide a minimum of 30 articles, ensuring the most recent studies that examined all the relevant bionomics were included in the summary.

\section{Results}

The presence of one or more Asian-Pacific DVS was reported by 875 sources from 10116 independent sites, of which 8853 were successfully geo-referenced. These data related to 19110 occurrences (i.e. a study that sampled at one site on one occasion results in one occurrence and one site, a study that samples every month for a year at the same site results in one site but 12 occurrences) of which 15410 were from geo-referenced locations (Table 3). 
Table 2 Search results for bionomics survey for the 19 Asian and Pacific DVS.

\begin{tabular}{|c|c|}
\hline Species & References \\
\hline An. aconitus & {$[10,100,154,156-158,161,163,164,174-177,179,181,182,186,187,189-191]$} \\
\hline An. annularis & {$[10,12,13,92,154,156-158,161,163-165,174,179,182,186,187,189-191,215,216,230,262,301,304,478,479,481,482,487,490,526-528]$} \\
\hline An. balabacensis & {$[11,221,222,227,230,232,237,308,529]$} \\
\hline An. barbirostris* & {$[10,12,92,100,154,156-158,161,163,164,174,177,179,182,186,187,189-191,215,247,262,349,472,479,481,482,487,528-531]$} \\
\hline An. culicifacies* & {$[10,12,13,156-158,161,163,164,186,190,191,215,216,252,262,322,472,479,481,482,487,490,526,527,530-542]$} \\
\hline An. dirus* & {$[9,35,155,175,181,182,189,215,275,278,280-282,284,285,289-294,348,349,351,533,543-553]$} \\
\hline An. farauti* & {$[30,31,371,381,389-391,397,408,409,411,413,420,554-563]$} \\
\hline An. flavirostris & {$[174,187,227,230,296,301,303-305,307,308]$} \\
\hline An. fluviatilis* & {$[156-158,161,163,191,203,216,283,294,316,319-324,490,537,564-566]$} \\
\hline An. koliensis & {$[31,383,386,391,402,406,408,412,425,561,567,568]$} \\
\hline An. lesteri & {$[36,121,467,485,569-573]$} \\
\hline $\begin{array}{l}\text { An. leucosphyrus \& An. } \\
\text { latens }\end{array}$ & {$[221,329]$} \\
\hline An. maculatus group & {$[40,92,100,155,156,158,174-177,181,182,187,189,215,247,281,283,284,304,305,319,343,348,349,472,546,553,574-576]$} \\
\hline An. minimus* & {$[27,35,40,143,150,155,181,182,189,215,247,281,283,294,348-351,360,364,369,528,533,545-548,577-580]$} \\
\hline An. punctulatus* & {$[31,371,381,386,389-391,401,403,408,411-413,425,581,582]$} \\
\hline An. sinensis* & {$[14,36,100,121,128,138,139,141-143,177,181,182,189,467,485,569,573,583-587]$} \\
\hline An. stephensi & {$[16,161,163,190,191,322,428,438,440-443,464,476,479,487,489,490,527,542,588-597]$} \\
\hline An. subpictus* & {$[10,12,13,16,154,156-158,161,163-165,179,186,190,191,230,252,262,452,458,467,470,472,474,476,478-490,527,598]$} \\
\hline An. sundaicus* & {$[181,187,461,486,497,505,518,529,599-603]$} \\
\hline
\end{tabular}

Focussing only on the geo-referenced data, 7430 sites (12353 occurrences) were reported at a resolution that could be applied to the BRT models, including 6952 points $\left(<10 \mathrm{~km}^{2}\right)$ and 478 wide-areas (between $10-25$ $\mathrm{km}^{2}$ ). Data from small and large polygons $\left(25-100 \mathrm{~km}^{2}\right.$ and $>100 \mathrm{~km}^{2}$ respectively) were not used in the BRT models.

Of the 31 countries with a reported presence of one or more of the 19 DVS, the greatest number of sites were across Myanmar, including 1791 mappable locations (i.e. both points and wide areas collectively, henceforth referred to as 'points'). The greatest number of occurrences (3935) were reported from India; however, this included a very high number reported from polygons (2002), so the number of occurrences from points (1933) was subsequently lower than those from Myanmar (2724 points from 2777 total occurrences) (Table 3). Four countries only had a single site where DVS presence was reported (Singapore: An. maculatus subgroup, TimorLeste: An. subpictus complex, Turkey: An. barbirostris and United Arab Emirates: An. stephensi).

The An. farauti complex was reported from the greatest number of independent sites, of which 1465 were points (Table 4). This was due, in part, to the inclusion of two comprehensive surveys in Papua New Guinea (PNG) [31] and northern Australia [30], which provided a total of 846 points. Anopheles leucosphyrus/An. latens were identified from the fewest number of locations (14, of which 12 were points), with An. balabacensis also reported from relatively few sites (17, of which 14 were points) (Table 4).

Myanmar appeared to contain the greatest number of DVS, with 10 species recorded at 16 sites. These included the concurrent presence of An. aconitus, An. annularis, An. barbirostris complex, An. culicifacies complex, An. dirus complex, Maculatus Group, An. minimus complex, An. sinensis complex, An. stephensi (replaced by An. sundaicus complex in some coastal sites) and An. subpictus complex [22,78].

Larval collection was by far the most popular sampling method employed in the capture of the DVS from the Asian-Pacific region with 199 sources reporting this sampling method from 2123 sites. A total of 84 sources did not mention the sampling methods used at one or more of their sampled sites (1349 sites).

Of those studies that described the methodologies applied in species identification, morphological examination was the most common and was used on samples from 3766 sites, reported from 265 sources.

\section{Mapping trials}

The mapping trials, evaluated visually and guided by the statistical metric output of the BRT models, indicated that the 'optimal' output for the Asian Pacific species 
Table 3 Geo-referenced independent site and occurrence (includes multiple sampling at a single site) data for the 19 Asian-Pacific species by country.

\begin{tabular}{|c|c|c|c|c|c|c|}
\hline \multirow[b]{2}{*}{ Country } & \multicolumn{3}{|c|}{ Site } & \multicolumn{3}{|c|}{ Occurrence } \\
\hline & All & Data & Polygons & All & Data & Polygons \\
\hline Afghanistan & 14 & 1 & 13 & 55 & 1 & 54 \\
\hline Australia & 505 & 493 & 12 & 658 & 645 & 13 \\
\hline Bangladesh & 35 & 14 & 21 & 39 & 18 & 21 \\
\hline Cambodia & 43 & 37 & 6 & 46 & 40 & 6 \\
\hline China & 355 & 160 & 195 & 665 & 328 & 337 \\
\hline Eritrea & 1 & 1 & 0 & 1 & 1 & 0 \\
\hline India & 1529 & 673 & 856 & 3935 & 1933 & 2002 \\
\hline Indonesia & 890 & 865 & 25 & 931 & 906 & 25 \\
\hline Iran & 59 & 49 & 10 & 161 & 120 & 41 \\
\hline Iraq & 4 & 1 & 3 & 4 & 1 & 3 \\
\hline Japan & 7 & 6 & 1 & 10 & 9 & 1 \\
\hline Korea, Democratic People's Republic of & 30 & 30 & 0 & 44 & 44 & 0 \\
\hline Korea, Republic of & 242 & 234 & 8 & 319 & 267 & 52 \\
\hline Lao People's Democratic Republic & 139 & 121 & 18 & 210 & 192 & 18 \\
\hline Malaysia & 145 & 132 & 13 & 317 & 297 & 20 \\
\hline Myanmar & 1830 & 1791 & 39 & 2777 & 2724 & 53 \\
\hline Nepal & 33 & 33 & 0 & 263 & 263 & 0 \\
\hline Pakistan & 54 & 41 & 13 & 209 & 144 & 65 \\
\hline Papua New Guinea & 1503 & 1487 & 16 & 1742 & 1725 & 17 \\
\hline Philippines & 124 & 113 & 11 & 188 & 147 & 41 \\
\hline Singapore & 1 & 1 & 0 & 1 & 1 & 0 \\
\hline Solomon Islands & 160 & 157 & 3 & 291 & 270 & 21 \\
\hline Sri Lanka & 303 & 273 & 30 & 1229 & 1121 & 108 \\
\hline Taiwan Province of China & 14 & 6 & 8 & 15 & 7 & 8 \\
\hline Thailand & 505 & 412 & 93 & 908 & 791 & 117 \\
\hline Timor-Leste & 1 & 1 & 0 & 1 & 1 & 0 \\
\hline Turkey & 1 & 0 & 1 & 1 & 0 & 1 \\
\hline United Arab Emirates & 1 & 1 & 0 & 1 & 1 & 0 \\
\hline Vanuatu & 36 & 33 & 3 & 36 & 33 & 3 \\
\hline Viet Nam & 275 & 255 & 20 & 334 & 314 & 20 \\
\hline Yemen & 14 & 9 & 5 & 19 & 9 & 10 \\
\hline Total & 8853 & 7430 & 1423 & 15410 & 12353 & 3057 \\
\hline
\end{tabular}

'Data' include points $\left(\leq 10 \mathrm{~km}^{2}\right)$ and wide areas $\left(10-25 \mathrm{~km}^{2}\right)$ both of which are used in the BRT model and displayed on the predictive maps (Additional file 3). 'Polygons' include small $\left(25-100 \mathrm{~km}^{2}\right)$ and large $\left(>100 \mathrm{~km}^{2}\right)$ polygons which are not included in the models or shown on the maps.

maps included a $1500 \mathrm{~km}$ buffer where pseudo-absences at a ratio of 10:1 (pseudo-absences to presence data) were randomly allocated. The 'hybrid' model, where occurrence data were supplemented with 500 halfweighted pseudo-presences allocated within the EO species range, created maps with a much greater predictive performance than those based on 1000 pseudo-presences randomly allocated in the EO range alone. Those maps produced using the occurrence data alone, without any supplemental pseudo-presences, produced the lowest, and therefore 'better' deviance values. However, on inspection, the maps were judged to be visually poorer, with less predictive value, specifically for those species with limited available data (e.g. An. leucosphyrus/An. latens, An. balabacensis). This 'hybrid' method, was also judged to provide the best maps for those DVS found in Africa, Europe, the Middle East and the Americas $[43,79]$ suggesting that, especially in areas where data is sparse, an educated addition of pseudo-presences can greatly improve the final mapping output. The results for each mapping trial conducted are provided in Additional file 2 (Additional file 2: Summary tables showing 
Table 4 Geo-referenced and non geo-referenced data by species and area type: 'Point' is all mapped data included in the BRT model: point $\left(\leq 10 \mathrm{~km}^{2}\right)$, wide areas $\left(10-25 \mathrm{~km}^{2}\right)$ and 'Polygon' details data not incorporated in BRT model: small $\left(25-100 \mathrm{~km}^{2}\right)$ and large (>100 km2) polygons, for the 19 Asian-Pacific DVS (geographically independent sites (Site) and temporal independent occurrences (Occ)).

\begin{tabular}{|c|c|c|c|c|c|c|c|c|}
\hline \multirow[b]{3}{*}{ Species } & \multicolumn{4}{|c|}{ Geo-referenced } & \multicolumn{4}{|c|}{ Non geo-referenced } \\
\hline & \multicolumn{2}{|c|}{$\begin{array}{l}\text { Point and wide } \\
\text { area ('Point') }\end{array}$} & \multicolumn{2}{|c|}{ Polygon } & \multicolumn{2}{|c|}{$\begin{array}{l}\text { Point and wide } \\
\text { area ('Point') }\end{array}$} & \multicolumn{2}{|c|}{ Polygon } \\
\hline & Site & Occ & Site & Occ & Site & Occ & Site & Occ \\
\hline An. aconitus & 424 & 616 & 74 & 115 & 42 & 54 & 32 & 67 \\
\hline An. annularis & 496 & 851 & 156 & 332 & 82 & 188 & 32 & 87 \\
\hline An. balabacensis & 14 & 42 & 3 & 3 & 4 & 9 & 2 & 8 \\
\hline An. barbirostris* & 872 & 1064 & 69 & 93 & 70 & 94 & 24 & 56 \\
\hline An. culicifacies* & 550 & 1568 & 271 & 774 & 178 & 930 & 64 & 371 \\
\hline An. dirus* & 372 & 727 & 60 & 87 & 31 & 60 & 12 & 26 \\
\hline An. farauti* & 1465 & 1737 & 25 & 28 & 35 & 50 & 1 & 1 \\
\hline An. flavirostris & 103 & 122 & 11 & 33 & 4 & 4 & 4 & 4 \\
\hline An. fluviatilis* & 83 & 318 & 138 & 352 & 80 & 330 & 27 & 149 \\
\hline An. koliensis & 325 & 363 & 7 & 7 & 24 & 26 & 2 & 3 \\
\hline An. lesteri & 47 & 80 & 65 & 89 & 17 & 18 & 8 & 14 \\
\hline An. leucosphyrus \& An. latens & 12 & 12 & 2 & 2 & 2 & 2 & 0 & 0 \\
\hline An. maculatus group & 471 & 765 & 83 & 145 & 75 & 188 & 24 & 113 \\
\hline An. minimus* & 445 & 711 & 93 & 111 & 75 & 113 & 59 & 153 \\
\hline An. punctulatus* & 379 & 581 & 9 & 26 & 30 & 42 & 2 & 3 \\
\hline An. sinensis* & 568 & 792 & 121 & 293 & 43 & 108 & 12 & 22 \\
\hline An. stephensi & 261 & 646 & 81 & 220 & 19 & 41 & 12 & 59 \\
\hline An. subpictus* & 410 & 1143 & 127 & 317 & 87 & 219 & 27 & 67 \\
\hline An. sundaicus* & 133 & 215 & 28 & 30 & 12 & 12 & 9 & 9 \\
\hline Total & 7430 & 12353 & 1423 & 3057 & 910 & 2488 & 353 & 1212 \\
\hline
\end{tabular}

An asterisk $(*)$ denotes that a "species" is now recognised as a species complex.

evaluation statistics for all mapping trials and final BRT environmental and climatic variable selections for the final, optimal predictive maps).

\section{Predictive maps}

The final predictive maps for the 19 Asian-Pacific DVS are given in Additional file 3 (Additional file 3: Predictive species distribution maps for the 19 DVS of the Asian-Pacific region). Spatial constraints prevent all species being discussed in detail, however, the $A n$. dirus complex (Figure 1), due to its longevity and the highly anthropophilic behaviour of its members, is considered to be the dominant vector group in any area where its species exist (Manguin, unpub obs) and, therefore, is discussed below.

The maps produced for the An. dirus complex (and for all other species complexes) do not differentiate between the members of the complex. Simply, this is due to a lack of consistent sibling species identification reported in the current literature, a status that will improve with the increasing development of reliable molecular identification methods and the rising acceptance that understanding bionomics differences in sibling species is a prerequisite for efficient control.

Behaviourally, the members of the An. dirus complex have clear differences (see below), but ecologically, they tend to occupy the same ecological niche and are generally considered as forest-dwelling species, specifically in mountainous areas and foothills, with an affinity for humid, shaded environments where they make use of transient or temporary larval habitats such as pools and puddles.

The phase of the annual cycle of LST (LST (P1)) was selected by the BRT model as the most influential variable (58.9\%). Interestingly, for all $A n$. dirus complex outputs in each of the mapping trials conducted, this variable was always found to be the most influential. LST (P1) was also chosen as the primary influence for the distribution of $A n$. aconitus (47.55\%), An. annularis (37.14\%), the An. maculatus group (64.0\%) and the $A n$. subpictus complex (34.21\%) and, to a slightly lesser degree, for $A n$. minimus complex (31.46\%). The common 


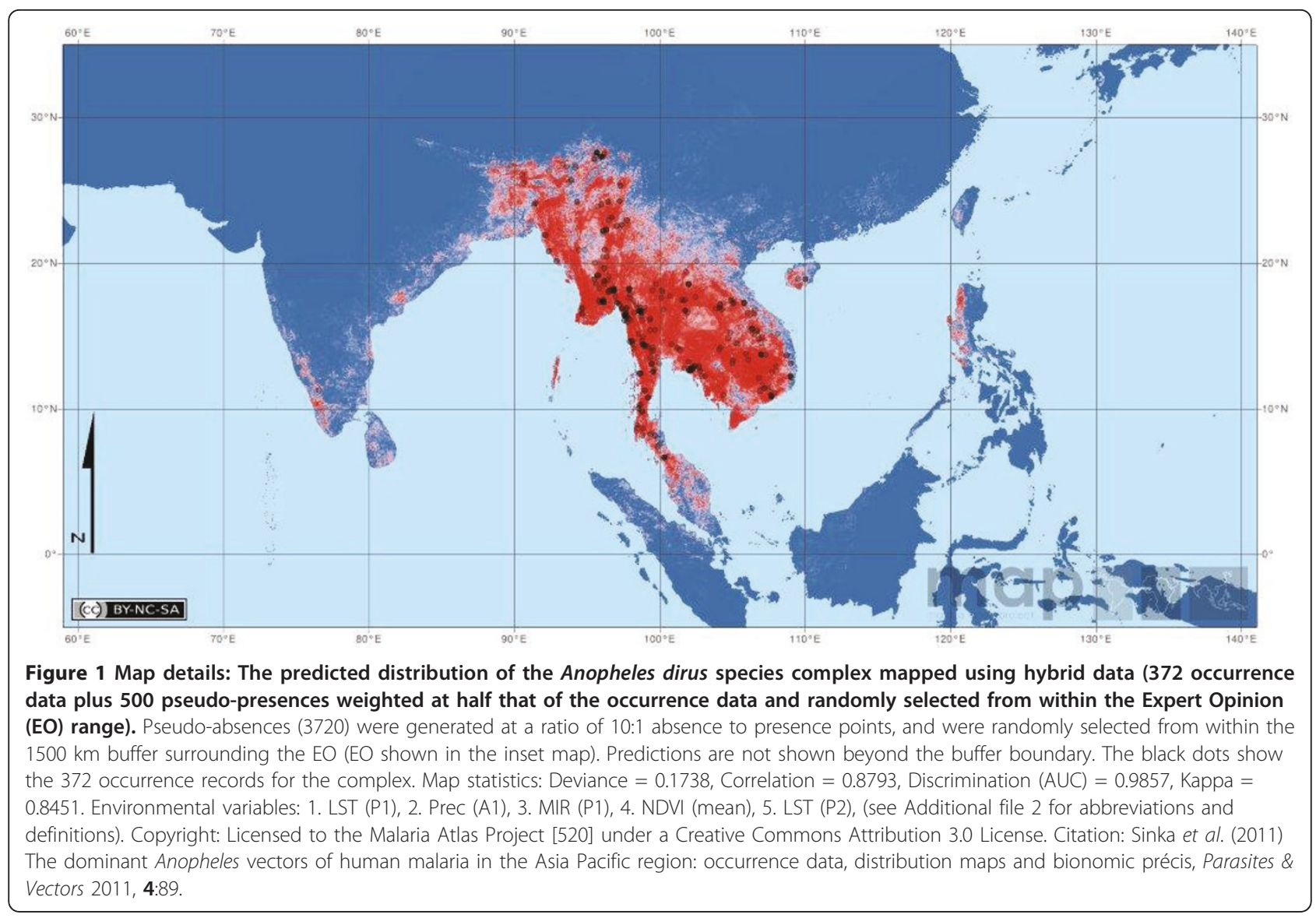

characteristic to each of these species and species complexes appears to be a distribution that includes hilly or forested hilly areas, both of which (altitude and an increased evapotranspiration rate over forest, specifically during the rainy season) could be highly influential in any satellite-derived LST measurement.

The amplitude of the annual cycle of precipitation, ranked second by the BRT model, exerted an influence of $10.47 \%$ on the distribution of the An. dirus complex. This corresponds to the suggested influence of seasonal LST (P1), and to the creation of temporary pools and puddles utilised for female oviposition and as a habitat for the immatures of the An. dirus complex.

The final three variables selected within the top five, in ranked order, are MIR, the phase of the annual cycle (8.70\%); mean NDVI (7.91\%); and LST, phase of the biannual cycle (3.95\%). MIR discriminates land cover and is able to penetrate better through aerosol particles, including water, and is thus able to distinguish between vegetation, soil, rock and water [61] which, alongside the NDVI, may also refer to the influence of the forested areas in the distribution of the An. dirus complex.

\section{Bionomics}

Tables 5, 6, 7, 8, 9, 10, 11, 12 show a summary of larval and adult bionomics data extracted from individual studies reported in the literature ('Summary') combined with the common 'accepted' bionomics of each species ('TAG').

\section{Anopheles (Anopheles) barbirostris van der Wulp species complex (Barbirostris Complex)}

Anopheles barbirostris and 12 related species comprise the medically important and taxonomically complex Barbirostris Group of malaria vectors in the Oriental Region. Six of these species, including An. barbirostris, comprise the Barbirostris Subgroup of species that are almost identical in adult morphology but differ in their roles in the transmission of malaria and filariasis in Southeast Asia.

Mosquitoes traditionally identified as An. barbirostris are common and widely distributed from India through mainland Southeast Asia and southward through Indonesia to Sulawesi, all of the Lesser Sunda island chain to Timor Island and possibly the eastern fringe of the Maluku (Mollucas) archipelago [80,81]. Records of this 
Table 5 Larval site characteristics.

\begin{tabular}{|c|c|c|c|c|c|c|c|c|c|c|c|}
\hline \multirow[b]{2}{*}{ Species } & \multirow[b]{2}{*}{ Source } & \multicolumn{2}{|c|}{ Light intensity } & \multicolumn{2}{|c|}{ Salinity } & \multicolumn{2}{|c|}{ Turbidity } & \multicolumn{2}{|c|}{ Movement } & \multicolumn{2}{|c|}{ Vegetation } \\
\hline & & $\begin{array}{l}\text { Helio- } \\
\text { philic }\end{array}$ & $\begin{array}{l}\text { Helio- } \\
\text { phobic }\end{array}$ & $\begin{array}{c}\text { High } \\
\text { (brackish) }\end{array}$ & $\begin{array}{l}\text { Low } \\
\text { (fresh) }\end{array}$ & Clear & Turbid & $\begin{array}{c}\text { Still or } \\
\text { stagnant }\end{array}$ & Flowing & $\begin{array}{l}\text { Higher } \\
\text { plants, } \\
\text { algae etc }\end{array}$ & No Veg \\
\hline An. aconitus & Summary & - & - & - & - & 1 & 1 & - & 3 & 2 & 1 \\
\hline An. aconitus & TAG & $\bullet$ & & & $\bullet$ & $\bullet$ & $\circ$ & $\bullet$ & $\circ$ & $\bullet$ & \\
\hline An. annularis & Summary & 1 & - & - & 1 & 1 & 1 & 1 & 2 & 7 & 2 \\
\hline An. annularis & TAG & $\bullet$ & & & $\bullet$ & $\bullet$ & $\circ$ & $\bullet$ & $\circ$ & $\bullet$ & $\circ$ \\
\hline An. balabacensis & Summary & - & 1 & - & - & - & - & - & - & - & 1 \\
\hline An. balabacensis & TAG & $\circ$ & $\bullet$ & & $\bullet$ & & & $\bullet$ & & $\circ$ & $\circ$ \\
\hline An. barbirostris* & Summary & 2 & 1 & - & - & 4 & 3 & 1 & 1 & 5 & 2 \\
\hline An. barbirostris* & TAG & $\bullet$ & $\bullet$ & & & $\bullet$ & $\circ$ & & & $\bullet$ & \\
\hline An. culicifacies* & Summary & 2 & - & 1 & 2 & 3 & 1 & 3 & 3 & 3 & 2 \\
\hline An. culicifacies* & TAG & $\bullet$ & & $\circ$ & $\bullet$ & $\bullet$ & $\circ$ & $\bullet$ & $\bullet$ & $\bullet$ & $\bullet$ \\
\hline An. dirus* & Summary & 1 & 10 & - & 2 & 4 & 3 & 1 & - & - & 2 \\
\hline An. dirus* & TAG & & $\bullet$ & & $\bullet$ & $\bullet$ & $\bullet$ & $\bullet$ & $\circ$ & & $\bullet$ \\
\hline An. farauti* & Summary & 1 & 6 & 8 & 14 & 2 & 4 & 2 & 1 & 18 & 2 \\
\hline An. farauti* & TAG & $\bullet$ & $\circ$ & $\bullet$ & $\bullet$ & $\bullet$ & $\circ$ & $\bullet$ & & $\bullet$ & $\bullet$ \\
\hline An. flavirostris & Summary & - & 2 & - & - & - & - & - & 2 & 1 & 1 \\
\hline An. flavirostris & TAG & & $\bullet$ & & $\bullet$ & $\bullet$ & & $\circ$ & $\bullet$ & $\bullet$ & $\circ$ \\
\hline An. fluviatilis* & Summary & 1 & - & - & 1 & - & - & 1 & 3 & 2 & 1 \\
\hline An. fluviatilis* & TAG & $\bullet$ & & & $\bullet$ & 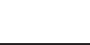 & & $\circ$ & $\bullet$ & $\bullet$ & $\circ$ \\
\hline An. koliensis & Summary & - & - & - & 1 & - & - & - & - & 1 & 1 \\
\hline An. koliensis & TAG & $\bullet$ & $\circ$ & & $\bullet$ & $\bullet$ & & $\bullet$ & & $\bullet$ & $\circ$ \\
\hline
\end{tabular}

TAG: $\bullet$ = typical, $\circ=$ examples exist.

Numbers indicate the number of studies that found larvae under each listed circumstance. An asterisk (*) denotes that a "species" is now recognised as a species complex.

species in the Maluku region and New Guinea are questionable and are more likely to be misidentifications of related species, notably An. vanus Walker. Published records of An. barbirostris in the Philippines refer to other species of the Barbirostris Group [82]. Anopheles barbirostris is generally found in highland areas $[81,83]$, but in western Timor it is considered a coastal species [83].

Sequence data for the COI mtDNA gene and the ITS2 rDNA locus [84-86], as well as electrophoretic profiles of salivary gland proteins [87], indicate that An. barbirostris is a complex of three to five sibling species with undefined distributions. The question of how many species constitute the Barbirostris Complex needs to be resolved because correct recognition and identification has important implications in the choice of methods applied to malaria and lymphatic filariasis control. Anopheles barbirostris is considered an important vector of malaria and Brugian filariasis in Sulawesi, Flores and Timor [88-92], whereas it appears to be a non-vector in other regions [82]. A recent survey in northern Sumatra identified $A n$. barbirostris as a potential vector of malaria [93], and Limrat et al. [94] and Apiwathnasorn et al. [95] reported that either An. barbirostris or An. campestris Reid (these species could not be reliably distinguished) is a probable vector of malaria in Sa Kaeo Province of Thailand where high numbers of females were captured landing on humans both indoors and outdoors.

Saeung et al. $[84,85]$ provided strong evidence for at least two species within the Barbirostris Subgroup based on a series of cross-mating experiments (also Choochote et al. [96]), cytogenetic studies and sequence analysis of ITS2, COI and COII using isolines derived from wild-caught females. Unfortunately, a comparison of COI sequence data obtained by ParedesEsquivel et al. [86] with those from Saeung et al. [85] proved to be impossible because the regions sequenced do not overlap. The A3 form of Saeung et al. [85] has a much smaller ITS2 amplicon than the corresponding region investigated by Paredes-Esquivel et al. [86], suggesting that it is not closely related to An. barbirostris s.l. Sequence comparisons showed that Clades I and II of Paredes-Esquivel et al. [86] were not included in the analyses of Saeung et al. [85], and that Clades III and $\mathrm{V}$ of Paredes-Esquivel et al. [86] correspond to form 
Table 6 Larval site characteristics (cont.).

\begin{tabular}{|c|c|c|c|c|c|c|c|c|c|c|c|}
\hline \multirow[b]{2}{*}{ Species } & \multirow[b]{2}{*}{ Source } & \multicolumn{2}{|c|}{ Light intensity } & \multicolumn{2}{|c|}{ Salinity } & \multicolumn{2}{|c|}{ Turbidity } & \multicolumn{2}{|c|}{ Movement } & \multicolumn{2}{|c|}{ Vegetation } \\
\hline & & $\begin{array}{l}\text { Helio- } \\
\text { philic }\end{array}$ & $\begin{array}{l}\text { Helio- } \\
\text { phobic }\end{array}$ & $\begin{array}{c}\text { High } \\
\text { (brackish) }\end{array}$ & $\begin{array}{l}\text { Low } \\
\text { (fresh) }\end{array}$ & Clear & Turbid & $\begin{array}{l}\text { Still or } \\
\text { stagnant }\end{array}$ & Flowing & $\begin{array}{l}\text { Higher } \\
\text { plants, } \\
\text { algae etc }\end{array}$ & No Veg \\
\hline An. lesteri & Summary & - & 1 & - & - & - & - & - & - & 1 & - \\
\hline An. lesteri & TAG & & & & $\bullet$ & & & & & & \\
\hline An. leucosphyrus \& An. latens & Summary & - & - & - & - & - & - & - & - & - & - \\
\hline An. leucosphyrus \& An. latens & TAG & & $\bullet$ & & $\bullet$ & $\bullet$ & $\bullet$ & $\bullet$ & & & \\
\hline An. maculatus group & Summary & 2 & 1 & - & - & 2 & 1 & 2 & 1 & 1 & 1 \\
\hline An. maculatus group & TAG & $\bullet$ & & & $\bullet$ & $\bullet$ & & $\bullet$ & $\bullet$ & $\bullet$ & \\
\hline An. minimus* & Summary & 1 & 1 & - & - & 2 & - & 3 & 2 & 3 & 1 \\
\hline An. minimus* & TAG & $\circ$ & $\bullet$ & & $\bullet$ & $\bullet$ & & $\bullet$ & $\bullet$ & $\bullet$ & \\
\hline An. punctulatus* & Summary & 3 & - & - & 1 & 2 & 1 & - & - & 2 & 4 \\
\hline An. punctulatus* & TAG & $\bullet$ & $\circ$ & & $\bullet$ & $\bullet$ & $\bullet$ & $\bullet$ & & $\circ$ & $\bullet$ \\
\hline An. sinensis* & Summary & - & - & - & - & 1 & - & 2 & 2 & 2 & 1 \\
\hline An. sinensis* & TAG & & & & $\bullet$ & $\bullet$ & & $\bullet$ & $\circ$ & $\bullet$ & \\
\hline An. stephensi & Summary & 2 & 1 & 1 & 1 & 3 & 2 & 2 & 1 & 2 & 1 \\
\hline An. stephensi & TAG & $\circ$ & $\bullet$ & $\circ$ & $\bullet$ & $\bullet$ & $\bullet$ & $\bullet$ & & $\bullet$ & $\bullet$ \\
\hline An. subpictus* & Summary & 2 & - & 7 & 4 & 3 & 4 & 2 & 1 & 6 & 2 \\
\hline An. subpictus* & TAG & $\bullet$ & & $\bullet$ & $\bullet$ & $\bullet$ & $\bullet$ & $\bullet$ & & $\bullet$ & \\
\hline An. sundaicus* & Summary & 3 & 1 & 7 & 4 & 1 & - & 1 & - & 2 & 1 \\
\hline An. sundaicus* & TAG & $\bullet$ & $\circ$ & $\bullet$ & $\circ$ & $\bullet$ & $\bullet$ & $\bullet$ & 0 & $\bullet$ & 0 \\
\hline
\end{tabular}

TAG: $\bullet=$ typical, $\circ=$ examples exist.

Numbers indicate the number of studies that found larvae under each listed circumstance. An asterisk $\left(^{*}\right)$ denotes that a "species" is now recognised as a species complex.

A1 and An. campestris of Saeung et al. [85], which they described as a zoophilic and more anthropophilic species, respectively. Zoophilic and anthropophilic forms of An. barbirostris were previously reported by Lien et al. [90], but these behavioural differences, which would influence their capacity to transmit malaria protozoa or filarial nematodes, could not be associated with distinct morphological characters [91] and may only reflect relative availability of different hosts. Saeung et al. [85] identified specimens with ITS2 sequences similar to Clade IV of Paredes-Esquivel et al. [86] as An. barbirostris, however specimens of Clade IV are morphologically distinct from An. barbirostris. Based on available data, it is not possible to determine which genetic species correspond to vector populations. Further analyses require extensive sampling in areas where An. barbirostris has been reported to be anthropophilic, such as Sulawesi [90] and Flores [91]. Molecular analyses indicate that Clades I and II of Paredes-Esquivel et al. [86] occur in the type locality of An. barbirostris in eastern Java (H. Townson \& R. Harbach, pers com), but which of these two genetic species is conspecific with $A n$. barbirostris s.s. is unknown.

Females of An. barbirostris s.l. bite humans but generally prefer to feed on other animals, especially bovids
[81,91,97-99]. Feeding apparently takes place outdoors, but adults have been collected resting inside houses and animal shelters as well as outside [81]. Outdoor biting in peninsular Malaysia near the Thai border takes place throughout the night [100] (Table 11). Reports that $A n$. barbirostris is a vector of malarial and filarial parasites came before the recognition of the Barbirostris Complex, and these reports may refer to other species of very similar morphology. In view of the feeding preferences and behaviour of females, An. barbirostris s.s. probably plays little if any role in the transmission of malaria and filariasis in most areas where it occurs. Since Clades III and IV of Paredes-Esquivel et al. [86] appear to be predominantly zoophilic, they may be of limited importance in the transmission of human pathogens. Unfortunately, there is very limited information on the habitats of Clades I and II, and none on their bloodfeeding preferences. Anopheles barbirostris s.l. is a confirmed vector of $P$. falciparum malaria in Sri Lanka [99] and Timor-Leste [92] based on the enzyme-linked immunosorbent assay (ELISA) detection of sporozoites in the head-thorax portions of females, which in the case of the latter study were collected in human-landing catches. Both P. vivax and P. falciparum have been detected by ELISA in females of An. barbirostris s.l. in 
Table 7 Large larval sites.

\begin{tabular}{|c|c|c|c|c|c|c|c|c|c|c|c|}
\hline \multirow[b]{2}{*}{ Species } & \multirow[b]{2}{*}{ Source } & \multicolumn{5}{|c|}{ Large natural water collections } & \multicolumn{5}{|c|}{ Large man-made water collections } \\
\hline & & Lagoons & Lakes & Marshes & $\begin{array}{c}\text { Slow } \\
\text { flowing } \\
\text { rivers }\end{array}$ & Other & $\begin{array}{l}\text { Borrow } \\
\text { pits }\end{array}$ & $\begin{array}{l}\text { Rice } \\
\text { fields }\end{array}$ & $\begin{array}{l}\text { Fish } \\
\text { ponds }\end{array}$ & $\begin{array}{l}\text { Irrigation } \\
\text { channels }\end{array}$ & Other \\
\hline An. aconitus & Summary & - & 1 & - & 2 & 3 & - & 5 & 1 & 2 & 2 \\
\hline An. aconitus & TAG & & $\circ$ & $\bullet$ & $\circ$ & & $\circ$ & $\bullet$ & $\bullet$ & $\bullet$ & \\
\hline An. annularis & Summary & - & - & 1 & 4 & 2 & - & 14 & - & 4 & 6 \\
\hline An. annularis & TAG & & & $\bullet$ & & & & $\bullet$ & & & \\
\hline An. balabacensis & Summary & - & - & 1 & - & - & - & 1 & - & - & - \\
\hline An. balabacensis & TAG & & & & & & & $\circ$ & & & \\
\hline An. barbirostris* & Summary & - & - & 3 & 5 & 4 & - & 17 & 3 & 5 & 6 \\
\hline An. barbirostris* & TAG & . & $\bullet$ & $\bullet$ & $\bullet$ & & . & $\bullet$ & $\bullet$ & $\bullet$ & \\
\hline An. culicifacies* & Summary & - & 1 & 1 & 5 & 3 & - & 14 & - & 7 & 5 \\
\hline An. culicifacies* & TAG & & & & $\bullet$ & & & $\bullet$ & & $\bullet$ & \\
\hline An. dirus* & Summary & - & - & - & - & 3 & - & 3 & 1 & - & - \\
\hline An. dirus* & TAG & & & & & & & $\circ$ & & & \\
\hline An. farauti* & Summary & 5 & - & - & 2 & 11 & - & 2 & 2 & - & 3 \\
\hline An. farauti* & TAG & $\bullet$ & $\circ$ & $\bullet$ & $\circ$ & & $\circ$ & $\circ$ & $\circ$ & $\circ$ & \\
\hline An. flavirostris & Summary & - & - & - & 1 & - & - & - & - & - & - \\
\hline An. flavirostris & TAG & & & & $\circ$ & & & $\circ$ & $\circ$ & $\circ$ & \\
\hline An. fluviatilis* & Summary & - & - & - & 5 & 2 & - & 6 & - & 1 & - \\
\hline An. fluviatilis* & TAG & & & & $\bullet$ & & & $\bullet$ & & $\bullet$ & \\
\hline An. koliensis & Summary & - & - & - & - & - & - & - & 1 & - & 1 \\
\hline An. koliensis & TAG & $\circ$ & & $\bullet$ & & & $\circ$ & & $\circ$ & $\bullet$ & \\
\hline
\end{tabular}

TAG: $\bullet$ = typical, $\circ=$ examples exist.

Numbers indicate the number of studies that found larvae under each listed circumstance. An asterisk (*) denotes that a "species" is now recognised as a species complex.

Bangladesh, but it is not known whether sporozoites, oocysts or both were present as whole mosquitoes were assayed for infection [101].

Larvae can occupy a great variety of aquatic habitats throughout the range of the complex. Anopheles barbirostris s.l. is a swamp breeder, typically found in deep fresh water that is still or slow moving. However, it is not uncommon in or near rice fields and is tolerant of relatively high levels of organic pollution including sewage, and can be found in ground pools with high concentrations of animal dung. Other habitats vary from sunlit to moderately shaded ground-water bodies, including river and stream margins and pools, ditches, moats, lakes, permanent and temporary ground pools, rice fields, wells, canals, marshes, rock pools, ponds, springs, swamps and animal footprints. The habitats usually contain some vegetation $[80,81]$ (Tables 5, 7, 9).

\section{Anopheles (Anopheles) lesteri Baisas \& $\mathrm{Hu}$}

Anopheles lesteri, originally described from Luzon Island in the Philippines, is a member of the Hyrcanus Group of mosquitoes within the Myzorhynchus Series [6]. Xu \& Feng [102] described and named An. anthropophagus as a subspecies of An. lesteri from mosquitoes collected in Jhangsu (as Kiangsu) Province, China. Ma [103] raised anthropophagus to species status based on its morphology, distribution and vectorial capacity. Wilkerson et al. [104], however, synonymised An. anthropophagus with $A n$. lesteri based on identical ITS2 sequences found in $A n$. lesteri from its type locality in Laguna Province, the Philippines, and An. anthropophagus from Jhangsu Province, China. Ma \& Xu [105] compared ITS2 sequences among 12 species of the Hyrcanus Group in China and agreed that $A n$. anthropophagus is a synonym of An. lesteri. Likewise, Hwang et al. [106] reported that sequences of the ITS2 region provide strong evidence that $A n$. lesteri in Japan and $A n$. anthropophagus in China are the same species.

Anopheles lesteri readily attacks humans and is considered a primary vector of malaria in eastern, central and southern areas of China [102,103,107-109] [as $A n$. anthropophagus], and is believed to be a principal vector in Japan and Korea [110-112]. Shin et al. [113] showed that $A n$. lesteri was able to develop sporozoites of $P$. vivax after feeding on a Korean malaria patient. Joshi et al. [114] detected high densities of sporozoites in 
Table 8 Large larval sites (cont.).

\begin{tabular}{|c|c|c|c|c|c|c|c|c|c|c|c|}
\hline \multirow[b]{2}{*}{ Species } & \multirow[b]{2}{*}{ Source } & \multicolumn{5}{|c|}{ Large natural water collections } & \multicolumn{5}{|c|}{ Large man-made water collections } \\
\hline & & Lagoons & Lakes & Marshes & $\begin{array}{l}\text { Slow } \\
\text { flowing } \\
\text { rivers }\end{array}$ & Other & $\begin{array}{c}\text { Borrow } \\
\text { pits }\end{array}$ & $\begin{array}{l}\text { Rice } \\
\text { fields }\end{array}$ & $\begin{array}{l}\text { Fish } \\
\text { ponds }\end{array}$ & $\begin{array}{l}\text { Irrigation } \\
\text { channels }\end{array}$ & Other \\
\hline An. lesteri & Summary & - & - & - & - & 4 & - & 3 & - & 1 & 1 \\
\hline An. lesteri & TAG & & $\bullet$ & $\bullet$ & & & & $\bullet$ & & & \\
\hline An. leucosphyrus \& An. latens & Summary & - & - & - & - & - & - & - & - & - & - \\
\hline An. leucosphyrus \& An. latens & TAG & & & & & & & & & & \\
\hline An. maculatus group & Summary & - & - & - & 3 & 4 & - & 8 & - & 1 & - \\
\hline An. maculatus group & TAG & & $\bullet$ & & & & & $\bullet$ & & $\bullet$ & \\
\hline An. minimus* & Summary & - & - & - & - & 5 & - & 8 & 5 & 1 & 2 \\
\hline An. minimus* & TAG & & & & & & & $\bullet$ & $\bullet$ & & \\
\hline An. punctulatus* & Summary & - & - & - & - & 1 & - & - & 1 & - & - \\
\hline An. punctulatus* & TAG & & & & & & & & $\circ$ & & \\
\hline An. sinensis* & Summary & - & - & 1 & - & 3 & - & 11 & - & 2 & 2 \\
\hline An. sinensis* & TAG & & & $\bullet$ & & & & $\bullet$ & & $\bullet$ & \\
\hline An. stephensi & Summary & - & 1 & 1 & 5 & 3 & - & 5 & - & 4 & 3 \\
\hline An. stephensi & TAG & & & & $\bullet$ & & & $\bullet$ & & $\bullet$ & \\
\hline An. subpictus* & Summary & 1 & - & 2 & 3 & 4 & - & 13 & - & 6 & 5 \\
\hline An. subpictus* & TAG & $\bullet$ & & $\bullet$ & & & & $\bullet$ & & $\bullet$ & \\
\hline An. sundaicus* & Summary & - & - & 2 & - & 3 & - & 2 & 1 & - & 1 \\
\hline An. sundaicus* & TAG & $\bullet$ & & $\bullet$ & & & & & $\bullet$ & & \\
\hline
\end{tabular}

TAG: $\bullet=$ typical, $\circ=$ examples exist.

Numbers indicate the number of studies that found larvae under each listed circumstance. An asterisk (*) denotes that a "species" is now recognised as a species complex.

salivary glands of An. lesteri infected with the Korean strain of $P$. vivax and concluded that An. lesteri should be a highly competent vector of $P$. vivax malaria provided its survival is sufficiently long in the field. Molecular [115] and morphological identifications [116] have extended the distribution of An. lesteri northward in China to $42^{\circ} \mathrm{N} 120^{\circ} \mathrm{W}$ and $42.5^{\circ} \mathrm{N} 123.41^{\circ} \mathrm{W}$, respectively; localities which are farther north than the Korean Peninsula. The biting behaviour of An. lesteri is unknown in the Philippines and Guam, but it is not known to transmit malarial parasites in these areas [117]. This species is also regarded as an important vector of lymphatic filariasis (B. malayi) in China [118].

Larvae of An. lesteri are found in fresh-water ground pools, ditches, margins of streams and ponds, rice fields, marshes, swamps, lakes and other impounded waters [112,119-121] (Tables 6, 8, 10). Adults of An. lesteri rest in cool and shaded places. Adult populations reach peak densities during the summer in Hokkaido [122], and during June and October in Honshu and Kyushu, Japan [123]. In Hong Kong, An. lesteri commonly occurs in hilly areas and grassy fields [124]. Basio \& Reisen [125] found larvae in a wallow on Guam and Whang [126] collected adults in cow sheds and houses in villages during malaria surveys in Korea. Anopheles lesteri has been confused with $A n$. sinensis and other members of the Hyrcanus Group, and some published records of its distribution and bionomics are likely not to be accurate, particularly in Japan, Korea and China [117].

\section{Anopheles (Anopheles) sinensis Wiedemann}

Anopheles sinensis is also a member of the Hyrcanus Group in the Myzorhynchus Series [6]. It is widely distributed in southern Asia from Afghanistan to northern China, Japan, Korea, Taiwan and southward into western Indonesia (Sumatra and West Kalimantan) [81,112,127-130]. There is evidence that An. sinensis is refractory to $P$. falciparum $[131,132]$, but it is still considered an important vector of $P$. vivax malaria (and $B$. malayi) in both China and Korea [104,108,118,133-137]. It is the most common anopheline species in Japan $[112,138]$, where it is regarded as an important 'historical' vector of malaria [123]. Anopheles sinensis is also considered to be a minor malaria vector in Indonesia (Sumatra only) [130]. Anopheles sinensis has little or no involvement in malaria transmission in Thailand due to its zoophilic and exophilic behaviour and its prevalence primarily in areas where there is little or no malaria [81] (Table 12).

Along the border between North and South Korea, Strickman et al. [139] reported that An. sinensis (based on morphological identifications) comprised $80 \%$ of the anopheline mosquitoes attacking humans during an outbreak of $P$. vivax malaria. Lee et al. [140] found that a 
Table 9 Small larval sites.

\begin{tabular}{|c|c|c|c|c|c|c|c|c|c|c|c|c|c|c|c|}
\hline \multirow[b]{2}{*}{ Species } & \multirow[b]{2}{*}{ Source } & \multicolumn{6}{|c|}{ Small natural water collections } & \multicolumn{7}{|c|}{ Small man-made water collections } & \multirow{2}{*}{$\begin{array}{c}\text { Artificial } \\
\text { sites } \\
\text { Empty } \\
\text { cans, } \\
\text { shells } \\
\text { etc. }\end{array}$} \\
\hline & & $\begin{array}{c}\text { Small } \\
\text { streams }\end{array}$ & $\begin{array}{l}\text { Seepage } \\
\text { springs }\end{array}$ & Pools & Wells & $\begin{array}{l}\text { Dips } \\
\text { in the } \\
\text { ground }\end{array}$ & Other & $\begin{array}{c}\text { Overflow } \\
\text { water }\end{array}$ & $\begin{array}{l}\text { Irrigation } \\
\text { ditches }\end{array}$ & $\begin{array}{l}\text { Borrow } \\
\text { pits }\end{array}$ & $\begin{array}{l}\text { Wheel } \\
\text { ruts }\end{array}$ & $\begin{array}{l}\text { Hoof } \\
\text { prints }\end{array}$ & $\begin{array}{l}\text { Puddles } \\
\text { near } \\
\text { rice } \\
\text { fields }\end{array}$ & Other & \\
\hline An. aconitus & Summary & 3 & - & 5 & 2 & 1 & - & - & - & 2 & 1 & 1 & - & 1 & - \\
\hline An. aconitus & TAG & $\circ$ & $\circ$ & $\bullet$ & $\circ$ & $\circ$ & $\circ$ & $\circ$ & $\bullet$ & $\circ$ & $\circ$ & $\circ$ & $\circ$ & & $\circ$ \\
\hline An. annularis & Summary & 2 & - & 10 & 4 & - & 1 & - & 1 & 2 & 1 & 2 & 1 & 1 & 1 \\
\hline An. annularis & TAG & $\circ$ & $\circ$ & $\bullet$ & $\circ$ & & & & $\circ$ & $\circ$ & $\circ$ & $\circ$ & $\circ$ & & \\
\hline An. balabacensis & Summary & - & - & 1 & - & - & - & - & - & - & - & - & - & - & - \\
\hline An. balabacensis & TAG & $\circ$ & & $\bullet$ & & $\bullet$ & & . & $\bullet$ & & $\bullet$ & $\bullet$ & $\circ$ & & $\circ$ \\
\hline An. barbirostris* & Summary & 10 & 1 & 13 & 5 & 1 & 3 & - & - & 2 & 1 & 1 & - & 2 & - \\
\hline An. barbirostris* & TAG & $\bullet$ & $\bullet$ & $\bullet$ & $\bullet$ & & & . & 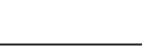 & & $\bullet$ & $\bullet$ & & & . \\
\hline An. culicifacies* & Summary & 5 & - & 14 & 5 & - & 5 & - & 2 & 5 & 1 & 4 & 1 & 4 & 2 \\
\hline An. culicifacies* & TAG & $\bullet$ & 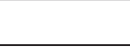 & $\bullet$ & $\bullet$ & & & . & $\bullet$ & $\bullet$ & $\bullet$ & $\bullet$ & $\bullet$ & & \\
\hline An. dirus* & Summary & 3 & - & 13 & 4 & 1 & 3 & - & - & 1 & 5 & 4 & - & 3 & - \\
\hline An. dirus* & TAG & $\bullet$ & . & $\bullet$ & $\bullet$ & $\bullet$ & & . & . & $\bullet$ & $\bullet$ & $\bullet$ & , & & . \\
\hline An. farauti* & Summary & 10 & - & 22 & 3 & - & 8 & - & - & 1 & 10 & 7 & - & 12 & - \\
\hline An. farauti* & TAG & & & $\bullet$ & & $\circ$ & & $\circ$ & $\circ$ & $\circ$ & $\circ$ & $\circ$ & & & $\circ$ \\
\hline An. flavirostris & Summary & 5 & - & 1 & - & - & - & - & - & - & - & - & - & - & - \\
\hline An. flavirostris & TAG & $\bullet$ & $\circ$ & $\circ$ & $\circ$ & $\circ$ & & $\circ$ & $\circ$ & & & & & & \\
\hline An. fluviatilis* & Summary & 7 & - & 3 & 3 & - & 4 & - & 2 & 3 & - & 1 & - & 2 & - \\
\hline An. fluviatilis* & TAG & $\bullet$ & 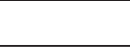 & $\circ$ & $\circ$ & . & & . & $\bullet$ & $\circ$ & & & 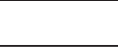 & & . \\
\hline An. koliensis & Summary & 1 & - & 1 & 1 & - & 1 & - & - & - & 1 & 1 & - & 1 & - \\
\hline An. koliensis & TAG & $\circ$ & & $\bullet$ & & $\bullet$ & & & $\bullet$ & o & $\circ$ & $\circ$ & & & \\
\hline
\end{tabular}

TAG: $\bullet=$ typical, $\circ=$ examples exist.

Numbers indicate the number of studies that found larvae under each listed circumstance. An asterisk $\left(^{*}\right)$ denotes that a "species" is now recognised as a species complex. 
Table 10 Small larval sites (cont.).

\begin{tabular}{|c|c|c|c|c|c|c|c|c|c|c|c|c|c|c|c|}
\hline \multirow[b]{2}{*}{ Species } & \multirow[b]{2}{*}{ Source } & \multicolumn{6}{|c|}{ Small natural water collections } & \multicolumn{7}{|c|}{ Small man-made water collections } & \multirow{2}{*}{$\begin{array}{c}\text { Artificial sites } \\
\text { Empty } \\
\text { cans, } \\
\text { shells etc. }\end{array}$} \\
\hline & & $\begin{array}{c}\text { Small } \\
\text { streams }\end{array}$ & $\begin{array}{l}\text { Seepage } \\
\text { springs }\end{array}$ & Pools & Wells & $\begin{array}{l}\text { Dips in } \\
\text { the } \\
\text { ground }\end{array}$ & Other & $\begin{array}{c}\text { Overflow } \\
\text { water }\end{array}$ & $\begin{array}{l}\text { Irrigation } \\
\text { ditches }\end{array}$ & $\begin{array}{l}\text { Borrow } \\
\text { pits }\end{array}$ & $\begin{array}{l}\text { Wheel } \\
\text { ruts }\end{array}$ & $\begin{array}{l}\text { Hoof } \\
\text { prints }\end{array}$ & $\begin{array}{l}\text { Puddles } \\
\text { near } \\
\text { rice } \\
\text { fields }\end{array}$ & Other & \\
\hline An. lesteri & Summary & 1 & - & 4 & - & - & 1 & - & 2 & - & 1 & - & - & 2 & - \\
\hline An. lesteri & TAG & $\bullet$ & & $\bullet$ & & & & & $\bullet$ & & & & & & \\
\hline An. leucosphyrus \& An. latens & Summary & - & - & - & - & - & - & - & - & - & - & - & - & - & - \\
\hline An. leucosphyrus \& An. latens & TAG & $\bullet$ & $\bullet$ & $\bullet$ & & & & & 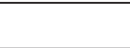 & & $\bullet$ & $\bullet$ & & & \\
\hline An. maculatus group & Summary & 10 & 2 & 9 & 1 & 2 & 5 & - & - & - & 1 & 1 & - & 1 & - \\
\hline An. maculatus group & TAG & $\bullet$ & $\bullet$ & $\bullet$ & $\bullet$ & $\bullet$ & & & & & $\bullet$ & $\bullet$ & & & \\
\hline An. minimus* & Summary & 18 & 2 & 9 & 1 & 1 & 4 & - & - & - & 2 & 1 & 3 & 1 & - \\
\hline An. minimus* & TAG & - & $\bullet$ & $\bullet$ & & & & . & & & & & & & \\
\hline An. punctulatus* & Summary & 3 & - & 4 & 1 & 1 & 5 & - & - & - & 4 & 1 & - & 3 & - \\
\hline An. punctulatus* & TAG & $\circ$ & & $\circ$ & & $\bullet$ & & $\circ$ & $\circ$ & $\bullet$ & $\bullet$ & $\bullet$ & & & $\circ$ \\
\hline An. sinensis* & Summary & 4 & - & 7 & - & 1 & 2 & - & 4 & - & 1 & - & - & 2 & 3 \\
\hline An. sinensis* & TAG & $\bullet$ & $\bullet$ & $\bullet$ & & & & & $\bullet$ & & $\bullet$ & & & & \\
\hline An. stephensi & Summary & 2 & - & 9 & 9 & 1 & 5 & 1 & 1 & 4 & 1 & 3 & - & 14 & 11 \\
\hline An. stephensi & TAG & $\bullet$ & & $\bullet$ & $\bullet$ & & & & & & & $\circ$ & & & $\bullet$ \\
\hline An. subpictus* & Summary & 2 & - & 10 & 4 & - & 2 & - & 2 & 2 & 1 & 2 & - & 5 & 2 \\
\hline An. subpictus* & TAG & & & $\bullet$ & $\bullet$ & & & & $\bullet$ & & & & & & $\bullet$ \\
\hline An. sundaicus* & Summary & 3 & - & 2 & 2 & - & 1 & - & - & 1 & - & - & - & 3 & - \\
\hline An. sundaicus* & TAG & & & $\bullet$ & & & & & & & & & & & \\
\hline
\end{tabular}

TAG: $\bullet=$ typical, $\circ=$ examples exist.

Numbers indicate the number of studies that found larvae under each listed circumstance. An asterisk $\left(^{*}\right)$ denotes that a "species" is now recognised as a species complex. 
Table 11 Adult feeding and resting behaviour.

\begin{tabular}{|c|c|c|c|c|c|c|c|c|c|c|c|c|c|}
\hline \multirow[b]{2}{*}{ Species } & \multirow[b]{2}{*}{ Source } & \multicolumn{2}{|c|}{ Feeding habit } & \multicolumn{2}{|c|}{ Biting habit } & \multicolumn{4}{|c|}{ Biting time } & \multicolumn{2}{|c|}{$\begin{array}{l}\text { Pre-feeding } \\
\text { resting habit }\end{array}$} & \multicolumn{2}{|c|}{$\begin{array}{l}\text { Post-feeding } \\
\text { resting habit }\end{array}$} \\
\hline & & $\begin{array}{l}\text { Anthro- } \\
\text { pophilic }\end{array}$ & $\begin{array}{l}\text { Zoo- } \\
\text { philic }\end{array}$ & $\begin{array}{l}\text { Exo- } \\
\text { phagic }\end{array}$ & $\begin{array}{l}\text { Endo- } \\
\text { phagic }\end{array}$ & Day & Dusk & Night & Dawn & $\begin{array}{l}\text { Exo- } \\
\text { philic }\end{array}$ & $\begin{array}{l}\text { Endo- } \\
\text { philic }\end{array}$ & $\begin{array}{l}\text { Exo- } \\
\text { philic }\end{array}$ & $\begin{array}{l}\text { Endo- } \\
\text { philic }\end{array}$ \\
\hline An. aconitus & Summary & 1 & 3 & 4 & 3 & - & 2 & 5 & - & - & 1 & 1 & 2 \\
\hline An. aconitus & TAG & $\circ$ & $\bullet$ & $\bullet$ & $\bullet$ & & $\circ$ & $\bullet$ & & $\bullet$ & $\circ$ & $\bullet$ & $\circ$ \\
\hline An. annularis & Summary & - & 8 & 4 & 1 & - & 3 & 5 & - & 1 & 3 & 1 & 5 \\
\hline An. annularis & TAG & $\circ$ & $\bullet$ & $\bullet$ & $\bullet$ & & $\circ$ & $\bullet$ & & $\circ$ & $\bullet$ & $\circ$ & $\bullet$ \\
\hline An. balabacensis & Summary & 4 & - & 3 & 2 & - & 1 & 4 & - & - & 1 & - & 2 \\
\hline An. balabacensis & TAG & $\bullet$ & & $\bullet$ & $\bullet$ & & $\bullet$ & $\bullet$ & & $\circ$ & $\circ$ & $\circ$ & $\circ$ \\
\hline An. barbirostris* & Summary & - & 3 & 2 & 1 & - & 5 & 3 & - & 2 & 1 & 3 & 2 \\
\hline An. barbirostris* & TAG & $\circ$ & $\bullet$ & $\bullet$ & $\circ$ & & $\bullet$ & $\bullet$ & & $\bullet$ & $\circ$ & $\bullet$ & $\circ$ \\
\hline An. culicifacies* & Summary & - & 9 & 2 & 2 & - & 3 & 11 & - & 1 & 4 & 1 & 5 \\
\hline An. culicifacies* & TAG & $\bullet$ & $\bullet$ & $\bullet$ & $\bullet$ & & $\bullet$ & $\bullet$ & & $\circ$ & $\bullet$ & $\circ$ & $\bullet$ \\
\hline An. dirus* & Summary & 12 & 1 & 10 & 7 & - & - & 17 & - & 2 & 1 & 2 & - \\
\hline An. dirus* & TAG & $\bullet$ & & $\bullet$ & $\bullet$ & & $\circ$ & $\bullet$ & & $\bullet$ & & $\bullet$ & \\
\hline An. farauti* & Summary & 5 & - & 3 & - & - & 5 & 10 & 1 & 1 & - & 1 & - \\
\hline An. farauti* & TAG & $\bullet$ & $\circ$ & $\bullet$ & $\bullet$ & o & $\circ$ & $\bullet$ & & $\bullet$ & $\circ$ & $\bullet$ & $\circ$ \\
\hline An. flavirostris & Summary & 2 & 4 & 6 & 3 & - & - & 4 & - & - & 1 & 1 & 1 \\
\hline An. flavirostris & TAG & $\bullet$ & $\bullet$ & $\bullet$ & $\bullet$ & & & $\bullet$ & & $\bullet$ & $\circ$ & $\bullet$ & \\
\hline An. fluviatilis* & Summary & 5 & 6 & 3 & 4 & - & 2 & 5 & 1 & 3 & 5 & 5 & 7 \\
\hline An. fluviatilis* & TAG & $\bullet$ & $\bullet$ & $\bullet$ & $\bullet$ & & $\bullet$ & $\bullet$ & $\circ$ & & & & \\
\hline An. koliensis & Summary & 3 & - & 4 & 6 & - & 1 & 6 & 1 & - & - & - & - \\
\hline An. koliensis & TAG & $\bullet$ & $\circ$ & $\bullet$ & $\bullet$ & $\circ$ & $\circ$ & $\bullet$ & $\circ$ & $\bullet$ & $\circ$ & $\bullet$ & $\circ$ \\
\hline
\end{tabular}

TAG: • = typical, $\circ=$ examples exist.

Numbers indicate the number of studies that found adults under each listed circumstance. An asteriosk (*) denotes that a "species" is now recognised as a species complex.

third of An. sinensis females that fed on volunteers infected with a Korean strain of $P$. vivax became infective based on the ELISA detection of sporozoites. The mosquitoes were collected in a non-epidemic area of the country to ensure that uninfected mosquitoes were used in the study. Joshi et al. [114] performed feeding experiments with the Korean strain of $P$. vivax and found that An. sinensis females develop oocysts but only a reduced number of sporozoites were detected in salivary glands compared with females of An. lesteri.

Lee et al. [141] found that An. sinensis delivered a relatively high biting rate ( 87.6 bites/person/night) during human-bait collections conducted in Paju, South Korea. The parity of An. sinensis from human-bait collections fluctuated from 41-71\% (mean 48.8\%) from June (mean $35.2 \%$ ) to July (mean 55.0\%) and August (mean 66.2\%). From these data, Lee et al. [141] estimated that the probability of daily survival of An. sinensis in the summer season is 0.79 , with an assumed three-day gonotrophic cycle [142] and the expectancy of infective life through 11 days as 0.073 . In contrast, Ree et al. [142] calculated parity rates of $75.2 \%$ in July, $56.5 \%$ in August, $78.5 \%$ in September and $60.0 \%$ in
October, and a slightly higher probability of daily survival rate (0.89) for An. sinensis in Gyonggi-do, South Korea. Based on blood meal analysis (ELISA), Lee et al. [141] reported that only $0.8 \%$ of An. sinensis females obtained blood meals from human hosts, as opposed to $61.8 \%$ from cows. In comparison, Ree et al. [142] found that only $0.7 \%$ of females had fed on humans, $89.8 \%$ on bovines and the remaining on either swine (3.3\%), dogs $(0.7 \%)$, chickens $(1.6 \%)$ or both bovines and swine $(0.7 \%)$. Both studies concluded that the malaria transmission potential of An. sinensis is very low despite the high number of females that attack humans, i.e. vectorial capacity would be high only in the presence of large population densities. Chang et al. [143] reported that females of An. sinensis collected from resting sites in villages in Taiwan, $86.4 \%$ were found to have fed on pig, $9.1 \%$ on bovine and $4.5 \%$ on horse, as determined by polymerase chain reaction (PCR) analyses of blood meals. Females were routinely collected outside human dwellings and near larval habits, but none were collected inside human habitations. Mwandawiro et al. [144] studied the host preferences of An. sinensis females in an extensive rice growing area at Nishi Arita, Saga 
Table 12 Adult feeding and resting behaviour (cont.).

\begin{tabular}{|c|c|c|c|c|c|c|c|c|c|c|c|c|c|}
\hline \multirow[b]{2}{*}{ Species } & \multirow[b]{2}{*}{ Source } & \multicolumn{2}{|c|}{ Feeding habit } & \multicolumn{2}{|c|}{ Biting habit } & \multicolumn{4}{|c|}{ Biting time } & \multicolumn{2}{|c|}{$\begin{array}{l}\text { Pre-feeding } \\
\text { resting habit }\end{array}$} & \multicolumn{2}{|c|}{$\begin{array}{l}\text { Post-feeding } \\
\text { resting habit }\end{array}$} \\
\hline & & $\begin{array}{l}\text { Anthro- } \\
\text { pophilic }\end{array}$ & $\begin{array}{l}\text { Zoo- } \\
\text { philic }\end{array}$ & $\begin{array}{l}\text { Exo- } \\
\text { phagic }\end{array}$ & $\begin{array}{l}\text { Endo- } \\
\text { phagic }\end{array}$ & Day & Dusk & Night & Dawn & $\begin{array}{l}\text { Exo- } \\
\text { philic }\end{array}$ & $\begin{array}{l}\text { Endo- } \\
\text { philic }\end{array}$ & $\begin{array}{l}\text { Exo- } \\
\text { philic }\end{array}$ & $\begin{array}{l}\text { Endo- } \\
\text { philic }\end{array}$ \\
\hline An. lesteri & Summary & 2 & 2 & - & - & - & 1 & 1 & - & - & 2 & - & 2 \\
\hline An. lesteri & TAG & $\bullet$ & $\bullet$ & & & & $\bullet$ & $\bullet$ & & & $\bullet$ & & $\bullet$ \\
\hline An. leucosphyrus \& An. latens & Summary & - & - & - & - & - & 1 & 2 & - & - & - & - & - \\
\hline An. leucosphyrus \& An. latens & TAG & $\bullet$ & & $\bullet$ & $\bullet$ & & $\circ$ & $\bullet$ & & $\bullet$ & & $\bullet$ & \\
\hline An. maculatus group & Summary & 1 & 9 & 12 & 4 & - & 7 & 12 & 1 & 2 & 1 & 3 & 1 \\
\hline An. maculatus group & TAG & $\circ$ & $\bullet$ & $\bullet$ & $\bullet$ & & $\bullet$ & $\bullet$ & & & & & \\
\hline An. minimus* & Summary & 6 & 14 & 12 & 6 & - & 6 & 12 & 1 & 3 & 2 & 4 & 4 \\
\hline An. minimus* & TAG & $\bullet$ & $\bullet$ & $\bullet$ & $\bullet$ & & $\bullet$ & $\bullet$ & $\circ$ & $\bullet$ & $\bullet$ & $\bullet$ & $\bullet$ \\
\hline An. punctulatus* & Summary & 2 & - & 3 & 3 & - & - & 7 & 2 & - & - & - & - \\
\hline An. punctulatus* & TAG & $\bullet$ & $\circ$ & $\bullet$ & $\bullet$ & o & $\circ$ & $\bullet$ & $\circ$ & $\bullet$ & $\circ$ & $\bullet$ & $\circ$ \\
\hline An. sinensis* & Summary & 1 & 9 & 2 & - & - & 3 & 5 & - & 1 & - & 1 & - \\
\hline An. sinensis* & TAG & & $\bullet$ & $\bullet$ & & & $\bullet$ & $\bullet$ & & $\bullet$ & & $\bullet$ & \\
\hline An. stephensi & Summary & 2 & 4 & - & - & - & 1 & 2 & - & - & 8 & - & 8 \\
\hline An. stephensi & TAG & $\circ$ & $\bullet$ & $\circ$ & $\bullet$ & & $\bullet$ & $\bullet$ & & & $\bullet$ & & $\bullet$ \\
\hline An. subpictus* & Summary & 1 & 9 & 3 & 2 & - & 6 & 5 & - & 1 & 6 & 1 & 7 \\
\hline An. subpictus* & TAG & & $\bullet$ & $\bullet$ & $\bullet$ & & $\bullet$ & $\bullet$ & & & $\bullet$ & & $\bullet$ \\
\hline An. sundaicus* & Summary & 1 & 1 & 1 & 3 & - & - & 3 & - & 1 & 1 & 1 & 1 \\
\hline An. sundaicus* & TAG & $\bullet$ & $\circ$ & $\bullet$ & $\bullet$ & & & $\bullet$ & & $\bullet$ & $\bullet$ & $\bullet$ & $\bullet$ \\
\hline
\end{tabular}

TAG: $\bullet=$ typical, $\circ=$ examples exist.

Numbers indicate the number of studies that found adults under each listed circumstance. An asterisk $(*)$ denotes that a "species" is now recognised as a species complex.

Prefecture, Japan by collecting resting mosquitoes from animal sheds. Blood meal analysis (ELISA) found that females preferred cows and pigs to chickens in both terraced hill-side and rice field locations. None were found to have fed on humans or dogs.

Lee et al. [145] found An. sinensis to be the most abundant Anopheles mosquito captured from cowshed resting sites in both high and low-risk malaria areas in South Korea. However, An. pullus Yamada and An. kleini Rueda had higher concentrations of circumsporozoite antigen for $P$. vivax when analysed by ELISA, indicating greater numbers of sporozoites present in salivary glands. Moreover, An. kleini and An. pullus developed higher infection rates than An. sinensis in laboratory studies by feeding on malaria-infected blood from patients. The findings suggest that An. sinensis is a less effective vector of malaria in Korea than other members of the Hyrcanus Group.

Anopheles sinensis is prevalent in Korea from late April/early May to October, with populations peaking in late June to mid-July and declining in August $[128,133]$. The species is present throughout the year in southern Taiwan, with peak densities in spring (February-March) and autumn (September-October) that coincide with the two periods of rice cultivation [133].
Female An. sinensis feed throughout the night, with peak activity apparently occurring at different hours depending on locality $[108,128,133,139]$. Whang [146] observed that the biting activity of An. sinensis is influenced by wind speed and direction. Under normal circumstances, females are predominantly zoophilic and exophilic, infrequently biting humans in the presence of their preferred hosts (buffalo and cattle), and are rarely found inside human habitations (Table 12).

The immature stages of $A n$. sinensis are primarily found in lowland, shallow, fresh-water habitats with emergent and/or floating vegetation in open agriculture lands (mainly rice fields). They also utilise stream margins, irrigation ditches, ponds, marshes, swamps, bogs, pits, stump ground holes, grassy pools, flood pools, stream pools, rock pools, seepage-springs and wheel tracks $[29,81,112,128,130,138,147]$ (Tables 6, 8, 10). Shading requirements vary, but this species is more often associated with exposed and sunlit aquatic environments.

In northern temperate climates, An. sinensis females hibernate in sheltered places from the end of October, when the temperature drops to $13-15^{\circ} \mathrm{C}$, to April when temperatures begin to reach $19^{\circ} \mathrm{C}[108,133]$. Hibernating mosquitoes are nulliparous but mated. 


\section{Anopheles (Cellia) aconitus Dönitz}

Anopheles aconitus is a member of the Funestus Group of the Myzomyia Series [148,149]. There are three recognised members in the Aconitus Subgroup (An. aconitus, An. pampanai Büttiker \& Beales and An. varuna Iyengar). All three species can be found in sympatry in mainland areas of Southeast Asia. Only An. aconitus has an extensive geographical range. Adults are similar to those of the Minimus Subgroup and the two taxa exhibit overlapping characters. Consequently, molecular techniques have been developed for differentiating these species [149-152].

Anopheles aconitus is broadly distributed throughout Indochina from southern Asia, through Southeast Asia and into the western fringe of the Australasian Region. Its range extends from Sri Lanka, southern and eastern India and southern Nepal eastward to southern China (Hainan Island and Yunnan Province), south into Indonesia as far east as Babar Island in the southern Maluku archipelago. The species is present in Bangladesh $[153,154]$, Bhutan, Cambodia [155], China, India [156-165], the Indonesia archipelago [83,166-174], including Alor, Babar, Bali, Flores, Java, southeast Kalimantan, Kisar, Lombok, Pantar, Sulawesi, Sumatra, Sumba, Sumbawa, Timor and Timor-Leste [92], Laos [175], peninsular Malaysia [100,176,177], Myanmar [178], Nepal [127], Singapore [80], Sri Lanka [10,179], Thailand $[29,180]$ and Vietnam [150,181,182]. Although suitable habitats exist, $A n$. aconitus has not been reported in the Philippine Islands [183] or Taiwan. Three chromosomal forms (karyotypes A, B, C) have recently been described for An. aconitus [29,184], however little is known about their individual bionomics and epidemiological significance. Forms B and C do not appear to be distinct species, rather cytological races of the same species.

Anopheles aconitus can be found from sea level to upland hill zones at higher altitudes $(600-800 \mathrm{~m})$, but is generally restricted to below $1000 \mathrm{~m}$. Depending on the season (rainfall and/or agricultural cycle), it can be a very abundant mosquito $[174,185]$. Larvae are frequently found in open country near foothills and forest fringes with rice fields (active and fallow), various shallow pools (rock, stream, seepage, flood) and slow moving streams $[154,158]$ with grassy margins (Tables 7,9$)$. Both coastal plain and upland rice fields (young and older plants) are particularly favoured habitats $[37,161,163,169,174,182$, $186,187]$, especially when plants are closer to maturity and greater than $1.5 \mathrm{~m}$ in height $[127,163,188]$. Larvae can also be found in abundance in fallow rice fields and rain-fed pools in dry fields (Tables 7,9 ). Aquatic habitats are almost exclusively clear (non-polluted but sometimes turbid or slightly cloudy), stagnant or slow-flowing fresh water, mostly sun-exposed (heliophilic), and only on occasion are larvae found in small running (lotic) streams $[158,174,189]$. In most cases, common larval habitats contain various floating higher plants (e.g. water hyacinth) and algae $[29,154,164]$ (Table 5). Other natural and human-made larval sites include lakes [154], swamps, marshes, flooded grassland [182], shallow ponds $[154,190]$, ground depressions $[154,182]$, pools in rocks, creeks and river beds $[158,174,182,190,191]$, irrigation channels $[10,174,190]$, fish ponds [177], roadside storm water drains, open ditches and tanks (reservoirs) with grassy margins [29] (Table 7, 9). On rare occasions this species has been found in wells, borrow pits, wheel ruts, hoof prints or small container habitats $[158,191]$ (Table 9).

Adult mosquitoes can be found throughout the year in many localities but often show strong seasonal population peaks and periodicities that coincide with the time of rice harvest. Females are primarily zoophilic, sometimes strongly so, and although larger animals (e.g. bovids) are the commonly preferred hosts, when they are scarce, they will feed on humans as an alternative host [10,180-182] (Table 11). Females will feed on humans both inside and outside houses and in varying proportions, depending on location, generally with no strong preference reported [100,175,187]. Feeding can occur throughout the evening, typically beginning at dusk $[100,176]$, with the majority of females feeding on humans before midnight $[161,179,192,193]$ (Table 11). In Timor-Leste, peak feeding commonly occurred during the first hour of the evening and continued only sporadically for the remainder of the evening [92]. Variation in feeding habits has been noted by location (e.g. coastal vs upland) and season [161,187]. Some blood-fed females will rest indoors by day $[156,157]$, but overall this species is considered strongly exophilic throughout its range [10,156,162,171,181] (Table 11). Natural outdoor adult resting places include steep, shaded stream banks, irrigation ditches and low shaded undergrowth [188]. Common human-made resting sites are found in and around animal shelters. Little is known about adult flight range and dispersal. Older literature has described movement as limited ( 0.5 to $1 \mathrm{~km}$ ) whereas others have indicated this species is capable of much longer flights [188].

Throughout much of its geographical range $A n$. aconitus is considered a secondary (incidental) malaria vector $[80,180]$ and has been implicated in the transmission of Bancroftian filariasis [194]. However, under 'ideal conditions', this species can play a major role in malaria transmission, and thus its inclusion as a DVS. This species has been incriminated as a secondary, but important regional vector of malarial parasites in Thailand $[195,196]$ and Bangladesh [153]. In Indonesia, it is considered a primary, but focal, vector throughout much of 
Java and areas of Sumatra, especially in locations with intense rice cultivation $[185,197]$. It appears to play no, or only a very minor, role as a vector in Sulawesi, Kalimantan and the Lesser Sunda island group (e.g. Bali, Lombok, etc.). In general, vectorial capacity is diminished by marked tendencies for zoophilic feeding behaviour but can be compensated by large seasonal or continuous biting densities. Even in areas where $A n$. aconitus is still regarded as a primary vector (e.g. upland areas of Java and Sumatra) [174,193], its epidemiological importance appears density dependent (both mosquito and human) and is likely to be influenced by the number of cattle or buffalo present in relation to humans. During seasonal peak periods when large numbers of adults are in close proximity to more concentrated human populations, especially when fewer cattle or other non-human hosts are available, its medical importance can dramatically increase [80]. The close association of An. aconitus with rice cultivation practices and periodic adult population peaks has been linked to increased malaria transmission in central Java during the two main periods of harvest (March-April and August-September) [185]. In fact, in the early decades of malaria control in Indonesia, knowledge of the close relationship of this species with rice and irrigation schemes lead to the development of successful, non-chemical, vector control practices using environmental and mechanical interventions such as intermittent irrigation and drainage schemes [188].

\section{Anopheles (Cellia) annularis van der Wulp}

Anopheles annularis is the nominotypical member of the Annularis Group in the Neocellia Series [6]. The Group currently includes five formally named species in southern Asia: An. annularis, An. nivipes (Theobald) and An. philippinensis Ludlow, which are widespread in the region, An. pallidus Theobald, which is known in Sri Lanka, India and Myanmar, and An. schueffneri Stanton, which occurs in Java and Sumatra. Anopheles annularis is widely distributed in southern Asia from Afghanistan eastward through areas of Pakistan, India, Nepal, Sri Lanka, Bangladesh, Myanmar, southern China, Taiwan, Thailand, Cambodia, Malaysia, Indonesia, Timor-Leste, Vietnam and the Philippines. It is an important vector of malaria in India, Nepal and Sri Lanka [13,198-206], but is considered to be of minor importance elsewhere $[80,199]$. It plays a role in malaria transmission in Myanmar [207] and has been incriminated as a vector along border areas of Thailand and Cambodia [208]. Differences observed in the vectorial capacity of $A n$. annularis may be due to variation in population densities or genetic structures in different localities. The species has been reported to occur, for example, in very large numbers in Sri Lanka [204] and India [13] in association with irrigation, and was incriminated as a vector of $P$. vivax in villages with river-irrigated rice fields in Afghanistan [209]. Anopheles annularis is regarded as a secondary vector in Myanmar [22], but is responsible for epidemic outbreaks of malaria in the Rakhine coastal region where population densities increase dramatically after major cyclone activity [210,211]. Similarly, An. annularis may transmit malaria in areas where humans are the most available hosts, for example, Maheswary et al. [212] found a high rate of sporozoite infections in An. annularis during a $P$. vivax epidemic in a village in the Narayanganj District of Bangladesh where cattle were absent near houses.

Differences observed in the banding patterns of the ovarian polytene chromosomes led Atrie et al. [213] to conclude that An. annularis consists of two sibling species in India, which they provisionally designated as species A and B. More recently, Alam et al. [214] developed PCR-restriction-fragment length polymorphism (PCR-RFLP) assays based on endonuclease restriction sites in the ITS2 and D3 regions of rDNA which accurately distinguished the two species. However, the assays were developed using specimens collected from areas where Atrie et al. [213] found chromosomal forms $A$ and B, i.e. assays were not directly correlated with cytologically identified specimens.

Species A and B are sympatric in the Shahjahanpur and Ghaziabad Districts in Uttar Pradesh, India, but only species A has been found in Assam, Haryana, Orissa and Rajasthan. Both species have been collected in non-riverine and canal-irrigated ecotypes in Shahjahanpur District. Species A has been found in similar ecotypes in districts where species B is not known to occur, and has also been found in hilly-forested areas [213]. Anopheles annularis is only considered to be a vector in areas of Assam and Orissa States where species $\mathrm{B}$ is absent. Consequently, the realisation that $A n$. annularis consists of two species does not explain why it is a vector in only certain areas of India. Whether species A and B are more widely distributed in India and in other countries needs to be investigated.

Larvae of An. annularis are typically found in clean, still bodies of water with abundant vegetation, especially ponds, swamps and rice fields [80] (Tables 5, 7). They are strongly associated with hill rice fields in Java [83] and have been found in a wide variety of habitats in Thailand, including ponds, swamps, marshes, ditches, pits, wells, sand pools, ground pools, flood pools, stream pools, stream margins, seepage springs, rice fields, animal footprints and rock pools [29] (Tables 7, 9). Harbach et al. [215] collected larvae of An. annularis in association with larvae of $A n$. minimus Theobald, $A n$. nivipes (Theobald) and An. vagus Dönitz in a rice field pool near the Thai- Myanmar border. Females will enter 
human dwellings and animal shelters [80,216]. They are primarily zoophilic (e.g. Parida et al., [216]) but are known to bite humans in the presence of cattle [217] (Table 11).

\section{Anopheles (Cellia) balabacensis Baisas}

Anopheles balabacensis is a member of the Leucosphyrus Complex, which is placed in the Leucosphyrus Subgroup of the Leucosphyrus Group within the Neomyzomyia Series. The complex also includes An. leucosphyrus Dönitz, An. latens Sallum \& Peyton and $A n$. introlatus Colless [28]. All but An. introlatus are vectors of human malaria.

Anopheles balabacensis inhabits forested areas of the Philippine Islands (Balabac, Culion, Palawan), Brunei, Malaysian Borneo (eastern Sarawak, Sabah) and Indonesia (East Kalimantan, South Kalimantan, Java, Lombok, Sumbawa, Sumba) $[28,166,218-222]$. The immature stages are principally found in shaded temporary pools of stagnant fresh water, including puddles, animal footprints, wheel tracks, ditches and rock pools (Tables 5, 9). Larvae have been collected in animal wallows in primary forest in Sabah ([223] Harbach, unpub obs). They are sometimes found at the edges of swamps, streams and rice fields, and less frequently in containers (e.g. coconut shells, cocoa pods, barrels, drums and buckets) in shaded, partially shaded or sunny locations (Tables 7 , 9).

Anopheles balabacensis is considered the main vector of human malaria in northern and eastern areas of Borneo [193,223-228], central Java [169,229] and in the mountainous area of Lombok Island [167]. Harbach et al. [221] found an infection rate of $1.3 \%$ for P. falciparum in South Kalimantan, Indonesia based on the ELISA detection of sporozoites. On Banggi Island off the northern coast of Sabah, An. balabacensis was found positive for $P$. falciparum sporozoite antigen by IRMA [227]. Based on human-landing rates and sporozoite positive females, Hii et al. [227] calculated an entomological inoculation rate of 160 infective bites per person per year, and estimated vectorial capacity to be 1.4419.70 in Kapitangan and 7.44-9.97 in Palau Darat (Indonesia). Anopheles balabacensis is considered to be a secondary vector of malaria on Palawan Island (the Philippines) [230], and Vythilingam et al. [11] found that An. (Anopheles) donaldi Reid appears to have replaced $A n$. balabacensis as the main vector in the Kinabatangan area of Sabah as a result environmental changes (deforestation) and malaria control activities. In central Java, this species is closely associated with heavily forested (natural and agricultural) foothill environments and has been collected in shaded salak palm (Salacca edulis) plantations (Bangs, unpub obs). Anopheles balabacensis is also involved in the transmission of Brugian and Bancroftian lymphatic filariasis [226,231-233].

Schultz [230] found that An. balabacensis on Palawan Island entered houses and fed on humans principally between 20:00-03:00 h. In Sabah, An. balabacensis females mainly feed outdoors, with peak activity between 22:00-02:00 h, but will also feed indoors and rest outdoors afterwards [234-238]. Chiang et al. [239], however, observed that peak biting activity occurred shortly after midnight in three villages in Sabah. In contrast, Vythilingam et al. [11] found that An. balabacensis feed outdoors throughout the night with peak activity between 19:00 and 20:00 h, whereas indoor feeding peaked between 22:00 and 23:00 h. The biting activity of An. balabacensis is strongly exophagic in the mountainous area of Lombok Island, Indonesia where biting activity was highest from 19:00-21:00 $\mathrm{h}$ and gradually decreased toward morning [167] (Table 11).

\section{Anopheles (Cellia) culicifacies Giles species complex (Culicifacies Complex)}

Anopheles culicifacies is a complex of species within the Funestus Group of the Myzomyia Series [6]. The Culicifacies Complex includes five isomorphic species informally designated species A, B, C, D and E. The members of the complex have been cytogenetically separated and exhibit biological differences in their behaviour, seasonal prevalence, distribution and vectorial capacity [240,241]. More recently, molecular assays have been developed, including PCR-RFLP assays [242,243], allele-specific PCR assays [244,245], and a multiplex PCR [246]. However, no single currently available application can directly identify all five species, indicating that the techniques are weak, raising some doubt about their validity. More sequences need to be analysed in order to identify those that show more clear species differences (Manguin, unpub obs).

The Culicifacies Complex is widely distributed across Southeast Asia, including southern China, India, Pakistan, southern Afghanistan and Iran, with a western extension into the Arabian Peninsula (Yemen) and Ethiopia [99,209,247-250]. The bionomics and ecology of the species within this complex have been largely studied in India [23,241,251] and Sri Lanka [99,252,253], but there is a general lack of detailed information from other regions, especially the western areas [8]. Four species of the complex (A, C, D, E) are reportedly malaria vectors in India where they are apparently responsible for transmitting $60-65 \%$ of all cases of malaria in periurban and urban environments [254]. Anopheles culicifacies E, due to its high anthropophilic and endophilic behaviour [255,256], is the most important and efficient vector of $P$. falciparum and $P$. vivax in southern India and Sri Lanka. Species A, C and D appear to be mainly 
zoophilic with very low anthropophilic indices of 3-4\% [251] (Table 11). Therefore, these three species generally play very minor roles in malaria transmission compared to species E [257]; however, species $C$ was found to be responsible for local malaria transmission in deforested riverine areas of central India [258]. Due to its highly zoophilic behaviour, species B is considered to be a poor or non-vector [241,259] (Table 11). This species has the widest distribution of all members of the complex, occurring from Iran and Sri Lanka to Southeast Asia, and is the only species of the complex found in the far eastern areas of southern China (Sichuan), Vietnam, Laos, Cambodia and northwestern Thailand [180,247-250,253,260]. Species B occurs in sympatry with other species of the complex, particularly species E, in western areas of its distribution. Sympatric populations of two or more sibling species are also common in India [254].

Species of the Culicifacies Complex are abundant in plains, hilly and mountainous areas up to elevations of 1500 to $2000 \mathrm{~m}$ in Afghanistan (Kabul region) and the Indian Himalayas [23,261]. They occur in different ecotypes, ranging from forested areas with perennial streams to deforested riverine ecosystems and irrigated areas. Larval habitats include irrigated canals, stream margins, seepages, borrow pits, hoof marks, rock pools, sandy pools near rice fields, rock quarries, newly dug pits, ponds, domestic wells, tanks and gutters [23,249,252,254,262-264] (Tables 7, 9). Immature stages develop in fresh-water habitats but tolerance to moderate salinity has been reported in Oman where larvae have been collected in concrete reservoir tanks containing brackish water [265] (Table 5). Similarly, species E is able to tolerate variable salinity due to monsoonal rain in Sri Lanka [252] where it otherwise exploits a wide range of aquatic habitats, reflecting the significant environmental adaptability of this malaria vector [264]. Nanda et al. [258] studied the presence of species A, B and $\mathrm{C}$ in forested and deforested ecosystems in Orissa (India) and found that An. culicifacies C (71\%) greatly outnumbered species $B$ in forested areas, whereas species C (78\%), B (21\%) and A (1\%) were present in quite different proportions in deforested areas. These data also reflect the ability of An. culicifacies $\mathrm{C}$ to inhabit different ecosystems. In India, species A has been shown to be more abundant in villages with domestic wells, whereas species B was found in higher densities in villages with streams [23]. Studies have shown that adult biting activity occurs during the first half of the night in cooler months (November-March) and during the second and third quarters of the evening in the warmer months (September-October), whereas others reported peak biting activity occurring around 23:00 h to midnight $[266,267]$. Post-feeding behaviour of the species showed a higher tendency for resting indoors, mainly in cattle sheds, but outdoor resting has also been reported $[268,269]$. As members of the Culicifacies Complex exhibit distinctly different vectorial capacities and behaviour, a more thorough study of the bionomics of each species must be undertaken to specifically and efficiently target control efforts against those species involved in malaria transmission.

\section{Anopheles (Cellia) dirus Peyton \& Harrison species complex (Dirus Complex)}

Species of the Dirus Complex are closely related to members of the Leucosphyrus Complex, and this has been the cause of considerable confusion in the published literature [8]. Numerous studies, mainly based on crossing experiments, cytogenetics, allozyme data and more recently molecular methods, have been necessary to recognise the individual species and to confirm their taxonomic status [28,220,270-274].

Members of the Dirus Complex inhabit forested mountains and foothills, cultivated forests, plantations (e.g. rubber) and forest fringes. As Rosenberg et al. [275] stated, "The danger from An. dirus s.l. is not only that it is very resistant to control within its habitat but that it is an extraordinarily efficient vector, so long-lived and anthropophilic that only a small population is necessary to maintain high malaria endemicity". The situation is, however, more complicated as the Dirus Complex includes seven species that vary from highly competent vectors of malaria and Bancroftian filariasis to non-vectors. Each member of the complex has now been formally named: An. dirus (formerly An. dirus species A), An. cracens Sallum \& Peyton (formerly sp. B), An. scanloni Sallum \& Peyton (formerly sp. C), An. baimaii Sallum \& Peyton (formerly sp. D), An. elegans (James) (formerly sp. E), An. nemophilous Peyton \& Ramalingam (formerly sp. F) and An. takasagoensis Morishita [218,274,276,277]. The primary disease vectors are $A n$. dirus and $A n$. baimaii, which transmit $P$. falciparum and $P$. vivax, as well as Wuchereria bancrofti $[7,19,278-281]$. Both species are highly anthropophilic, exophagic as well as endophagic and exophilic [181,271,278,280,282-284] (Table 11). Studies have shown that biting activity is species-specific, for example in Thailand, An. dirus has a tendency to bite between 20:00 and 23:00 h and An. baimaii from 22:00 h to $02: 00 \mathrm{~h}[28,274,285]$, although in India earlier biting at 20:00-21:00 h was also recorded for An. baimaii [278] (Table 11). Anopheles scanloni is also anthropophilic and plays a more focal role in malaria transmission of both P. falciparum and P. vivax in Thailand [286]. This is an early evening biter with peak activity starting at dusk, between 18:00-19:00 h [285]. There is no clear evidence that An. cracens (restricted to the Thai-Malaysian 
peninsular) and An. elegans (only present in hill forests of southwestern India) are involved in malaria transmission $[274,286]$.

The recent development of two allele-specific PCR assays that identify sympatric species, such as $A n$. dirus, An. cracens, An. scanloni, An. baimaii and An. nemophilous [287,288], will allow for more precise determination of the degree by which each species may be involved in malaria transmission. The two remaining species of the complex, An. nemophilous and An. takasagoensis, the latter species being restricted to Taiwan, appear to be non-vectors of human malaria due to their strict zoophilic behaviour $[271,276]$.

Larvae of the Dirus Complex typically inhabit small, shallow, usually temporary, mostly shaded bodies of fresh, stagnant (or very slowly flowing) water, such as pools, puddles, small pits (e.g. gem pits), animal footprints (e.g. elephant footprints), wheel ruts, hollow logs, streams and even wells located in primary, secondary evergreen or deciduous forests, bamboo forests and fruit or rubber plantations [7,271,289-292] (Tables 5, 9). Water can be clear or turbid [293], and habitats with nitrogenous wastes, due to elephant and buffalo excreta or rotten leaves, appear more productive [291] (Table 5). These species are most abundant during the rainy (monsoon) season due to the larval requirement and oviposition preference for small temporary pools [271,284,293,294].

\section{Anopheles (Cellia) farauti Laveran species complex (Farauti Complex)}

See Anopheles (Cellia) punctulatus Dönitz species group below.

\section{Anopheles (Cellia) flavirostris (Ludlow)}

Anopheles flavirostris is a member of the Minimus Subgroup within the Myzomyia Series [295]. For many decades, this species was regarded as a subspecies of $A n$. minimus, but once elevated, its species status has been supported by most authorities $[119,180]$. Somboon et al. [296] presented conclusive evidence supporting specific status using hybridisation experiments and internal morphology (cibarial armature). Molecular studies of rDNA have further substantiated An. flavirostris as a valid species [295,297,298]. All previous records of An. minimus from the Philippines, Sabah and Indonesia are now considered invalid with only An. flavirostris regarded as present in these areas.

Anopheles flavirostris occurs extensively throughout the Philippines, through much of Indonesia, in eastern Malaysia (Sabah, Borneo) $[19,80,296,298]$ and TimorLeste [92]. In Indonesia, it has been reported on the larger islands of Sumatra, Java, Kalimantan and Sulawesi, and is scattered across the smaller islands of the Lesser
Sunda island group, extending as far east as Timor [173]. Records from smaller islands include Bali, Lombok, Sumbawa, Sumba, Flores and western Timor [166-168,170,296,298,299] (Bangs, unpub obs). Older records of its presence in the Maluku island group (Seram) have not been verified. Interestingly, species distribution on the island of Borneo (Kalimantan) appears confined to the eastern side of the island and nearer the coast. It has not been reported from northwestern (Sarawak, Malaysia) or western Kalimantan. It occurs in sympatry with three other species of the Minimus Group: An. aconitus (Indonesia), An. filipinae Manalang and An. mangyanus (Banks) (the Philippines). The absence of a pale fringe spot at vein $1 \mathrm{~A}$ on the hind margin of the wing distinguishes this species from An. aconitus and An. filipinae. The species differs from An. mangyanus (an incidental malaria vector in the Philippines) in usually lacking a presector pale spot on the costa or the absence of pale scales basal to the sector pale spot.

Epidemiologically, this species has been incriminated frequently as a vector of human malarial parasites in the Philippines [300,301] and is regarded as the primary vector throughout much of the country [302]. Despite normally low numbers of sporozoite-infected mosquitoes detected, under favourable circumstances low infective rates remain sufficient to maintain endemic transmission or cause outbreaks [302]. It has been implicated in malaria transmission above $1000 \mathrm{~m}$ elevation in Luzon (Villanueva \& Kalaw in [302]). It has also been incriminated as a vector of $W$. bancrofti on Luzon and Palawan Islands in the Philippines [80]. It is a confirmed malarial vector in Sabah (Malaysian Borneo) along the eastern coast (Banggi Island, Semporna, Pitas) [223] (Bangs, unpub obs). Only a few historical records of natural infections are known from Indonesia $[185,188]$, specifically in western Java, Sulawesi and Palau Laut in southeastern Kalimantan (Borneo). In Indonesia, this species is seldom encountered in humanlanding collections and is regarded as only an incidental, focal vector.

Anopheles flavirostris is quintessentially a 'foothill', stream-breeding species but is by no means entirely restricted to such lotic environments (Table 5). In the Philippines, An. flavirostris can be found from the coastal plains near sea level to elevations up to $1500 \mathrm{~m}$ [302], although it is more commonly found no higher than 600 $m$ elevation throughout its range $[119,167,188]$.

Given its importance as a malaria vector, the majority of bionomic information on this species has come from the Philippines [302,303]. Characteristically, this species has a high preference for clear, slow-moving fresh-water habitats that are typically partly shaded by surrounding overhead vegetation and with margins containing emergent plants or grasses [304] (Table 5). In the foothills of 
western Java, it has been commonly collected from margins of forested streams with moderate to high flow rates [174]. It can also be found at the edges of seepage pools, slow-flowing, grassy river edges, canals and irrigation ditches. It has been reported from natural wells and occasionally stagnant pools, and very rarely from rice fields or ponds [188] and pools in stream beds [305] (Tables 7, 9). It typically has a low tolerance for salinity [119] and prefers more alkaline (7.3-8.2) water [302]. Foley et al. [306] also reported that most larvae occurred in areas dominated by overhanging vegetation other than grass. They also found early instar larvae were more likely to be present in heavily shaded sites, suggesting sunnier areas were less preferred as oviposition sites, whereas overall larval abundance was higher in less shady locations. Late instars were more evenly dispersed and their presence only weakly related to available shaded conditions (Table 5). Larval habitats have been described as being relatively close to human habitation compared to many other species $[174,306]$. In western Java, Stoops et al. [174] examined environmental determinants of spatial distribution for Anopheles and found An. flavirostris associated with lower elevation foothill sites, lower water temperatures with less acidity, greater water depth, higher water current, rocky substrate, higher canopy cover, greater forested riparian vegetation and higher amounts of low emergent vegetation compared to most other anopheline species in the area.

Adult females are primarily zoophilic, preferring to feed on larger animals (e.g., water buffalo, cows), although they will readily attack humans both indoors and outdoors [167,301,305,307]. Hii et al. [227,308] described this species as primarily human-biting and endophagic in Sabah. It is regarded as exophagic, but varies depending on the circumstances and season [307]. This species may be opportunistic in feeding habits and can show a varying preference for biting location that appears dependent on the availability of hosts. Near equal biting proportions between indoors and outdoors have also been reported [187,227,230,301,305,307]. Females blood-feed throughout the evening with lower numbers in the early evening gradually increasing to peak biting frequency on humans nearer midnight and for several hours afterwards (22:00-03:00 h), with a sharp drop off in activity before dawn $[187,230,305,307,308]$ (Table 11).

Females are strongly exophilic, resting during the day on low vegetation, often near cool, damp overhanging stream banks close to larval habitats [302]. Very seldom are they found resting indoors during daylight hours, although pre- and post-feeding indoor resting does occur $[227,309]$, but rarely for long periods before exiting the house (Table 11). The flight range is considered short, at a maximum of 1-2 km from origin (Russell \& Santiago in [302]).

\section{Anopheles (Cellia) fluviatilis James species complex (Fluviatilis Complex)}

Anopheles fluviatilis is a complex of species within the Funestus Group of the Myzomyia Series [6]. Members of the complex are widely distributed in forested hills and mountainous regions of southwestern Asia, including Iran, Pakistan, Afghanistan, India, Nepal, Bangladesh and Myanmar [160,161,249,258,283,310]. However, little detailed information is available on the bionomics, ecology and distribution of the species outside of India and Iran [8]. The complex includes three sibling species, informally designated $\mathrm{S}, \mathrm{T}$ and $\mathrm{U}$, based on cytogenetic differences [310], and a form $\mathrm{V}$ of uncertain status [311]. Molecular techniques have been developed to distinguish the three sibling species [312-314]. Species $T$ has the widest distribution, which includes India, Nepal, Pakistan and Iran [311]. Species $U$ has been recorded in northern India and Iran, and species $\mathrm{S}$ appears to be restricted to India [311,315]. Anopheles fluviatilis S is the most anthropophilic and endophilic species of the complex [258], and is regarded as a highly efficient malaria vector in hilly regions of India [257,316]. Anopheles fluviatilis $\mathrm{T}$ and $\mathrm{U}$ are primarily zoophilic, exophagic and exophilic, and are considered to be poor or non-vectors in India [316] (Table 11). However, in Pakistan, Nepal and Iran, species $\mathrm{T}$ has been recorded as an important malaria vector in general, or a localised vector for maintaining malaria in mountainous and hilly regions [199,317,318]. Biting activity begins around 19:00 $\mathrm{h}$ and peaks between 20:00 $\mathrm{h}$ and 21:00 h, but may also occur throughout the night until dawn without an apparent peak [161] (Table 11). A study conducted in Orissa State of India showed that members of the complex are essentially absent in deforested areas, but An. fluviatilis $\mathrm{S}$ is the predominant species in forested areas (98\% species S; 2\% species T) [258].

Larvae of An. fluviatilis are generally associated with slow-flowing streams or river margins, in direct or diffuse sunlight. They have also been reported from rice fields, often in low numbers, possibly washed into the fields from the irrigation channels where they tend to be found in higher densities [158,163,191,294,319-324] (Tables 5, 7, 9)

\section{Anopheles (Cellia) koliensis Owen}

See Anopheles (Cellia) punctulatus Dönitz species group below.

\section{Anopheles (Cellia) leucosphyrus Dönitz and An. (Cel.) latens Sallum \& Peyton}

Anopheles leucosphyrus and An. latens are members of the Leucosphyrus Complex, which is placed in the 
Leucosphyrus Subgroup of the Leucosphyrus Group within the Neomyzomyia Series. The subgroup also includes An. balabacensis Baisas and An. introlatus Colless [28]. All but An. introlatus are competent vectors of human malaria.

Anopheles leucosphyrus and An. latens are sister species [325]. The former is found in forested areas of Sumatra and the latter in forested areas from the extreme south of Thailand through peninsular Malaysia, and northern and eastern areas of Borneo (excluding Sabah except its western border area with Sarawak) [274]. Both species are important vectors of malaria in areas where they occur. Anopheles leucosphyrus and $A n$. latens were regarded as the same species (An. leucosphyrus) until Baimai et al. [326] provided evidence from mitotic karyotypes and cross-mating studies that they were separate species. Most of the published literature on "An. leucosphyrus" refers to An. latens, and little information pertains to the genetic species in Sumatra that is now known as An. leucosphyrus.

Females of $A n$. leucosphyrus are attracted to humans inside and outside houses situated at the edge of forest [274,326] (Table 12). This species has been shown to be a vector of human malaria in Sumatra ([80] and in older literature cited by Sallum et al. [274]). Little else is known about its bionomics but it is presumably similar to other members in the Leucosphyrus Group.

Anopheles latens is a primary vector of human malaria in forested areas and villages near forests in Sarawak [327-330]. Females bite throughout the night, but peak activity occurs at different times in different locations. de Zulueta [328] found that biting females were more abundant between 24:00 $\mathrm{h}$ and 02:00 $\mathrm{h}$ in mountainous areas, Colless [327] observed peaks of activity from 22:00-04:00 h during the dry season and from 22:0024:00 $\mathrm{h}$ in the wet season in the Akah River region, and Chang et al. [329] recorded peak activity around midnight in forested areas and soon after dusk in village settlements in the Baram District. Adults do not rest in houses by day, but will enter to bite at night, mostly after 22:00 h [327] (Table 12). Macdonald \& Traub [331] and Wharton et al. [332] noted that An. latens was collected more frequently in the canopy than at ground level in lowland secondary dipterocarp forests in peninsular Malaysia. The species also occurs in environments that have been altered by human activities, for example, areas of secondary forest with fruit and rubber plantations [274].

In Sarawak, Chang et al. [329,330] found An. latens more abundant and malaria transmission more intense at farms located in forest fringe areas than in village settlements further removed from forest. The entomological inoculation rate for An. latens was calculated at 0.11 infective bites per person per night in a village perimeter site and 0.15 in a forested area in the Baram District [329]. In contrast, Chang et al. [330] estimated the inoculation rate in farm huts in the Belaga District to be 0.023 [330]. Harbach et al. [221] recorded a sporozoite infection rate of $1.0 \%$ in a remote village in South Kalimantan, Indonesia, where $A n$. latens females attacked humans in higher numbers than in nearby forest.

In addition to human malarial parasites, An. latens is also known to transmit the monkey malarial parasite Plasmodium knowlesi to humans in the Kapit District of Sarawak [333]. Tan et al. [334] found that An. latens is the main vector of $P$. knowlesi in dense jungle and forest fringes in the district. Nearly $90 \%$ of females attracted to humans were collected in forest (50\%) and at a farm located amid fruit trees and secondary vegetation (40\%). In contrast, only $10 \%$ were collected in a longhouse (traditional home of indigenous people) surrounded by trees and shrubs near a river, and of these, 71\% were collected outdoors. The inoculation rates of $P$. knowlesi by An. latens in the forest and farm were estimated at 4.6 and 7.8 infective bites per person per year, respectively.

Like other members of the Leucosphyrus Group, larval habitats of $A n$. latens are mostly shaded temporary pools and natural containers of clear or turbid water on the ground in forest areas (Table 6). Wharton [335] noted that larvae of $A n$. latens were usually found in clear seepage pools in forest swamps in peninsular Malaysia. In Sarawak, Colless [327] found larvae in pools beside a forest stream and in swampy patches in hilly country. Habitats occupied by An. latens in Thailand include stump ground holes, sand pools, ground pools, flood pools, rock pools, stream pools, stream margins, seepage-springs, wheel tracks and elephant footprints [29,274] (Table 10).

\section{Anopheles (Cellia) maculatus Theobald species group (Maculatus Group)}

Anopheles maculatus belongs to the Maculatus Subgroup within the Maculatus Group of the Neocellia Series. In addition to $A n$. maculatus, the group includes eight other formally named species [6,336]: An. dravidicus Christophers (the second member of the Maculatus Subgroup); An. notanandai Rattanarithikul \& Green, An. rampae Harbach \& Somboon (formerly An. maculatus species K; see Somboon et al. [336]) and An. sawadwongporni Rattanarithikul \& Green, which belong to the Sawadwongporni Subgroup, and four species, $A n$. dispar Rattanarithikul \& Harbach, An. greeni Rattanarithikul \& Harbach, An. pseudowillmori (Theobald) and An. willmori (James), which are unplaced within the group [337]. Members of the group have a varied distribution from Afghanistan and Pakistan to southern China, Indonesia and the Philippines. Two species, $A n$. dispar and $A n$. greeni, are found exclusively in the Philippines 
$[338,339]$ and can be identified using a PCR-RFLP assay [339]. The application of this molecular method may help shed light on the vector status of these two species as data collected on previously undifferentiated $A n$. maculatus s.l. in the Philippines are considered unreliable. In addition, two allele-specific PCR assays have been developed to distinguish An. dravidicus, An. maculatus, An. pseudowillmori, An. sawadwongporni and either An. willmori [337] or An. rampae [340]. These species are variously involved in malaria transmission [8,341-343]. However, again, the vector role of each species is not precisely known due to previous misidentifications based solely on overlapping morphological characters. Further uncertainty arises within this group as the vectorial capacity of a species appears to vary depending on geographical location. In general, females are more strongly attracted to cattle than humans, but freely bite people both inside and outside houses (Table 12). Anopheles maculatus and An. sawadwongporni appear to be the least zoophilic of the species and exhibit early biting activity, peaking between 18:00 h and 21:00 h $[155,182,215]$. Even though An. maculatus has the widest distribution of all species of the group, it is only an important vector of human malarial parasites in hilly areas of eastern India, southern Thailand, peninsular Malaysia and south-central Java [169,196,281, 341,344]. Anopheles sawadwongporni has been found with malaria sporozoite rates of $1-2 \%$ in Thailand where it is considered an important vector [345,346]. Anopheles pseudowillmori is a secondary vector in northwestern Thailand along the Myanmar border [196,272]. Anopheles willmori is one of the primary vectors in Nepal [347], but it is seldom collected in Thailand and does not appear to be involved in malaria transmission there. Anopheles dispar and An. greeni, regarded as secondary vectors in the Philippines, exhibit strong exophagic and zoophilic behaviours, with a biting rate on water buffalo that is 50 times greater than on humans [305]. Anopheles notanandai, An. dravidicus and An. rampae are not known to be involved in malaria transmission $[33,336]$.

Members of the Maculatus Group are typically found in or near hilly and mountainous areas. Larvae have been collected in a diverse number of permanent or semi-permanent bodies of clean water that are often exposed to direct sunlight, including ponds, lakes, swamps, ditches, wells, different types of pools (grassy, sandy, ground, flood, stream), margins along small, slow-flowing streams, gravel pits along stream margins, seepages, springs, rice fields, foot and wheel prints, and occasionally tree holes and bamboo stumps $[29,189,215$, 348-351] (Tables 6, 8, 10). More specific studies have shown that each species has a preferred habitat. For instance, larvae of An. willmori are found only along stream margins at altitudes between 990 and $1450 \mathrm{~m}$ in northern Thailand, whereas larvae of An. pseudowillmori have been collected primarily in rice fields, stream margins, ponds, pits and wells [29,351]. Anopheles maculatus prefers to use pools of water formed on the banks of rivers and waterfalls. The most common larval habitats are shallow pools 5-15 cm deep with clear water, mud substrate and emergent plants. This species also requires, or strongly prefers, open to partially shaded habitats. Habitats are commonly located at 100-400 m from the nearest human settlement [352] (Table 6). The combination of the early evening biting activity of these malaria vectors (particularly An. maculatus and $A n$. sawadwongporni) and their zoophilic and exophilic tendencies indicates that they will be less affected by vector control methods based on IRS and ITNs. However, a strategy of creating a barrier using insecticide on vegetation near cattle or other animal hosts may prove significant in the control of these vectors [182].

\section{Anopheles (Cellia) minimus Theobald species complex (Minimus Complex)}

The Minimus Complex belongs to the Minimus Subgroup within the Funestus Group of the Myzomyia Series. Anopheles minimus s.l. is considered a primary malaria vector taxon in the hilly forested regions of mainland Southeast Asia. Anopheles minimus s.l. comprises three sibling species, namely An. minimus (formerly species A), An. harrisoni Harbach \& Manguin (formerly sp. C) and An. yaeyamaensis Somboon \& Harbach (formerly sp. E) [353-355]. Whereas An. minimus and $A n$. harrisoni have a broad distribution in much of Southeast Asia [8], An. yaeyamaensis is restricted to the Ryukyu Archipelago in southern Japan where it played a major role as a disease vector until 1962 when malaria was eradicated [356,357]. Despite historical records of An. minimus in Indonesia, all are considered invalid and now regarded as An. flavirostris. The two other species, An. minimus and An. harrisoni, are vectors of malaria parasites throughout their respective distributions, although further investigation needs to be conducted on An. harrisoni as its implication in malaria transmission appears weaker than that of An. minimus [24]. Anopheles minimus is also involved in the transmission of W. bancrofti in southern China [358] and most likely in Thailand, as demonstrated under laboratory conditions by Pothikasikorn et al. [359]. Larvae are generally found in small to moderate-sized streams or canals with slowrunning, clear and cool water, partially shaded and with grassy margins where females prefer to lay their eggs $[180,189,351,360]$ (Tables 6,10$)$. They develop in various pools (rock, ground, stream and seepage) [180,221] (Table 10). Unusual larval habitats for An. minimus (e.g. rain water tanks) have also been reported in the suburbs 
of Hanoi, Vietnam [361]. Anopheles minimus s.l. is commonly found at elevations ranging from 200 to $900 \mathrm{~m}$ and is rare at altitudes above $1500 \mathrm{~m}$ [22,180,362]. In northern Vietnam and western Thailand, An. minimus occupies a greater variety of habitats, ranging from dense canopy forest to open agricultural fields, particularly traditional rice agro-ecosystems (Table 8). Anopheles harrisoni has a narrower habitat preference, being more closely linked to recently altered agro-ecosystems (e.g. maize cultivation) in deforested areas [24,34]. These differences in habitat choice may explain the wider distribution of An. minimus in Southeast Asia, although $A n$. minimus and $A n$. harrisoni are found sympatrically in several regions, including southern China, northern and central Vietnam [38], northern Laos, western and northern Thailand (Somboon, pers comm) and central and eastern Myanmar [8]. Anopheles minimus is the only species of the Minimus Complex found in Cambodia and northwestern India, as well as other regions of Southeast Asia not mentioned above $[24,65,363]$. In contrast, only in the central part of China (up to $32.5^{\circ} \mathrm{N}$ latitude) can $A n$. harrisoni be found in the absence of $A n$. minimus [358].

The adult behaviour of $A n$. minimus s.l. is reported as highly diverse for two main reasons: (1) most studies do not differentiate $A n$. minimus and An. harrisoni and (2) these two species are highly opportunistic in their habits, exhibiting considerable behavioural and ecological plasticity [24]. Females of An. minimus mainly bite humans (up to $93 \%$ in Assam, India), but the degree of anthropophily/zoophily depends on the availability of alternative hosts (e.g. cattle) [181,364,365]. This species is mainly endophagic in India, Thailand and central Vietnam, and more exophagic in Cambodia and northern Vietnam [181,360,366] (Table 12). Studies showed that housing in central Vietnam, made with incomplete walls of split bamboo and very large eaves, allows easy entry of the mosquito which would otherwise show exophagic behaviour [181]. Its resting behaviour is reported as exophilic in southern China, Thailand and Vietnam, and mainly endophilic in India [181,360,366]. However, the degree of endophagy and endophily of An. minimus is also largely influenced by the use of IRS, provoking either a modified behavioural response [367] or a drastic reduction in population density [368]. In contrast, the few studies conducted on An. harrisoni have shown a greater tendency for exophagy, exophily and zoophily and thus its role in malaria transmission is more questionable [181,369,370], despite it being reported as a main vector in China [358]. Anopheles harrisoni exhibits two peaks of biting activity in western Thailand, the first in the early evening, between 18:00-21:00 h, with a second, smaller peak from midnight to $02: 00 \mathrm{~h}$ or from 03:00-06:00 h [364,369]. The early evening peak (before
22:00 h) has also been observed in northern Vietnam [181]. Anopheles minimus tends to bite later, with peak activity occurring around 22:00 h in Cambodia and Thailand, after 22:00 $\mathrm{h}$ in Vietnam and between 01:0004:00 h in Assam, India [181,215,360] (Table 12).

Clearly more studies are required on An. minimus and $A n$. harrisoni across a wider geographical area as many uncertainties exist in relation to their respective habitats, behaviour, involvement in malaria transmission and geographic distribution. These studies will need to utilise molecular assays to distinguish the sibling species, as well as related sympatric species such as $A n$. aconitus, $A n$. pampanai Büttiker \& Beales and $A n$. varuna Iyengar [151,152]. Moreover, the many older records of $A n$. minimus from the Indonesian archipelago require confirmation, either based on adults with associated larval and pupal exuviae or, preferably, DNA analysis (Harbach, unpub obs).

\section{Anopheles (Cellia) punctulatus Dönitz species group (Punctulatus Group)}

The Punctulatus Group is comprised of at least 12 sibling species which collectively span most tropical areas of the Australasian region [21,371]. Some members in the group are major vectors of malaria, and in many areas they also transmit the nocturnal periodic form of Bancroftian filariasis (W. bancrofti) [372-387]. The major malaria vectors include $A n$. punctulatus, $A n$. koliensis Owen, An. farauti Laveran, An. hinesorum Schmidt and An. farauti No. 4 [388-392] (Bangs, unpub data). The important characteristics these species share include an ability to occur in high densities, a predilection to feed on humans (Tables 11, 12) and a high vectorial competence (i.e. ability to develop human malaria parasites). Most of the information available on vector incrimination is based on spatially and temporally limited studies from a small number of localities, predominately in PNG.

The species group extends from the far eastern regions of Indonesia (Maluku island group and Papua), PNG (including the Bismarck Archipelago) and into the southwestern Pacific to the limits of all anopheline species distributions (Solomon Islands and Vanuatu) [393]. The group occupies a variety of different habitats, predominately in the lowlands, but extending from the coastal zone to elevations as high as $2250 \mathrm{~m}$ above sea level. Only recently has the taxonomy and phylogeny of this group become better defined using DNA-based molecular methods to overcome the inherent problems of accurately identifying both allopatric and sympatric populations morphologically (because of identical or overlapping characters) and those that comprise a complex of near-identical cryptic species (Anopheles farauti s.l.) [393-396]. The geographical isolation of numerous 
insular populations, and in some cases populations separated by significant physical barriers, has lead to the genetic divergence, speciation and radiation in the group. By far, the centre of evolution for this group has taken place on the island of New Guinea [31]. This has resulted in some species showing niche-specific habitat preferences whereas others show a much wider selection and diversity in habitats and behaviour. However, differences in biology and behaviour among the members of the Punctulatus Group do not appear to be reliable characters for determining phylogenetic relationships, and even closely related sympatric species (e.g. small rDNA genetic distances) can show very dissimilar bionomics [371,397].

Across the range of species, oviposition sites appear variable [31] and often dependent on seasonal availability. Generally, most species utilise earthen-bound (often non-porous, clay-like substrates) collections of fresh water that are exposed to direct sunlight either entirely or partially. Water sources shaded by thick jungle are unfavourable. Only a few members of the Farauti Complex show salt-tolerance, but brackish water is not obligatory for oviposition $[30,371,398]$. Ideally, water is stagnant, clear to muddy (turbid), but never heavily polluted [399] (Tables 5, 6). For those species that have been studied in more detail (An. punctulatus, An. koliensis and An. farauti s.l.), most show a high degree of synanthropy, and although females appear to be opportunistic blood-feeders that attack a wide range of hosts, they often have a stronger preference for humans. Other animals (pigs, dogs, cats, cattle, goats, fowl) can serve as alternative or primary blood sources, depending on locality [384]. In general, the primary vector species of the group are more exophilic in resting habits and facultatively exo- and endophagic in host blood feeding (Tables 11, 12). Outside resting sites are largely unknown or otherwise poorly described. Blood-feeding activity is predominately nocturnal whereas frequency and peak activity appears variable by locality, prevailing environmental conditions, season, time and investigative methods used for study [377,384,400-402]. Other studies suggest physiological condition (e.g. age, parity) and malaria infection can influence biting frequency and time [401,403]. Larval habitats of all vector species of the group are generally found in close proximity with human habitation.

The relatively recent understanding of the inter-specific morphological variation and genetic diversity in this taxon casts doubt on past data on mosquito behaviour, larval habitat preferences $[377,384,404]$ and on the interpretation of those studies conducted before the advent and common use of biochemical and molecular methods to accurately identify species [371,389,391,394,396, 405-407]. Moreover, intra-species heterogeneity in both bionomics and behaviour over each species' range further complicates interpretation of the data collected before the existence of sibling species within the group was fully recognised and appreciated. Variations in study designs also undoubtedly contribute to the apparent heterogeneity, and sometimes, conflicting observations. More recently, studies have begun to identify specific differences in ecology and behaviour (e.g., larval habitats, biting cycles and host preferences) of some of the sibling species using molecular-based (primarily nuclear and mitochondrial DNA) identification techniques [391,394,408,409]. However, much more work is needed on the group to better understand the bionomics, respective role and epidemiological contribution of each species/morphotype in malaria and filarial transmission and to improve vector control strategies.

In general, there is more published work describing species distribution and adult behaviour in relation to disease transmission and control but far less on larval biology and habitat characteristics [31,371,410,411]. Moreover, compared to PNG, northern Australia and the malaria endemic island groups in the southwestern Pacific, there is a significant paucity of information on this species group from Papua (western half of New Guinea Island) and the Maluku Archipelago in eastern Indonesia.

\section{Anopheles (Cellia) punctulatus Dönitz species complex (Punctulatus Complex)}

Anopheles punctulatus is the nominotypical member of the Punctulatus Group of the Neomyzomyia Series. Anopheles punctulatus s.l. comprises two apparent species, An. punctulatus and An. sp. near punctulatus [393]. Anopheles sp. near punctulatus is relatively uncommon and has only been found in a few remote highland localities on the island of New Guinea (Papua, Indonesia and PNG), and very little is known about its biology or role in disease transmission $[31,392,412,413]$. Anopheles punctulatus, however, is highly susceptible to infection by Plasmodium parasites and is an efficient and important vector of human malaria in many areas throughout its range. This species is also a vector of periodic Bancroftian filariasis in New Guinea and Guadalcanal $[374,378,386,387]$. It can be found in lowland river valleys and plains with extensions up to elevations above $1700 \mathrm{~m}$, possibly extending above $2000 \mathrm{~m}$ on occasion [31]. Its distribution appears to be very limited west of New Guinea Island (excluding Halmahera Island in northern Maluku, its presence remains questionable throughout the rest of the island chain) and is apparently of less epidemiological importance moving eastward of the PNG mainland into the Bismarck Archipelago and the Solomon Islands chain [371,390]. 
The immature stages of An. punctulatus prefer small, scattered, shallow, sunlit (although partial shade is tolerated) temporary pools of fresh water (Tables 6, 10). Oviposition has been observed on muddy pools and even moist soil [399]. Water can be clear or turbid (muddy), but never brackish. In some cases, high organic content (e.g. animal excrement, typically pigs) is tolerated (Bangs, unpub data) (Table 6). Most transient sites are maintained by rainfall or are found in areas with high water tables. Other natural sites include sand or gravel ground pools in small streams and riverbeds, and larvae are only occasionally found in rock pools [31] (Table 10). Often sites are completely free of natural predators with little or no vegetation (occasionally algae or sparse emergent plants). This species will generally only thrive in areas with perennial rainfall, however eggs can withstand desiccation and larvae have the ability to survive in damp mud in the absence of free water for several days during limited periods of drought [399]. Often man-made small ground depressions or those created by animals (rooting pigs, hoof prints) become ideal habitats, as well as recently disturbed areas such as land clearing for gardens and road construction, and natural landslides. Larvae are able to withstand water temperatures exceeding $40^{\circ} \mathrm{C}$ and typically have rapid growth and a short development period to adults (5-9 days). High densities of larvae and general abiotic conditions of recently created sites can result in significant cannibalism as a survival mechanism. Not infrequently, this species is found in habitats with $A n$. farauti s.l. and $A n$. koliensis.

Anopheles punctulatus is particularly effective at exploiting disturbed ecology [414]. Populations may reach high densities in very short periods of time when environmental and seasonal conditions are favourable. Under optimal conditions with rapid, synchronous larval development, this species can quickly invade recently disturbed (cleared) and previously uncolonised areas to produce large numbers of adults. The efficiency by which this species can quickly exploit sudden and dramatic changes in habitat (e.g. temporary pools formed by recession of rivers in drought conditions) has resulted in severe and unexpected outbreaks of malaria in the highlands of New Guinea [415].

Adults are often found in close proximity to human habitation and larval habitats, with females readily attacking humans outdoors but also entering houses in search of hosts. Individuals that feed in houses may rest indoors for the entire evening and daytime but the vast majority of females leave before dawn to rest outdoors $[399,416,417]$. Feeding frequency and peak activity is variable by locality, environmental conditions and season with peak activity occurring around or after midnight in some areas, and the majority of biting occurring before midnight in other localities (Table 12). Flight dispersal is regarded as limited, generally under $1 \mathrm{~km}(0.4-2.4 \mathrm{~km})$ [399].

\section{Anopheles (Cellia) farauti Laveran species complex (Farauti Complex)}

The Farauti Complex is comprised of eight cryptic (isomorphic) species and shows the widest distribution and greatest genetic divergence among members in the Punctulatus Group [393,418]. The complex extends from the Maluku island group (Moluccas) in Indonesia to the western Pacific (Vanuatu) in the east. Anopheles farauti s.s., An. hinesorum Schmidt (formerly An. farauti No. 2) and $A n$. farauti No. 4 are the only members that are considered to be important malaria vectors [391,392]. A newly identified taxon, tentatively named An. farauti No. 8 [419] has also been incriminated as a vector of malaria in PNG, whereas An. farauti No. 6 appears, based on circumstantial evidence, to be a major vector in the highland river valleys and intramontane plains of New Guinea up to $2000 \mathrm{~m}$ or higher [31,392]. Anopheles farauti s.s. has by far the widest distribution of any member in the Punctulatus Group. This species is predominately found within $1 \mathrm{~km}$ of coastal areas and is replaced by other members in the complex further inland [31]. Salinity tolerance appears to be a major factor in species distribution within the complex. For example, An. hinesorum has far less tolerance for salinity than $A n$. farauti and appears restricted to inland freshwater locations $[398,409,420]$. However, the degree of tolerance may be variable within a species range [397,398] (Table 5).

In general, more data are available on An. farauti s.l. compared to the other major malaria vectors of the Punctulatus Group yet still relatively little is known definitively about the ecology and behaviour of most of the species in the Farauti Complex. Unidentified members of the complex have been found in a wide range of aquatic habitats and adults appear to exhibit a preference for certain hosts in different regions. The time of peak biting activity also varies by locality. The heterogeneous behavioural patterns and wide range of aquatic habitats are proving to be attributable to specific differences between the individual species of the complex [391,399,409].

Anopheles irenicus Schmidt (formerly An. farauti 7) lives in sympatry with $A n$. farauti s.s. and appears to be restricted to the Solomon Islands [409]. Experimentally, this species shares the high salt-tolerance capabilities of An. farauti s.s. [397]; however, it is only found in freshwater habitats. This species is not anthropophilic and therefore not considered to have an important role in malaria transmission, whereas An. farauti s.s., which readily bites humans, is an important vector in the 
Solomon Islands $[371,388,389]$ and the more northerly islands such as Buka and Bougainville, PNG [390].

Larvae of An. farauti s.l. are commonly found in natural, rain-fed temporary pools to larger semi-permanent to permanent bodies of ground water, usually with some varying degree of floating or emergent vegetation (e.g. Ipomoea aquatica). They also sometimes occur in artificial containers, drums, coconut shells, canoes and other unusual habitats (Tables 9, 11). Collectively, the complex shows an ability to use a great variety of aquatic habitats. Habitat selection is also dependent on availability and influenced by dry and wet season precipitation patterns. Sites can be shaded or sunlit but usually consist of open areas away from heavy shade (canopy) (Table 5). The complex, being large and ecologically diverse, can utilise tidal and coastal brackish zones and a variety of inland fresh-water sites. Anopheles farauti s. $s$. can occupy brackish water pools high in organic debris and subject to tidal fluctuations in areas where vast stretches of mangroves occupy the coastline. Natural sites ranging from swamps (non-peat), dead river arms (oxbows) and open river flats to artificial sites including fish ponds and large ditches, burrow pits, pig wallows, garden pools and pools created along stream and river margins (Tables 7, 9). Anopheles farauti s.s. is not uncommonly found with An. punctulatus even though it generally prefers more undistributed ecology.

Feeding of An. farauti s.l. is mainly nocturnal and continues throughout the evening, however, daytime biting can occur. Although females will feed on birds and mammals, and when near human habitation, will often feed on domestic dogs, pigs and cattle, they have a higher proclivity for biting humans in most areas (Table 11). Host preference also appears to depend on the availability of host types. Adult females will readily attack humans inside and outside houses. Indoor resting behaviour before and after feeding occurs but habits are varied and daytime indoor resting has been observed. Individuals that feed inside houses may rest indoors for a period of time but the majority will exit before dawn to rest outdoors (Table 11). Daytime resting sites include cool, damp and darkened places near ground level.

Feeding frequency and peak activity is variable by locality and influenced by prevailing conditions and season, with some areas recording fairly uniform biting throughout the night. Other locations have seen peaks around or after midnight with other sites showing the majority of biting occurring before midnight [399,416, 417]. Early evening peaks have also been recorded in some localities (Table 11). Flight dispersal is regarded as limited, with most adults remaining close to their larval sites, generally under $1 \mathrm{~km}[399,421]$.

\section{Anopheles (Cellia) koliensis Owen}

Anopheles koliensis is an important vector of human malaria throughout its distribution. This species has been found naturally infected with $W$. bancrofti in PNG and the Solomon Islands. It is still regarded as a single species; however, it may be a complex of two or more cryptic species based on the recent discovery of three independently evolving rDNA genotypes that also apparently differ in biting behaviour [391]. Outside of New Guinea island, its distribution and occurrence becomes more limited and patchy [371], with some areas entirely devoid of the species despite the presence of apparently acceptable environmental conditions [390,411].

The larval habitats of An. koliensis appear to be intermediate between those of An. farauti s.l. and An. punctulatus $[417,422]$. They typically prefer more permanent collections of fresh water, such as irrigation ditches and ponds containing floating and emergent vegetation, temporary pools in open grassland and along the margins of jungle, mostly exposed to sunlight (Tables $5,7,9$ ). They sometimes occur in temporary pools also preferred by An. punctulatus. Other sites include still pools in Sago swamps and shallow-water fish ponds, often in association with An. farauti s.l. Anopheles koliensis larvae are rarely, if ever, found in artificial containers and never in brackish water. Larval habitats are often in close association with human habitation.

The biting habits of An. koliensis have been observed on New Guinea island [377,384,391,402,412,423,424] and the Solomon Islands [425]. Females are generally strongly anthropophilic but they will also feed on animals (birds, dogs and pigs). This species readily bites outdoors and will freely enter houses to feed but does not rest indoors for long periods of time either before or after feeding [422]. Females have been found resting inside dwellings throughout the evening and during the day, but this is rare [399]. Similar to An. punctulatus, biting occurs throughout the night both indoors and outdoors with the greatest activity often occurring later in the evening between midnight and dawn. Feeding frequency and peak activity are variable by locality and season; in some areas biting peaks occur before midnight and in others the majority of biting occurs during the early hours of the morning [422] (Table 11).

\section{Anopheles (Cellia) stephensi Liston}

Anopheles stephensi is an unplaced member of the Neocellia Series. It occupies a geographical range in southern Asia that extends across the Indian subcontinent with a westward extension through Iran and Iraq into the Middle East and Arabian Peninsula and eastward in Bangladesh, southern China, Myanmar and Thailand [426-428]. This species was first incriminated as a vector 
of malaria in Mumbai in 1911, Gujarat and Madras in 1938, Ahmedabad in 1943 and Broach in 1967 $[429,430]$. Anopheles stephensi has been recognised as an important vector of malaria in urban areas bordering the Persian Gulf, including western and northwestern India $[430,431]$. It includes three egg phenotypes, mysorensis Sweet \& Rao, typical and intermediate, based on egg dimensions and the numbers of ridges on the egg float [432]. The type form is an efficient vector of urban malaria whereas the mysorensis form is restricted to rural areas and has a poor vectorial capacity due to its highly zoophilic behaviour [433] (Table 12). Subbarao [434] indicated that the mysorensis form is considered an important vector in Iran. Sporozoite rates from southern Iran have been reported to range from 0.5 to $47 \%$ [427,435-437]. The intermediate form is typically found in rural villages and peri-urban areas, but very little is known about its vector status.

Larvae of $A n$. stephensi breed in various artificial containers in homes and collections of water associated with construction sites and other industrial locations. In rural areas, An. stephensi larvae utilise fresh-water pools, stream margins and stream beds, catch basins, seepage canals, wells and domestic water-storage containers [428] (Table 10). Larvae have also been found in domestic wells, overhead water tanks, room coolers, cisterns and roof gutters in the city of Delhi $[438,439]$, but greater numbers of larvae are typically found outdoors compared with indoors [440]. Larvae of the mysorensis form appear to exclusively inhabit stone pots and earthenware containers [441].

Anopheles stephensi is generally considered to be an endophilic and endophagic species even though it will bite outdoors during the warmer summer months due to greater outdoor activity of humans and domestic animals [442,443]. This species rests primarily in temporary or poorly constructed human and animal shelters rather than brick structures [444]. Outdoor blood-feeding activity varies seasonally, with females feeding later in the night during the summer months compared to the winter months [445]. However, indoor biting frequencies of An. stephensi appear to show no marked seasonal variation during different months of the year [430] (Table 12). In rural areas of Gujarat, An. stephensi is associated with canal-irrigated, non-irrigated and riverine villages all year round, but generally in low densities. In urban areas, An. stephensi is found throughout the year, but is most abundant in the summer months (between June and August) which coincides with the peak period of malaria transmission.

Blood-meal analyses of An. stephensi females collected in urban areas indicated an increased tendency to feed on humans rather than cattle [446] and other indications of variable anthropophily have been observed, depending on the availability of alternative hosts [430]. For example, in Delhi the anthropological index (AI) of $A n$. stephensi varies from $0.45 \%$ (near the riverine zone) to $1.40 \%$ (non-riverine zone). In Kheda (city), the AI was found to be $1.03 \%$. However, higher AI values of $8.6 \%$ and $4.9 \%$ were recorded in the cities of Ahmedabad and Surat, respectively [430]. In addition, sporozoite rates of females in the south of Iran reportedly range between 0.5 and $47 \%[427,435-437,447]$.

\section{Anopheles (Cellia) subpictus Grassi species complex (Subpictus Complex)}

The Subpictus Complex belongs to the Pyretophorus Series [6]. Anopheles subpictus was traditionally considered to be comprised of three subspecies, An. s. subpictus, An. s. malayensis Hacker and An. s. indefinitus (Ludlow), until Reid [448] concluded that the distinct morphological characteristics of their larvae indicated that $A n$. subpictus was actually two separate species, $A n$. subpictus and An. indefinitus (of which An. s. malayensis is a synonym), with partially overlapping distributions. Anopheles subpictus larvae were considered to mostly be found in brackish water habitats, with $A n$. indefinitus to be primarily a fresh-water species. Reid [448], based on previous reports of distinguishing features of egg morphology, also suggested that An. subpictus may be a complex consisting of two or more sibling species. Anopheles subpictus and An. indefinitus were classified, along with An. vagus Dönitz, as being within a 'Subpictus Group' by Rattanarithikul et al. [29], but this grouping has not been universally recognised [6].

After the separation of the confounding fresh-water $A n$. indefinitus from $A n$. subpictus, further investigation identified a fresh-water type and subsequent morphological and chromosomal examinations of specimens collected from inland and coastal localities in India confirmed the existence of two sibling species $[449,450]$, provisionally designated as species A and B. Continued investigation has led to the detection of two additional species, thus, the Subpictus Complex is currently considered to include four sibling species, designated species A, B, C and D [451]. Species B is the only species restricted to coastal brackish-water habitats [451-453], with species A, C, and D generally found in fresh-water sites including riverine pools and rice fields [451]. Abhayawardan et al. [452] reported the presence of species A in brackish-water coastal habitats, showing some level of salt tolerance, but densities of species A at these sites increased only after rain diluted the percentage of salinity. Indeed, Suguna et al. [451] reported the presence of all four species in waters with salinity ranging between 0.56 and $5.36 \%$ but it appears that only species $\mathrm{B}$ is found in great numbers under such conditions, or is able to tolerate the higher levels of salt content [453]. 
Recent investigations have, however, added doubt to some of these classifications, particularly where they are based solely on morphological characteristics. Surendran et al. [454] analysed rDNA from larval and adult specimens morphologically classified as species B, collected mainly from the Eastern Province of Sri Lanka. They demonstrated that the majority of these specimens were actually members of the Sundaicus Complex, another group of sibling species that are able to utilise both saltand fresh-water larval habitats (see below). A smaller number of those specimens initially characterised as species B did belong to the Subpictus Complex but were genetically related to species $\mathrm{A}, \mathrm{C}$ or D.

The Subpictus Complex has a wide distribution, ranging from northeastern Pakistan, across India, Sri Lanka, Bangladesh, Myanmar, Thailand and along coastal regions of southern Cambodia, Vietnam and coastal areas of Malaysia, Indonesia, Timor-Leste, Papua New Guinea and extending as far east as the Solomon Islands $[67,154,174,181,329,345,451,452,455-473]$. Species identification has not been widely reported and therefore informally named members of the complex are only known from limited areas of India, Sri Lanka, the Philippines and Thailand $[451,452,471,474,475]$.

Larvae of the Subpictus Complex are found in both clear and turbid waters but have been reported from highly polluted habitats including sites contaminated with organic waste such as waste stabilisation ponds [476], street pools and drains [477]. Habitats may be exposed and sunlit $[262,472]$ and larvae are frequently associated with floating algae or other vegetation $[164,262,452,476,478]$ (Table 6). Natural larval habitats for members of the complex include lagoons, shallow ponds, marshes, slow-flowing rivers, natural pools and margins of small streams $[12,158,190,191,262,467$, $470,472,479,480$ ] (Tables 8,10$)$, but the species are also highly associated with rice fields $[12,13,154,158,163$, $186,190,191,479-483]$ and irrigation schemes [13,190, 479] (Tables 8, 10), specifically in the earlier stages of rice cultivation $[13,163,481,482]$. Larvae have also been collected from small, artificial containers, including intra-domestic earthen pots, tanks and barrels $[16,479]$ (Table 10).

Members of the Subpictus Complex are generally zoophilic (Table 12), however species B will readily bite humans. Abhayawardana et al. [452] reported a high human biting rate, but this conclusion was based on only a single night of human-landing catches. Bloodmeal analyses from resting collections have revealed a preference for bovine blood. For example, blood analysed from females collected from inland locations in Sri Lanka (considered to represent species A) revealed that 87.2\% contained bovine blood [452]. Other studies conducted in Sri Lanka, West Bengal and Orissa, also reported high percentages of females to have fed on bovine hosts with few, if any, having fed on humans $[165,458,484]$. Landing collections also indicate zoophily, for example a study conducted during the implementation of the Mahaweli Development Project in eastern Sri Lanka found $37.4 \%$ of An. subpictus females collected were attracted to cattle compared to only $0.1 \%$ attracted to humans [10]. A similar result was reported from collections made in northwestern coastal Malaysia, with 166 females collected in cow-baited traps compared to none in human-baited nets, and only 14 captured in human-landing collections [485].

Where human-landing catches have been conducted, no clear preference for either indoor or outdoor biting has been reported [452,483] (Table 13). However, Kawada et al. [486], in a study conducted on Lombok Island, Indonesia, reported An. subpictus as one of the dominant anophelines collected outdoors. Indeed, Dash et al. [165] described An. subpictus as a zoophilic species that feeds outside and then enters houses to rest. Amerasinghe et al. [484] stated that An subpictus is the most abundant endophilic anopheline in Sri Lanka accounting for $>90 \%$ of specimens collected resting indoors. The majority of studies summarised (Table 12) indicate an endophilic resting habit [157,483,487-490], with only one study conducted in Jaffna District, Sri Lanka, suggesting a higher level of exophilic behaviour [474]. However, this conclusion was based on the assumption that the collections from cattle-baited huts can be interpreted as indicative of indoor resting behaviour whereas those from cattle-baited nets indicated outdoor resting. Authors reported species B, C and D being collected in higher numbers by cattle-baited net traps.

Two recent reviews have focussed on the Subpictus Complex and the capacity of its members as vectors, but the role in malaria transmission played by each species is still not clear [26,491]. Anopheles subpictus s.l. is confirmed as a malaria vector in Malaysia and Indonesia $[26,491]$ and has been reported naturally infected with malaria parasites and W. bancrofti in parts of eastern Indonesia (Flores, Timor and nearby islands) [194, $279,492,493]$. However the true identity of what has been called An. subpictus in Timor is questionable and may turn out to be another species [92]. Species B is frequently reported as a vector in coastal areas of southeastern India based on the work of Panicker et al. [494]. There is also evidence of sporozoite-positive members of the complex identified from inland areas of India and Sri Lanka $[10,157,484,495]$, yet with limited specific information and some doubt as to the classification of species B [454], further work is needed to confirm the vectorial capacity and distribution of each species across the wide geographical range of the complex [491]. 


\section{Anopheles (Cellia) sundaicus (Rodenwaldt) species complex (Sundaicus Complex)}

The Sundaicus Complex belongs to the Pyretophorus Series [6]. Members of the complex are predominately coastal vectors as their immature stages develop primarily in habitats containing levels of salinity ranging from low, brackish to sea water concentrations. Populations have also been recorded further inland in association with fresh water, particularly in northeastern India, Car Nicobar Island, peninsular Malaysia, Malaysian Borneo (Miri, Sarawak), northern Sumatra and Java, Indonesia [80,496-499] (Table 6). This ecological difference and behavioural heterogeneity led Reid [500] to suspect that An. sundaicus was a species complex. This was confirmed by Sukowati et al. $[499,501]$ who provided cytogenetic and allozyme evidence for the presence of three species (informally designated species A, B and C) in Sumatra, Java and Thailand. Based on molecular approaches, An. sundaicus is currently regarded a complex of at least four species that do not exhibit ecological differences such as fresh-water/brackish-water preference [502,503]. Anopheles sundaicus s.s. based on a neotype from the Lundu District of Sarawak, Malaysia is distributed along the coast of Borneo [504]; An. epiroticus Linton \& Harbach (formerly An. sundaicus species A) occurs most often along the mainland coastal areas from eastern India to Thailand, southern Vietnam and peninsular Malaysia; An. sundaicus species D appears to be restricted to the Nicobar and Andaman Islands of India [502,505]; and An. sundaicus species $\mathrm{E}$ is found in Sumatra and Java, Indonesia [503]. These four species are mainly allopatric but this does not preclude sympatry in some areas (e.g. An. epiroticus and An. sundaicus species E may coexist in northern Sumatra). A molecular assay developed to identify the species of the complex will help investigate the potential sympatry of the species [506]. The distribution of these species, especially An. epiroticus, often occurs in distinct foci along the coast of Thailand and Cambodia.

The immature stages generally require sunlit habitats containing pooled stagnant water, algae and non-invasive vegetation (Table 6). Filamentous floating algae and aquatic plants are crucial for the development of the larvae as they provide food (micro-algae and bacteria) and protection against predators. Particularly favourable habitats include ponds, swamps, lagoons, open mangrove, rock pools and coastal shrimp or fish ponds (active or abandoned/poorly maintained impoundments such as in Indonesia), as well as irrigated inland seawater canals [25,496,507-510]. The close association of An. epiroticus with aquaculture (shrimp and fish farms) in southern Vietnam [510,511] requires special attention as this economic activity is increasing throughout Southeast Asia. With an increase in vector density, the risk for malaria epidemics, as previously recorded in Indonesia [512], is of constant concern (Table 8).

Females are mainly anthropophilic and exhibit both endophagic and exophagic feeding habits. Peak biting activity typically occurs between 20:00 h and 03:00 h depending on locality. Blood-engorged females can be found resting inside or outside houses (Table 12). Varying degrees of indoor and outdoor resting occurs and some members of the complex have been reported to be predominantly endophilic during the gonotrophic cycle.

Species of the complex are considered as either major or secondary malaria vectors depending on location [7]. They are regarded as the main vectors of malaria along the coastal areas of India, southern Vietnam and much of Indonesia [170,199,510,513,514] where they transmit both $P$. falciparum and $P$. vivax, and are responsible for local outbreaks [498,514-516]. However, their current role in malaria transmission along coastal areas of Thailand, Cambodia, Malaysia and Nicobar Island remains questionable $[507,517,518]$, as well as the more recent role of $A n$. epiroticus in the Mekong Delta (southern Vietnam) where it was found with a null sporozoite rate in Bac Lieu Province despite very high biting densities (12.78 bites per hour) [519]. The ecological and behavioural plasticity of species of the Sundaicus Complex poses difficulties for developing efficient and appropriate vector control strategies [25].

\section{Discussion}

The predictive maps presented here have been created using the most up-to-date information available, including the EO species range maps, examined and updated by the TAG, many of whom have very specific and indepth knowledge of the 19 DVS of this region. The occurrence data are maintained in what we believe to be the most comprehensive database of global DVS occurrence currently available. The climatic and environmental variables, all from open access sources, also represent what we consider to be the best data available. However, despite these efforts, the maps can still not be considered as a true and precise representation of the ranges of each of the species and species complexes.

Any species mapping process will always be limited by the available data, in terms of its quantity, quality and distribution. The methodology applied in sampling mosquitoes in any given location can have an inherent effect on the abundance, but also in some cases, on the species collected. Moreover, a great deal of work on malaria vectors will, understandably, be conducted in areas where malaria is being transmitted to humans. Thus a great deal of sampling will occur in locations near human habitations or activity, and therefore will be a spatially biased sample. Nonetheless, maps that indicate a species distribution, accepting a human 'co-variable', 
are clearly of use, particularly where there is a need to focus limited resources on vector control efforts. However, by applying pseudo-presences taken from within the EO range of each species or species complex, some of this bias may be removed, and a better distribution of the full range of the taxon produced. As far as we are aware, there are no other DVS maps currently available that have incorporated EO ranges within the model, and thus while the maps produced will not be the true representation of each DVS distribution, they may be the best and most accurate currently available.

\section{Bionomics}

The bionomics summaries presented are the culmination of a joint effort by leading Anopheles experts. The need for continued research into the behaviour and ecology, combined with confirmed identification of the evolving and emerging sibling species and the complex status of many of the DVS in the Asian-Pacific region, is highlighted repeatedly. Simple, universal species-specific statements regarding the biology of these vectors are nearly impossible due to the locational diversity in behaviour and sympatric distributions of sibling species that contributes to a level of complexity not seen amongst the DVS of other regions. Here we have indicated the behavioural plasticity and locational variation in species behaviour where possible, and also where known and suspected species complexes exist. However, until the taxonomic situation is resolved, the behaviour of many of these DVS will remain unclear.

\section{Conclusions}

This is the third in a series of three articles presenting the global distribution maps of 41 of the most important malaria vectors currently known $[5,43,79]$. In each case, the maps are presented with the caveat that they represent only the beginning of a process to establish the distribution of these DVS, and that each will be greatly improved as more data become available. Moreover, the corresponding bionomics summaries will also evolve as more information and a clarification of the taxonomy of many of these species are reported. These three articles have been produced in collaboration with a number of Anopheles experts, willing to share both their time and their data to ensure the best information is presented. We have been continually surprised by the generosity of the vector research community in providing data and assistance, and in this spirit, and according to the open access principles of the MAP, all our data will be made available to the research community. In return, we hope to continue improving and adapting our maps and to cultivate new collaborations to ensure we can maintain a database of the most comprehensive DVS occurrence and bionomics available.

\section{Additional material}

Additional file 1: Shapefiles of the expert opinion distribution maps for the 19 DVS of the Asian-Pacific region.

Additional file 2: Summary tables showing evaluation statistics for all mapping trials and final Boosted Regression Tree environmental and climatic variable selections for the final, optimal predictive maps.

Additional file 3: Predictive species distribution maps for the 19 DVS of the Asian-Pacific region.

\section{List of abbreviations}

DVS: Dominant Vector Species; EO: Expert Opinion; BRT: Boosted Regression Tree; PAR: Population at Risk; IRS: Indoor Residual Spraying; ITNs: Insecticide Treated Bednets; TAG: Technical Advisory Group; AUC: Area Under the operating characteristic Curve; DEM: Digital Elevation Model; LST: Land Surface Temperature; MIR: Middle Infra-red Radiation; NDVI: Normalized Difference Vegetation Index; AVHRR: Advanced Very High Resolution Radiometer; PNG: Papua New Guinea; ELISA: Enzyme-Linked Immunosorbent Assay; PCR: polymerase chain reaction; PCR-RFLP: PCR-restriction-fragment length polymorphism; Al: Anthropological Index; MAP: Malaria Atlas Project.

\section{Acknowledgements}

We wish to thank Robi Okara, Rosalind Howes, Edward Haynes, Philip Mbithi, Owen Yang, Carolynn Tago, and Elisabeth Thiveyrat for help with primary data abstraction. We also thank the Technical Advisory Group for extended support over the duration of the project (in addition to co-authors Michael Bangs, Sylvie Manguin, Ralph Harbach and Theeraphap Chareonviriyaphap, these include, Maureen Coetzee, Janet Hemingway, Charles M. Mbogo and Yasmin Rubio-Palis). MES is funded by a project grant from the Wellcome Trust (\#083534) to $\mathrm{SIH}$. SIH is funded by a Senior Research Fellowship from the Wellcome Trust (\#079091) which also supports CWK and PWG. APP and WHT are funded by a Wellcome Trust Principal Research Fellowship (\#079080) to Professor Robert Snow. This work forms part of the output of the Malaria Atlas Project (MAP, http://www.map.ox.ac.uk), principally funded by the Wellcome Trust, U.K.

\section{Author details}

${ }^{1}$ Spatial Ecology and Epidemiology Group, Tinbergen Building, Department of Zoology, University of Oxford, South Parks Road, Oxford OX1 3PS, UK. ${ }^{2}$ Public Health and Malaria Control Department, PT Freeport Indonesia, Kuala Kencana, Papua, Indonesia. ${ }^{3}$ Institut de Recherche pour le Développement, Lab. d'Immuno-Physiopathologie Moléculaire Comparée, UMR-MD3/Univ. Montpellier 1, Faculté de Pharmacie, 15, Ave Charles Flahault, 34093 Montpellier, France. ${ }^{4}$ Department of Entomology, Faculty of Agriculture, Kasetsart University, Bangkok, Thailand. ${ }^{5}$ Eijkman-Oxford Clinical Research Unit, Jakarta, Indonesia. ${ }^{6}$ Malaria Public Health and Epidemiology Group, Centre for Geographic Medicine, KEMRI - Univ. Oxford - Wellcome Trust Collaborative Programme, Kenyatta National Hospital Grounds, P.O. Box 43640-00100 Nairobi, Kenya. ${ }^{7}$ Department of Entomology, The Natural History Museum, Cromwell Road, London, SW7 5BD, UK.

\section{Authors' contributions}

$\mathrm{SIH}$ conceived the study and managed its design and implementation. MES wrote the first draft of the manuscript and assembled the occurrence data with assistance from CWK and IRFE, CWK also digitised and edited all the expert opinion maps. WHT designed and maintained the databases and implemented the map figures. APP implemented the BRT scripts for predictive mapping. PWG processed the environmental and climatic data grids. Experiments were devised by SIH and MES and implemented by MES. MJB, SM, REH and TC advised on bionomics and nomenclature issues, and provided additional comments and input to the manuscript. All authors participated in the interpretation of results and in the writing and editing of the manuscript. All authors read and approved the final manuscript.

\section{Competing interests}

The authors declare that they have no competing interests. 
Received: 30 March 2011 Accepted: 25 May 2011

Published: 25 May 2011

\section{References}

1. Foley DH, Rueda LM, Wilkerson RC: Insight into global mosquito biogeography from country species records. J Med Entomol 2007, 44:554-567.

2. Hay SI, Okiro EA, Gething PW, Patil AP, Tatem AJ, Guerra CA, Snow RW: Estimating the global clinical burden of Plasmodium falciparum malaria in 2007. PLoS Med 2010, 7:e1000290.

3. Hay SI, Guerra CA, Gething PW, Patil AP, Tatem AJ, Noor AM, Kabaria CW, Manh BH, Elyazar IR, Brooker S, Smith DL, Moyeed RA, Snow RW: A world malaria map: Plasmodium falciparum endemicity in 2007. PLoS Med 2009, 6:e1000048.

4. Guerra CA, Howes RE, Patil AP, Gething PW, Van Boeckel TP, Temperley WH, Kabaria CW, Tatem AJ, Manh BH, Elyazar IR, Baird JK, Snow RW, Hay SI: The international limits and population at risk of Plasmodium vivax transmission in 2009. PLoS Negl Trop Dis 2010, 4:e774.

5. Hay SI, Sinka ME, Okara RM, Kabaria CW, Mbithi PM, Tago CC, Benz D, Gething PW, Howes RE, Patil AP, Temperley WH, Bangs MJ,

Chareonviriyaphap T, Elyazar IR, Harbach RE, Hemingway J, Manguin S, Mbogo CM, Rubio-Palis Y, Godfray HC: Developing global maps of the dominant Anopheles vectors of human malaria. PLOS Med 2010, 7:e1000209.

6. Harbach RE: The classification of genus Anopheles (Diptera: Culicidae): a working hypothesis of phylogenetic relationships. Bull Entomol Res 2004, 94:537-553.

7. Meek SR: Vector control in some countries of Southeast Asia: comparing the vectors and the strategies. Ann Trop Med Parasitol 1995, 89:135-147.

8. Manguin S, Garros C, Dusfour I, Harbach RE, Coosemans M: Bionomics, taxonomy, and distribution of the major malaria vector taxa of Anopheles subgenus Cellia in Southeast Asia: An updated review. Infect Genet Evol 2008, 8:489-503.

9. Van Bortel W, Harbach RE, Trung HD, Roelants P, Backeljau T, Coosemans M: Confirmation of Anopheles varuna in Vietnam, previously misidentified and mistargeted as the malaria vector Anopheles minimus. Am J Trop Med Hyg 2001, 65:729-732.

10. Amerasinghe FP, Amerasinghe PH, Peiris JS, Wirtz RA: Anopheline ecology and malaria infection during the irrigation development of an area of the Mahaweli Project, Sri Lanka. Am J Trop Med Hyg 1991, 45:226-235.

11. Vythilingam I, Chan ST, Shanmugratnam C, Tanrang H, Chooi KH: The impact of development and malaria control activities on its vectors in the Kinabatangan area of Sabah, East Malaysia. Acta Trop 2005, 96:24-30.

12. Amerasinghe FP, Indrajith NG: Post-irrigation breeding patterns of surface water mosquitoes in the Mahaweli Project, Sri Lanka, and comparisons with preceding developmental phases. J Med Entomol 1994, 31:516-523.

13. Singh N, Mishra AK: Anopheline ecology and malaria transmission at a new irrigation project area (Bargi Dam) in Jabalpur (Central India). J Am Mosa Control Assoc 2000, 16:279-287.

14. Lee DK: Effect of two rice culture methods on the seasonal occurrence of mosquito larvae and other aquatic animals in rice fields of southwestern Korea. J Vector Ecol 1998, 23:161-170.

15. WHO: World malaria report 2010. World Health Organization (WHO); 2010, 238.

16. Gupta DK, Bhatt RM, Sharma RC, Gautam AS, Rajnikant : Intradomestic mosquito breeding sources and their management. Indian J Malariol 1992, 29:41-46.

17. Takken W, Knols BGJ: A taxonomic and bionomic review of the anopheline vectors of Indonesia. In Environmental measures for malaria control in Indonesia: A historical review on species sanitation. Edited by: Takken W, Snellen WB, Verhave JP, Knols BGJ, Atmosoedjono S. Wageningen, The Netherlands: Wageningen Agricultural Univ. Papers; 1991:9-62.

18. Obsomer V, Defourny P, Coosemans M: The Anopheles dirus complex: spatial distribution and environmental drivers. Malar J 2007, 6:26.

19. Rahman WA, Che'Rus A, Ahmad AH: Malaria and Anopheles mosquitoes in Malaysia. Southeast Asian J Trop Med Public Health 1997, 28:599-605.

20. Rajavel AR, Das PK: A review of Leucosphyrus Group with particular reference to the Anopheles dirus complex (Diptera: Culicidae) in India. J Commun Dis 1998, 30:57-67.

21. Beebe NW, Cooper RD: Distribution and evolution of the Anopheles punctulatus group (Diptera: Culicidae) in Australia and Papua New Guinea. Int J Parasitol 2002, 32:563-574.
22. Oo $T$, Storch $V$, Becker $N$ : Review of the anopheline mosquitoes of Myanmar. J Vector Ecol 2004, 29:21-40.

23. Barik TK, Sahu B, Swain V: A review on Anopheles culicifacies: from bionomics to control with special reference to Indian subcontinent. Acta Trop 2009, 109:87-97.

24. Garros C, Van Bortel W, Trung HD, Coosemans M, Manguin S: Review of the Minimus Complex of Anopheles, main malaria vector in Southeast Asia: from taxonomic issues to vector control strategies. Trop Med Int Health 2006, 11:102-114.

25. Dusfour I, Harbach RE, Manguin S: Bionomics and systematics of the oriental Anopheles sundaicus complex in relation to malaria transmission and vector control. Am J Trop Med Hyg 2004, 71:518-524.

26. Chandra G, Bhattacharjee I, Chatterjee S: A review on Anopheles subpictus Grassi, a biological vector. Acta Trop 2010, 115:142-154.

27. Kengluecha A, Rongnoparut P, Boonsuepsakul S, Sithiprasasna R, Rodpradit $\mathrm{P}$, Baimai V: Geographical distribution of Anopheles minimus species A and C in western Thailand. J Vector Ecol 2005, 30:225-230.

28. Sallum MAM, Peyton EL, Harrison BA, Wilkerson RC: Revision of the Leucosphyrus group of Anopheles (Cellia) (Diptera: Culicidae). Rev Bras Entomol 2005, 49(Suppl 1):1-152.

29. Rattanarithikul R, Harrison BA, Harbach RE, Panthusiri P, Coleman RE, Panthusiri P: Illustrated keys to the mosquitoes of Thailand. IV. Anopheles. Southeast Asian J Trop Med Public Health 2006, 37(Suppl 2):1-128.

30. Cooper RD, Frances SP, Waterson DG, Piper RG, Sweeney AW: Distribution of anopheline mosquitoes in northern Australia. J Am Mosa Control Assoc 1996, 12:656-663.

31. Cooper RD, Waterson DG, Frances SP, Beebe NW, Sweeney AW: Speciation and distribution of the members of the Anopheles punctulatus (Diptera: Culicidae) group in Papua New Guinea. J Med Entomol 2002, 39:16-27.

32. White GB: Malaria. Geographical distribution of arthropod-borne diseases and their principal vectors. Geneva: World Health Organization, Division of Vector Biology and Control; 1989, WHO/NBC/89967, 7-22.

33. Manguin S, Carnevale P, Mouchet J, Coosemans M, Julvez J, RichardLenoble D, Sircoulon J: Biodiversity of malaria in the world Montrouge, France: John Libbey Eurotext; 2008.

34. Rongnoparut P, Ugsang DM, Baimai V, Honda K, Sithiprasasna R: Use of a remote sensing-based geographic information system in the characterizing spatial patterns for Anopheles minimus A and C breeding habitats in western Thailand. Southeast Asian J Trop Med Public Health 2005, 36:1145-1152.

35. Sithiprasasna R, Linthicum KJ, Liu GJ, Jones JW, Singhasivanon P: Some entomological observations on temporal and spatial distribution of malaria vectors in three villages in northwestern Thailand using a geographic information system. Southeast Asian J Trop Med Public Health 2003, 34:505-516.

36. Sithiprasasna R, Lee WJ, Ugsang DM, Linthicum KJ: Identification and characterization of larval and adult anopheline mosquito habitats in the Republic of Korea: potential use of remotely sensed data to estimate mosquito distributions. Int I Health Geogr 2005, 4:17.

37. Stoops CA, Gionar YR, Shinta, Sismadi P, Rachmat A, Elyazar IF, Sukowati S: Remotely-sensed land use patterns and the presence of Anopheles larvae (Diptera: Culicidae) in Sukabumi, West Java, Indonesia. J Vector Ecol 2008, 33:30-39.

38. Garros C, Nguyen CV, Trung HD, Van Bortel W, Coosemans M, Manguin S: Distribution of Anopheles in Vietnam, with particular attention to malaria vectors of the Anopheles minimus complex. Malar J 2008, 7:11.

39. Foley DH, Klein TA, Kim HC, Sames WJ, Wilkerson RC, Rueda LM: Geographic distribution and ecology of potential malaria vectors in the Republic of Korea. J Med Entomol 2009, 46:680-692.

40. Sithiprasasna R, Linthicum KJ, Liu GJ, Jones JW, Singhasivanon P: Use of GIS-based spatial modeling approach to characterize the spatial patterns of malaria mosquito vector breeding habitats in northwestern Thailand. Southeast Asian J Trop Med Public Health 2003, 34:517-528.

41. Foley DH, Rueda LM, Peterson AT, Wilkerson RC: Potential distribution of two species in the medically important Anopheles minimus complex (Diptera: Culicidae). J Med Entomol 2008, 45:852-860.

42. Foley DH, Klein TA, Kim HC, Wilkerson RC, Rueda LM: Malaria risk assessment for the Republic of Korea based on models of mosquito distribution. US Army Med Dep J 2008, 46-53.

43. Sinka ME, Rubio-Palis Y, Manquin S, Patil AP, Temperley WH, Gething PW, Van Boeckel T, Kabaria CW, Harbach RE, Hay SI: The dominant Anopheles 
vectors of human malaria in the Americas: occurrence data, distribution maps and bionomic précis. Parasit Vectors 2010, 3:72.

44. Web of Science. [http://isiwebofknowledge.com/products_tools/ multidisciplinary/webofscience/].

45. PubMed. [http://www.ncbi.nlm.nih.gov/pubmed/].

46. Malaria in the News (Roll Back Malaria) Archives. [http://www. rollbackmalaria.org/malariainthenews.html].

47. MalariaWorld database. [http://www.malariaworld.org/].

48. The Disease Vectors Database. [http://www.diseasevectors.org/references. php].

49. Walter Reed Biosystematics Unit (WRBU), Mosquito Catalog. [http://www. mosquitocatalog.org/default.aspx?.pglD=8].

50. Elith J, Leathwick JR, Hastie T: A working guide to boosted regression trees. J Anim Ecol 2008, 77:802-813.

51. De'ath G: Boosted trees for ecological modeling and prediction. Ecology 2007, 88:243-251.

52. R: A language and environment for statistical computing. R Foundation for Statistical Computing. [http://www.R-project.org].

53. Elith J, Graham CH, Anderson RP, Dudik M, Ferrier S, Guisan A, Hijmans RJ, Huettmann F, Leathwick JR, Lehmann A, Li J, Lohmann LG, Loiselle BA, Manion G, Moritz C, Nakamura M, Nakazawa Y, Overton JM, Peterson AT, Phillips SJ, Richardson K, Scachetti-Pereira R, Schapire RE, Soberon J, Williams S, Wisz MS, Zimmermann NE: Novel methods improve prediction of species' distributions from occurrence data. Ecography 2006, 29:129-151.

54. United States Geological Survey. [http://dds.cr.usgs.gov/srtm/version2_1/ SRTM30/srtm30_documentation.pdf].

55. NASA Jet Propulsion Laboratory. [http://www2.jpl.nasa.gov/srtm/].

56. MODIS (NASA). [http://modis.gsfc.nasa.gov/about].

57. Worldclim Database. [http://www.worldclim.org].

58. Hijmans RJ, Cameron SE, Parra JL, Jones PG, Jarvis A: Very high resolution interpolated climate surfaces for global land areas. Int I Climatol 2005, 25:1965-1978.

59. Myneni RB, Hall FG, Sellers PJ, Marshak AL: The interpretation of spectral vegetation indexes. IEEE T Geosci Remote 1995, 33:481-486.

60. Hay SI, Tatem AJ, Graham AJ, Goetz SJ, Rogers DJ: Global environmental data for mapping infectious disease distribution. Adv Parasitol 2006, 62:37-77.

61. Hay SI: An overview of remote sensing and geodesy for epidemiology and public health application. Adv Parasitol 2000, 47:1-35.

62. Boyd DS, Petitcolin F: Remote sensing of the terrestrial environment using middle infrared radiation (3.0-5.0 $\mu \mathrm{m})$. Int I Remote Sens 2004, 25:3343-3368.

63. The Globcover Project. [http://www.esa.int/due/ionia/globcover], http:// postel.mediasfrance.org.

64. Scharlemann JP, Benz D, Hay SI, Purse BV, Tatem AJ, Wint GR, Rogers DJ: Global data for ecology and epidemiology: a novel algorithm for temporal Fourier processing MODIS data. PLoS One 2008, 3:e1408.

65. Coosemans M, Thuan LK, Socheat D, Phompida S, Baimai V, Manguin S, Harbach RE, Hemingway J: Monitoring insecticide resistance and mapping malaria vectors in Southeast Asia: a prerequisite for sustainable malaria vector control. INCO report 2006, IC4-CT-2002-10041, 202.

66. MALVACASIA. [http://www.itg.be/malvecasia/].

67. Kelly-Hope LA, Yapabandara AM, Wickramasinghe MB, Perera MD, Karunaratne SH, Fernando WP, Abeyasinghe RR, Siyambalagoda RR, Herath PR, Galappaththy GN, Hemingway J: Spatiotemporal distribution of insecticide resistance in Anopheles culicifacies and Anopheles subpictus in Sri Lanka. Trans R Soc Trop Med Hyg 2005, 99:751-761.

68. Cui F, Raymond M, Qiao CL: Insecticide resistance in vector mosquitoes in China. Pest Manag Sci 2006, 62:1013-1022.

69. Djadid ND, Barjesteh H, Raeisi A, Hassanzahi A, Zakeri S: Identification, sequence analysis, and comparative study on GSTe2 insecticide resistance gene in three main world malaria vectors: Anopheles stephensi, Anopheles culicifacies, and Anopheles fluviatilis. J Med Entomol 2006, 43:1171-1177.

70. Komalamisra N, Trongtokit Y, Palakul K, Prummongkol S, Samung Y, Apiwathnasorn C, Phanpoowong T, Asavanich A, Leemingsawat S: Insecticide susceptibility of mosquitoes invading tsunami-affected areas of Thailand. Southeast Asian J Trop Med Public Health 2006, 37(Suppl 3):118-122.
71. Shukla RP, Sharma SN, Raghavendra K, Subbarao SK: A note on the susceptibility status of An. culicifacies and An. fluviatilis to malathion in Nainital and Udham Singh Nagar Districts, Uttarakhand. I Commun Dis 2006, 38:369-372.

72. Surendran SN, Ramasamy MS, De Silva BG, Ramasamy R: Anopheles culicifacies sibling species B and E in Sri Lanka differ in longevity and in their susceptibility to malaria parasite infection and common insecticides. Med Vet Entomol 2006, 20:153-156.

73. Perera MD, Hemingway J, Karunaratne SP: Multiple insecticide resistance mechanisms involving metabolic changes and insensitive target sites selected in anopheline vectors of malaria in Sri Lanka. Malar J 2008, $7: 168$

74. Van Bortel W, Trung HD, Thuan le K, Sochantha T, Socheat D, Sumrandee C, Baimai V, Keokenchanh K, Samlane P, Roelants P, Denis L, Verhaeghen K, Obsomer $V$, Coosemans $M$ : The insecticide resistance status of malaria vectors in the Mekong region. Malar J 2008, 7:102.

75. Verhaeghen K, Van Bortel W, Trung HD, Sochantha T, Coosemans M: Absence of knockdown resistance suggests metabolic resistance in the main malaria vectors of the Mekong region. Malar J 2009, 8:84.

76. Tiwari S, Ghosh SK, Ojha VP, Dash AP, Raghavendra K: Reduced susceptibility to selected synthetic pyrethroids in urban malaria vector Anopheles stephensi: a case study in Mangalore city, South India. Malar J 2010, 9:179.

77. Raghavendra K, Verma V, Srivastava HC, Gunasekaran K, Sreehari U, Dash AP: Persistence of DDT, malathion \& deltamethrin resistance in Anopheles culicifacies after their sequential withdrawal from indoor residual spraying in Surat District, India. Indian J Med Res 2010, 132:260-264.

78. Oo T: The biology and vector competence of the anopheline mosquitoes of Myanmar with special consideration of Anopheles dirus. Ruperto-Carola University of Heidelberg, Combined Faculties for the Natural Sciences and for Mathematics 2003.

79. Sinka ME, Bangs MJ, Manguin S, Coetzee M, Mbogo CM, Hemingway J, Patil AP, Temperley WH, Gething PW, Kabaria CW, Okara RM, Van Boeckel T, Godfray HCJ, Harbach RE, Hay SI: The dominant Anopheles vectors of human malaria in Africa, Europe and the Middle East: occurrence data, distribution maps and bionomic précis. Parasit Vectors 2010, 3:117.

80. Reid JA: Anopheline mosquitoes of Malaya and Borneo Malaysia; 1968.

81. Harrison BA, Scanlon JE: Medical entomology studies II. The subgenus Anopheles in Thailand (Diptera: Culicidae). Contrib Am Entomol Inst (Ann Arbor) 1975, 12:1-307.

82. Reid JA: The Anopheles barbirostris group (Diptera: Culicidae). Bull Entomol Res 1962, 53:1-57.

83. Ndoen E, Wild C, Dale P, Sipe N, Dale M: Relationships between anopheline mosquitoes and topography in West Timor and Java, Indonesia. Malar J 2010, 9:242.

84. Saeung A, Otsuka Y, Baimai V, Somboon P, Pitasawat B, Tuetun B, Junkum A, Takaoka H, Choochote W: Cytogenetic and molecular evidence for two species in the Anopheles barbirostris complex (Diptera: Culicidae) in Thailand. Parasitol Res 2007, 101:1337-1344.

85. Saeung A, Baimai V, Otsuka Y, Rattanarithikul R, Somboon P, Junkum A, Tuetun B, Takaoka H, Choochote W: Molecular and cytogenetic evidence of three sibling species of the Anopheles barbirostris Form A (Diptera: Culicidae) in Thailand. Parasitol Res 2008, 102:499-507.

86. Paredes-Esquivel C, Donnelly MJ, Harbach RE, Townson H: A molecular phylogeny of mosquitoes in the Anopheles barbirostris subgroup reveals cryptic species: implications for identification of disease vectors. $\mathrm{Mol}$ Phylogenet Evol 2009, 50:141-151.

87. Jariyapan N, Baimai V, Poovorawan Y, Roytrakul S, Saeung A, Thongsahuan S, Suwannamit S, Otsuka Y, Choochote W: Analysis of female salivary gland proteins of the Anopheles barbirostris complex (Diptera: Culicidae) in Thailand. Parasitol Res 2010, 107:509-516.

88. Atmosoedjono S, Partono F, Dennis DT, Purnomo: Anopheles barbirostris (Diptera: Culicidae) as a vector of the Timor filaria on Flores Island: preliminary observations. J Med Entomol 1977, 13:611-613.

89. Atomosoedjono S, Van Peenen PF, Putrali J: Anopheles barbirostris (Van der Wulp) still an efficient vector of Brugia malayi in Central Sulawesi (Celebes), Indonesia. Trans R Soc Trop Med Hyg 1976, 70:259.

90. Lien JC, Kawengian BA, Partono F, Lami B, Cross JH: A brief survey of the mosquitoes of South Sulawesi, Indonesia, with special reference to the identity of Anopheles barbirostris (Diptera: Culicidae) from the Margolembo area. J Med Entomol 1977, 13:719-727. 
91. Reid JA, Harrison BA, Atmosoedjono S: Variation and vector status in Anopheles barbirostris. Mosa Syst 1979, 11:235-251.

92. Cooper RD, Edstein MD, Frances SP, Beebe NW: Malaria vectors of TimorLeste. Malar J 2010, 9:40.

93. Syafruddin D, Asih PBS, Wahid I, Dewi RM, Tuti S, Laowo I, Hulu W, Zendrato P, Laihad F, Shankar AH: Malaria prevalence in Nias District, North Sumatra Province, Indonesia. Malar J 2007, 6.

94. Limrat D, Rojruthai B, Apiwathnasorn C, Samung Y, Prommongkol S: Anopheles barbirostris/campestris as a probable vector of malaria in Aranyaprathet, Sa Kaeo Province. Southeast Asian J Trop Med Public Health 2001, 32:739-744.

95. Apiwathnasorn C, Prommongkol S, Samung Y, Limrat D, Rojruthai B: Potential for Anopheles campestris (Diptera: Culicidae) to transmit malaria parasites in Pa Rai subdistrict (Aranyaprathet, Sa Kaeo Province), Thailand. J Med Entomol 2002, 39:583-586.

96. Choochote W, Sucharit S, Abeyewickreme W: Experiments in crossing two strains of Anopheles barbirostris van der Wulp 1884 (Diptera: Culicidae) in Thailand. Southeast Asian J Trop Med Public Health 1983, 14:204-209.

97. Reid JA: The attraction of mosquitoes by human and animal baits in relation to the transmission of disease. Bull Entomol Res 1961, 52:43-62.

98. Reuben R: Studies on the mosquitoes of North Arcot District, Madras State, India. 2. Biting cycles and behavior on human and bovine baits at two villages. J Med Entomol 1971, 8:127-134

99. Amerasinghe $\mathrm{PH}$, Amerasinghe FP, Konradsen F, Fonseka KT, Wirtz RA: Malaria vectors in a traditional dry zone village in Sri Lanka. Am J Trop Med Hyg 1999, 60:421-429.

100. Abu Hassan AA, Rahman WA, Rashid MZ, Shahrem MR, Adanan CR: Composition and biting activity of Anopheles (Diptera: Culicidae) attracted to human bait in a malaria endemic village in peninsular Malaysia near the Thailand border. J Vector Ecol 2001, 26:70-75.

101. Alam MS, Khan MG, Chaudhury N, Deloer S, Nazib F, Bangali AM, Haque R: Prevalence of anopheline species and their Plasmodium infection status in epidemic-prone border areas of Bangladesh. Malar J 2010, 9:15.

102. Xu JJ, Feng LC: Studies on the Anopheles hyrcanus group of mosquitoes in China [in Chinese]. Acta Entomol Sinica 1975, 18:77-98, 76 pls.

103. Ma SF: Studies on the Anopheles (A.) sinensis group of mosquitoes in China, including four new sibling species [in Chinese]. Sinozoologia 1981, 1:59-70, 54 pls

104. Wilkerson RC, Li C, Rueda LM, Kim HC, Klein TA, Song GH, Strickman D: Molecular confirmation of Anopheles (Anopheles) lesteri from the Republic of South Korea and its genetic identity with An. (Ano.) anthropophagus from China (Diptera: Culicidae). Zootaxa 2003, 378:1-14

105. Ma YJ, Xu JN: The Hyrcanus Group of Anopheles (Anopheles) in China (Diptera: Culicidae): Species discrimination and phylogenetic relationships inferred by ribosomal DNA internal transcribed spacer 2 sequences. J Med Entomol 2005, 42:610-619.

106. Hwang UW, Tang LH, Kobayashi M, Yong TS, Ree HI: Molecular evidence supports that Anopheles anthropophagus from China and Anopheles lesteri from Japan are the same species. J Am Mosq Control Assoc 2006, 22:324-326.

107. Ho C, Chou TC, Ch'En TH, Hsueh AT: The Anopheles hyrcanus group and its relation to malaria in east China. Chin Med J 1962, 81:71-78.

108. Chow C-Y: Malaria vectors in China. Proceeding of the IVth National Vector Control Symposium, Taichung, Taiwan Chinese Journal of Entomology Special Publication; 1991.

109. Tang LH, Qian HL, Xu SH: Malaria and its control in the People's Republic of China. Southeast Asian J Trop Med Public Health 1991, 22:467-476.

110. Otsuru M: A new species of Anopheles hyrcanus in Japan [in Japanese]. Fukuoka lgaku Zassi 1949, 40:139-148.

111. Kamimura K: The distribution and habit of medically important mosquitoes of Japan [in Japanese]. Jap J Sanit Zool 1968, 19:15-34

112. Tanaka K, Mizusawa K, Saugstad ES: A revision of the adult and larval mosquitoes of Japan (including the Ryukyu Archipelago and the Ogasawara Islands) and Korea (Diptera: Culicidae). Contrib Am Entomol Inst (Ann Arbor) 1979, 16:1-987.

113. Shin EH, Kim TS, Lee HW, Lee JS, Lee WJ: Vector competence of Anopheles lesteri Baisas and Hu (Diptera: Culicidae) to Plasmodium vivax in Korea. Korean J Parasitol 2002, 40:41-44.

114. Joshi D, Choochote W, Park MH, Kim JY, Kim TS, Suwonkerd W, Min GS: The susceptibility of Anopheles lesteri to infection with Korean strain of Plasmodium vivax. Malar J 2009, 8:42
115. Gao Q, Beebe NW, Cooper RD: Molecular identification of the malaria vectors Anopheles anthropophagus and Anopheles sinensis (Diptera: Culicidae) in central China using polymerase chain reaction and appraisal of their position within the Hyrcanus Group. J Med Entomol 2004, 41:5-11.

116. Rueda LM, Zhao TY, Ma YJ, Gao Q, Ding ZG, Khuntirat B, Sattabongkot J, Wilkerson RC: Updated distribution records of the Anopheles (Anopheles) hyrcanus species-group (Diptera: Culicidae) in China. Zootaxa 2007, 1407:43-55.

117. Rueda LM, Wilkerson RC, Li C: Anopheles (Anopheles) lesteri Baisas and Hu (Diptera: Culicidae): neotype designation and description. P Entomo/ SoC Wash 2005, 107:604-622.

118. Jinjiang X: Present filariasis situation in The People's Republic of China. In Proc WHO Regional Seminar; Kuala Lumpur Edited by: Mak JW, Yong HS 1985.

119. Baisas FE: The mosquito fauna of Subic Bay Naval Reservation. Republic of the Philippines: Headquarters, First Medical Service Wing (PACAF); 1974 Technical Report No. 72-2, 1-170 + illus.

120. Kim HC, Klein TA, Lee WJ, Collier BW, Chong ST, Sames WJ, Lee IY, Lee YJ, Lee DK: Mosquito species distribution and larval breeding habitats with taxonomic identification of anopheline mosquitoes in Korea. Entomol Res 2007, 37:29-35

121. Rueda LM, Brown TL, Kim HC, Chong ST, Klein TA, Foley DH, Anyamba A, Smith M, Pak EP, Wilkerson RC: Species composition, larval habitats, seasonal occurrence and distribution of potential malaria vectors and associated species of Anopheles (Diptera: Culicidae) from the Republic of Korea. Malar J 2010, 9:55.

122. Kamimura K: On Anopheles yesoensis Tsuzuki, 1901 reported from Hokkaido [in Japanese]. Jap J Sanit Zool 1976, 27.

123. Otsuru M, Ohmori Y: Malaria studies in Japan after World War II. Part II. The research for Anopheles sinensis sibling species group. Jpn J Exp Med 1960, 30:33-65.

124. Chau GW: An illustrated guide to the identification of the mosquitoes of Hong Kong Urban Council Publication, Hong Kong Government; 1982.

125. Basio RG, Reisen WK: On some mosquitoes of Guam, Marianas Islands (Diptera: Culicidae). Philipp Entomol 1971, 2:57-61.

126. Whang $\mathrm{CH}$ : Biological observations on anopheline mosquitoes in Korea, with special reference to Anopheles (Anopheles) sinensis Wiedemann. Yonsei Med J 1962, 3:39-50.

127. Darsie RF, Pradhan SP: The mosquitoes of Nepal: their identification, distribution and biology. Mosa Syst 1990, 22:69-130.

128. Ree HI: Studies on Anopheles sinensis, the vector species of vivax malaria in Korea. Korean J Parasitol 2005, 43:75-92.

129. Rueda LM, Ma Y, Song GH, Gao Q: Notes on the distribution of Anopheles (Anopheles) sinensis Wiedemann (Diptera: Culicidae) in China and the status of some Anopheles hyrcanus group type specimens from China. Proc Entomol Soc Wash 2005, 107:235-238.

130. O'Connor CT: The Anopheles hyrcanus group in Indonesia. Mosq Syst 1980, 12:293-305.

131. Rongsriyam $Y$, Jitpakdi A, Choochote W, Somboon P, Tookyang B, Suwonkerd W: Comparative susceptibility of two forms of Anopheles sinensis Wiedemann 1828 (Diptera: Culicidae) to infection with Plasmodium falciparum, $P$. vivax, $P$. yoelii and the determination of misleading factor for sporozoite identification. Southeast Asian J Trop Med Public Health 1998, 29:159-167.

132. Somboon P, Suwonkerd W, Lines JD: Susceptibility of Thai zoophilic anophelines and suspected malaria vectors to local strains of human malaria parasites. Southeast Asian J Trop Med Public Health 1994, 25:766-770.

133. Chow CY: Bionomics of malaria vectors in the western Pacific region. Southeast Asian J Trop Med Public Health 1970, 1:40-57.

134. Liu C: Comparative studies on the role of Anopheles anthropophagus and Anopheles sinensis in malaria transmission in China [in Chinese] Zhonghua Liu Xing Bing Xue Za Zhi 1990, 11:360-363.

135. Sleigh $A C$, Liu $X L$, Jackson S, Li P, Shang LY: Resurgence of vivax malaria in Henan Province, China. Bull World Health Organ 1998, 76:265-270.

136. Lee HW, Shin EH, Cho SH, Lee HI, Kim CL, Lee WG, Moon SU, Lee JS, Lee WJ, Kim TS: Detection of vivax malaria sporozoites naturally infected in anopheline mosquitoes from endemic areas of northern parts of Gyeonggi-do (Province) in Korea. Korean J Parasitol 2002, 40:75-81.

137. Kim DC: Brugian filariasis in Korea. In Proc WHO Regional Seminar; Kuala Lumpur Edited by: Mak JW, Yong HS 1985. 
138. Rueda LM, Iwakami M, O'Guinn M, Mogi M, Prendergast BE, Miyagi I, Toma T, Pecor JE, Wilkerson RC: Habitats and distribution of Anopheles sinensis and associated Anopheles hyrcanus group in Japan. J Am Mosa Control Assoc 2005, 21:458-463.

139. Strickman D, Miller ME, Kim HC, Lee KW: Mosquito surveillance in the demilitarized zone, Republic of Korea, during an outbreak of Plasmodium vivax malaria in 1996 and 1997. J Am Mosa Control Assoc 2000, 16:100-113.

140. Lee HW, Cho SH, Shin EH, Lee JS, Lee JS, Chai JY, Lee SH, Kim TS: Experimental infection of Anopheles sinensis with Korean isolates of Plasmodium vivax. Korean J Parasitol 2001, 39:177-183.

141. Lee HI, Lee JS, Shin EH, Lee WJ, Kim YY, Lee KR: Malaria transmission potential by Anopheles sinensis in the Republic of Korea. Korean J Parasitol 2001, 39:185-192.

142. Ree HI, Hwang UW, Lee IY, Kim TE: Daily survival and human blood index of Anopheles sinensis, the vector species of malaria in Korea. J Am Mosa Control Assoc 2001, 17:67-72.

143. Chang MC, Teng HJ, Chen CF, Chen YC, Jeng CR: The resting sites and blood-meal sources of Anopheles minimus in Taiwan. Malar J 2008, 7:105.

144. Mwandawiro C, Tsuda Y, Tuno N, Higa Y, Urakawa E, Sugiyama A, Yanagi T, Takagi M: Host-feeding patterns of Culex tritaeniorhynchus and Anopheles sinensis (Diptera: Culicidae) in a ricefield agroecosystem. Med Entomol Zool 1999, 50:267-273.

145. Lee WJ, Klein TA, Kim HC, Choi YM, Yoon SH, Chang KS, Chong ST, Lee IY, Jones JW, Jacobs JS, Sattabongkot J, Park JS: Anopheles kleini, Anopheles pullus, and Anopheles sinensis: potential vectors of Plasmodium vivax in the Republic of Korea. J Med Entomol 2007, 44:1086-1090.

146. Whang CY: Studies on the bionomics of Anopheles mosquitoes in Korea [in Korean]. Korean J Parasitol 1964, 9:49-74.

147. Rueda LM, Kim HC, Klein TA, Pecor JE, Li C, Sithiprasasna R, Debboun M, Wilkerson RC: Distribution and larval habitat characteristics of Anopheles hyrcanus group and related mosquito species (Diptera: Culicidae) in South Korea. J Vector Ecol 2006, 31:198-205.

148. Garros C, Harbach RE, Manguin S: Systematics and biogeographical implications of the phylogenetic relationships between members of the Funestus and Minimus groups of Anopheles (Diptera: Culicidae). J Med Entomol 2005, 42:7-18.

149. Garros C, Harbach RE, Manguin S: Morphological assessment and molecular phylogenetics of the Funestus and Minimus groups of Anopheles (Cellia). J Med Entomol 2005, 42:522-536.

150. Van Bortel W, Trung HD, Manh ND, Roelants P, Verle $P$, Coosemans $M$ : Identification of two species within the Anopheles minimus complex in northern Vietnam and their behavioural divergences. Trop Med Int Health 1999, 4:257-265.

151. Garros C, Koekemoer LL, Coetzee M, Coosemans M, Manguin S: A single multiplex assay to identify major malaria vectors within the African Anopheles funestus and the Oriental An. minimus groups. Am J Trop Med Hyg 2004, 70:583-590.

152. Phuc HK, Ball AJ, Son L, Hanh NV, Tu ND, Lien NG, Verardi A, Townson H: Multiplex PCR assay for malaria vector Anopheles minimus and four related species in the Myzomyia Series from Southeast Asia. Med Vet Entomol 2003, 17:423-428.

153. Maheswary NP, Habib MA, Elias M: Incrimination of Anopheles aconitus Dönitz as a vector of epidemic malaria in Bangladesh. Southeast Asian J Trop Med Public Health 1992, 23:798-801.

154. Renshaw M, Elias M, Maheswary NP, Hassan MM, Silver JB, Birley MH: A survey of larval and adult mosquitoes on the flood plains of Bangladesh, in relation to flood-control activities. Ann Trop Med Parasitol 1996, 90:621-634.

155. Socheath S, Seng C, Rath Ts, Deesin V, Deesin T, Apiwathanasorn C: Study on bionomics of principal malaria vectors in Kratie Province, Cambodia. Southeast Asian J Trop Med Public Health 2000, 31(Suppl 1):106-110.

156. Das PK, Gunasekaran K, Sahu SS, Sadanandane C, Jambulingam P: Seasonal prevalence and resting behaviour of malaria vectors in Koraput District, Orissa. Indian J Malariol 1990, 27:173-181.

157. Kulkarni SM: Density patterns of anophelines and their relation to malaria in Bastar District, Madhya Pradesh. Indian J Malariol 1990, 27:187-194.

158. Sahu SS, Parida SK, Sadanandane C, Gunasekaran K, Jambulingam P, Das PK: Breeding habitats of malaria vectors: $A$. fluviatilis, $A$. annularis and $A$. culicifacies, in Koraput District, Orissa. Indian J Malariol 1990, 27:209-216.
159. Malakar P, Das S, Saha GK, Dasgupta B, Hati AK: Anophelines of SiliguriNaxalbari block, Darjeeling, West Bengal. Indian J Malariol 1995, 32:133-139.

160. Malakar P, Das S, Saha GK, Dasgupta B, Hati AK: Indoor resting anophelines of north Bengal. Indian J Malariol 1995, 32:24-31.

161. Bhatt RM, Kohli VK: Biting rhythms of some anophelines in central Gujarat. Indian J Malariol 1996, 33:180-190.

162. Tiwari SN, Prakash A, Ghosh SK: Seasonality of indoor resting anophelines in stone quarry area of District Allahabad, U.P. Indian J Malariol 1997, 34:132-139.

163. Kant R, Pandey SD: Breeding preferences of Anopheles culicifacies in the rice agro-ecosystem in Kheda District, Gujarat. Indian J Malariol 1999, 36:53-60.

164. Kant R, Srivastava HC: Observations on anopheline breeding in relation to aquatic plants in different breeding habitats of Kheda (Gujarat). J Commun Dis 2004, 36:187-194.

165. Dash AP, Hazra RK, Mahapatra N, Tripathy HK: Disappearance of malaria vector Anopheles sundaicus from Chilika Lake area of Orissa State in India. Med Vet Entomol 2000, 14:445-449.

166. Barbara KA, Sukowati S, Rusmiarto S, Susapto D, Bangs MJ, Kinzer MH: Survey of Anopheles mosquitoes (Diptera: Culicidae) in West Sumba, Indonesia. Southeast Asian J Trop Med Public Health 2011, 42:71-82.

167. Maekawa Y, Yoshie T, Dachlan YP, Yotopranoto S, Gerudug IK, Yoshinaga K, Kanbara H, Takagi M: Anopheline fauna and incriminatory malaria vectors in malaria endemic areas of Lombok Island, Indonesia. Med Entomol Zool 2009, 60:1-11.

168. Dachlan YP, Yotopranoto S, Sutanto BV, Santoso SHB, Widodo AS, Kusmartisnawati, Sutanto A, Gerudug IKK, Takagi M, Tsuda Y, Tanabe K, Kawamoto F, Yoshinaga K, Kanbara H: Malaria endemic patterns on Lombok and Sumbawa islands, Indonesia. Trop Med Health 2005, 33:105-113.

169. Barcus MJ, Laihad F, Sururi M, Sismadi P, Marwoto H, Bangs MJ, Baird JK: Epidemic malaria in the Menoreh Hills of Central Java. Am J Trop Med Hyg 2002, 66:287-292.

170. Miyagi I, Takako T, Mogi M, Martono, Yotopranoto S, Arifin Z, Dachlan YP: Mosquito species (Diptera: Culicidae) from Lombok Island, Indonesia. Mosa Syst 1994, 26:19-24.

171. Sudomo M, Baroji, Sustriayu N: Chemical control on malaria vector Anopheles aconitus in Central Java, Indonesia. Southeast Asian J Trop Med Public Health 1985, 16:153-162.

172. Lee VH, Atmosoedjono S, Rusmiarto S, Aep S, Semendra W: Mosquitoes of Bali Island, Indonesia: common species in the village environment. Southeast Asian J Trop Med Public Health 1983, 14:298-307.

173. O'Connor CT, Sopa T: A checklist of the mosquitoes of Indonesia. Jakarta, Indonesia: US Naval Medical Research Unit No. 2; 1981, NAMRU-SP-45, 26.

174. Stoops CA, Gionar YR, Shinta, Sismadi P, Elyazar IRF, Bangs MJ, Sukowati S: Environmental factors associated with spatial and temporal distribution of Anopheles (Diptera: Culicidae) larvae in Sukabumi, West Java, Indonesia. J Med Ent 2007, 44:543-553.

175. Vythilingam I, Keokenchan K, Phommakot S, Nambanya S, Inthakone S: Preliminary studies of Anopheles mosquitoes in eight provinces in Lao PDR. Southeast Asian J Trop Med Public Health 2001, 32:83-87.

176. Rahman WA, Abu Hassan A, Adanan CR, Mohd Razha R: A report of Anopheles (Diptera: Culicidae) attracted to cow bait in a malaria endemic village in Peninsular Malaysia near the Thailand border. Southeast Asian J Trop Med Public Health 1995, 26:359-363.

177. Rahman WA, Adanan CR, Abu Hassan A: Species composition of adult Anopheles populations and their breeding habitats in Hulu Perak District, Peninsular Malaysia. Southeast Asian J Trop Med Public Health 2002, 33:547-550.

178. Oo TT, Kaiser A, Becker N: Illustrated keys to the anopheline mosquitoes of Myanmar. J Vector Ecol 2006, 31:9-16.

179. Amerasinghe FP, Indrajith NG: Nocturnal biting rhythms of mosquitoes (Diptera: Culicidae) in Sri Lanka. Trop Zool 1995, 8:43-53.

180. Harrison BA: Medical entomology studies - XIII. The Myzomyia Series of Anopheles (Cellia) in Thailand, with emphasis on intra-interspecific variations (Diptera: Culicidae). Contrib Am Entomol Inst (Ann Arbor) 1980, 17:1-195.

181. Trung HD, Bortel WW, Sochantha T, Keokenchanh K, Briet OJ, Coosemans M: Behavioural heterogeneity of Anopheles species in ecologically different localities in Southeast Asia: a challenge for vector control. Trop Med Int Health 2005, 10:251-262. 
182. Manh CD, Beebe NW, Van VN, Quang TL, Lein CT, Nguyen DV, Xuan TN, Ngoc AL, Cooper RD: Vectors and malaria transmission in deforested, rural communities in north-central Vietnam. Malar J 2010, 9:259.

183. Tsukamoto W, Miyagi I, Toma T: A revised checklist of the Philippine mosquitoes. Trop Biomed 1985, 2:149-160.

184. Junkum A, Komalamisra N, Jitpakdi A, Jariyapan N, Min GS, Park MH, Cho KH, Somboon P, Bates PA, Choochote W: Evidence to support two conspecific cytological races on Anopheles aconitus in Thailand. J Vector Ecol 2005, 30:213-224.

185. Soemarlan, Gandahusada S: The fight against malaria in Indonesia: A historical review and future outlook. Jakarta: Nat Inst HIth Res and Development, Ministry of Health; 1990, 63.

186. Prasad H, Prasad RN, Haq S: Control of mosquito breeding through Gambusia affinis in rice fields. Indian J Malariol 1993, 30:57-65.

187. Stoops CA, Rusmiarto S, Susapto D, Munif A, Andris H, Barbara KA, Sukowati S: Bionomics of Anopheles spp. (Diptera: Culicidae) in a malaria endemic region of Sukabumi, West Java, Indonesia. J Vector Ecol 2009, 34:200-207.

188. Takken W, Snellen WB, Verhave JP, Knols BGJ, Atmosoedjono S: Environmental measures for malaria control in Indonesia: A historical review on species sanitation Wageningen, The Netherlands: Wageningen Agricultural Univ. Papers; 1991.

189. Khan SA, Handique R, Tewari SC, Dutta P, Narain K, Mahanta J: Larval ecology and mosquito fauna of upper Brahmaputra valley, northeast India. Indian J Malariol 1998, 35:131-145.

190. Bhatt RM, Sharma RC, Kohli VK: Interspecific associations among anophelines in different breeding habitats of Kheda District, Gujarat. Part I: Canal irrigated area. Indian J Malariol 1990, 27:167-172.

191. Bhatt RN, Sharma RC, Srivastava HC, Gautam AS, Gupta DK: Interspecific associations among anophelines in different breeding habitats of Kheda District Gujarat: Part II. Non-canal area. Indian J Malariol 1993, 30:91-100.

192. Self LS, Usman S, Nelson MJ, Saroso JS, Pant CP, Fanara DM: Ecological studies of vectors of malaria, Japanese encephalitis and filariasis in rural areas of West Java. Bull Hith Stud Indonesia 1976, 4:41-55.

193. Kirnowardoyo S: Status of Anopheles malaria vectors in Indonesia. Southeast Asian J Trop Med Public Health 1985, 16:129-132.

194. Atmosoedjono S, Dennis DT: Anopheles aconitus and An. subpictus naturally infected with Wuchereria bancrofti in Flores, Indonesia. Mosq News 1977, 37:529.

195. Gould DJ, Esah S, Pranith U: Relation of Anopheles aconitus to malaria transmission in the central plain of Thailand. Trans $R$ Soc Trop Med Hyg 1967, 61:441-442.

196. Green CA, Rattanarithikul R, Pongparit S, Sawadwongporn P, Baimai V: A newly-recognized vector of human malarial parasites in the Oriental Region, Anopheles (Cellia) pseudowillmori (Theobald, 1910). Trans R Soc Trop Med Hyg 1991, 85:35-36.

197. Chow CY, Ibnoe MR, Josopoero ST: Bionomics of anopheline mosquitoes in inland areas of Java, with special reference to Anopheles aconitus Dön. Bull Entomol Res 1959, 50:647-660.

198. Dash AP, Bendley MS, Das AK, Das M, Dwivedi SR: Role of An. annularis as a vector of malaria in inland of Orissa. J Commun Dis 1982, 14:224.

199. Rao TR: The anophelines of India. New Delhi: Malaria Research Centre, Indian Council of Medical Research; 2 1984, xvi + 518.

200. Ghosh KK, Chakraborty S, Bhattacharya S, Palit A, Tandon N, Hati AK: Anopheles annularis as a vector of malaria in rural West Bengal. Indian $J$ Malariol 1985, 22:65-69.

201. Shrestha SL: Dynamics of malaria transmission with reference to development projects in Nepal. J Commun Dis 1985, 17:287-292.

202. Gunasekaran K, Sahu SS, Parida SK, Sadanandane C, Jambulingam P, Das PK: Anopheline fauna of Koraput District, Orissa state, with particular reference to transmission of malaria. Indian J Med Res 1989, 89:340-343.

203. Collins RT, Narasimham MV, Dhal KB, Mukherjee BP: Gel diffusion analysis of Anopheles bloodmeals from 12 malarious study villages of Orissa State, India. J Am Mosq Control Assoc 1991, 7:595-603.

204. Ramasamy R, De Alwis R, Wijesundere A, Ramasamy MS: Malaria transmission at a new irrigation project in Sri Lanka: the emergence of Anopheles annularis as a major vector. Am J Trop Med Hyg 1992, 47:547-553.

205. Prakash A, Bhattacharyya DR, Mohapatra PK, Mahanta J: Role of the prevalent Anopheles species in the transmission of Plasmodium falciparum and $P$. vivax in Assam state, north-eastern India. Ann Trop Med Parasitol 2004, 98:559-568.

206. Mahapatra N, Marai NS, Ranjit MR, Parida SK, Hansdah DP, Hazra RK, Kar SK: Detection of Plasmodium falciparum infection in Anopheles mosquitoes from Keonjhar District, Orissa, India. J Vector Borne Dis 2006, 43:191-194.

207. Bang YH: Implications in the control of malaria vectors with insecticides in tropical countries of South East Asia. Part. I. Insecticide resistance. J Commun Dis 1985, 17:199-218.

208. Baker EZ, Beier JC, Meek SR, Wirtz RA: Detection and quantification of Plasmodium falciparum and $P$. vivax infections in Thai-Kampuchean Anopheles (Diptera: Culicidae) by enzyme-linked immunosorbent assay. J Med Entomol 1987, 24:536-541.

209. Rowland M, Mohammed N, Rehman H, Hewitt S, Mendis C, Ahmad M, Kamal M, Wirtz R: Anopheline vectors and malaria transmission in eastern Afghanistan. Trans R Soc Trop Med Hyg 2002, 96:620-626.

210. Kyi KM: Malaria vectors in Burma 3. Anopheles annularis Van der Wulp, 1884. Union of Burma J Life Science 1972, 5:217-225.

211. Myo-Paing : Anopheline mosquitoes of Myanmar III. Myanmar Health Sci Res J 1990, 2:32-35.

212. Maheswary NP, Khan Z, Molla FR, Haq MI: Incrimination of Anopheles annularis van der Wulp-1854 [sic] as an epidemic malaria vector in Bangladesh. Southeast Asian J Trop Med Public Health 1993, 24:776-778.

213. Atrie B, Subbarao SK, Pillai MKK, Rao SRV, Sharma VP: Population cytogenetic evidence for sibling species within the taxon Anopheles annularis Van der Wulp (Diptera: Culicidae). Ann Entomol Soc Am 1999, 92:243-249.

214. Alam MT, Das MK, Dev V, Ansari MA, Sharma YD: PCR-RFLP method for the identification of four members of the Anopheles annularis group of mosquitoes (Diptera: Culicidae). Trans R Soc Trop Med Hyg 2007, 101:239-244.

215. Harbach RE, Gingrich JB, Pang LW: Some entomological observations on malaria transmission in a remote village in northwestern Thailand. J Am Mosa Control Assoc 1987, 3:296-301.

216. Parida SK, Hazra RK, Marai N, Tripathy HK, Mahapatra N: Host feeding patterns of malaria vectors of Orissa, India. J Am Mosa Control Assoc 2006, 22:629-634.

217. Ameen MU, Moizuddin M: Bionomics of the common mosquitoes of Dacca. J Nat Hist 1973, 7:1-21.

218. Peyton EL, Harrison BA: Anopheles (Cellia) dirus, a new species of the Leucosphyrus Group from Thailand (Diptera: Culicidae). Mosq Syst 1979, 11:40-52.

219. Hii JLK: Genetic investigations of laboratory stocks of the complex of Anopheles balabacensis Baisas (Diptera: Culicidae). Bull Entomol Res 1985 75:185-197.

220. Peyton EL: A new classification for the Leucosphyrus Group of Anopheles (Cellia). Mosa Syst 1989, 21:197-205.

221. Harbach RE, Baimai V, Sukowati S: Some observations on sympatric populations of the malaria vectors Anopheles leucosphyrus and Anopheles balabacensis in a village-forest setting in South Kalimantan. Southeast Asian J Trop Med Public Health 1987, 18:241-247.

222. Maekawa Y, Sunahara T, Dachlan YP, Yotoranoto S, Basuki S, Uemura H, Kanbara H, Takagi M: First record of Anopheles balabacensis from western Sumbawa Island, Indonesia. J Am Mosq Control Assoc 2009, 25:203-205.

223. Chooi CK: Status of malaria vectors in Malaysia. Southeast Asian J Trop Med Public Health 1985, 16:133-138.

224. Cheong WH, Loong KP, Mahadevan S, Mak JW, Kan SK: Mosquito fauna of the Bengkoka Peninsula, Sabah, Malaysia. Southeast Asian J Trop Med Public Health 1984, 15:19-26.

225. Hii JLK, Vun YS: A study of dispersal, survival and adult population estimates of the malaria vector, Anopheles balabacensis Baisas (Diptera: Culicidae) in Sabah, Malaysia. Trop Biomed 1985, 2:121-131.

226. Hii JLK, Kan S, Pereira M, Parmar SS, Campos RL, Chan MK: Bancroftian filariasis and malaria in island and hinterland populations in Sabah, Malaysia. Trop Geogr Med 1985, 37:93-101.

227. Hii JLK, Kan S, Vun YS, Chin KF, Tambakau S, Chan MK, Lye MS, Mak JW, Cochrane AH: Transmission dynamics and estimates of malaria vectorial capacity for Anopheles balabacensis and An. flavirostris (Diptera: Culicidae) on Banggi Island, Sabah, Malaysia. Ann Trop Med Parasitol 1988, 82:91-101.

228. Hoedojo : Vectors of malaria and filariasis in Indonesia. Buletin Penelitian Kesehatan 1989, 17:181-189. 
229. Baird JK, Sismadi P, Masbar S, Ramzan A, Purnomo BW, Sekartuti, Tjitra E, Rumoko BW, Arbani PR: A focus of endemic malaria in central Java. Am J Trop Med Hyg 1996, 54:98-104.

230. Schultz GW: Biting activity of mosquitos [sic] (Diptera: Culicidae) at a malarious site in Palawan, Republic of the Philippines. Southeast Asian J Trop Med Public Health 1992, 23:464-469.

231. Pokrovskii VI, Nguyen TA, Godovannyi BA: Filariasis in the developing countries of Southeast Asia [in Russian]. Med Parazitol (Mosk) 1986, 47-50.

232. Atmosoedjono S, Djoharti Purnomo, Bangs MJ: Anopheles balabacensis (Diptera: Culicidae), a vector of Wuchereria kalimantani (Nematoda: Onchocercidae) in east Kalimantan (Borneo), Indonesia. Med Vet Entomol 1993, 7:390-392.

233. Hii JLK, Kan S, Foh CK, Chan MK: Anopheles (Cellia) balabacensis Baisas is a vector of Wuchereria bancrofti in Sabah, Malaysia. Trans R Soc Trop Med Hyg 1984, 78:281-282.

234. Hii JLK: Evidence for the existence of genetic variability in the tendency of Anopheles balabacensis to rest in houses and to bite man. Southeast Asian J Trop Med Public Health 1985, 16:173-182.

235. Hii JLK, Vun YS: The influence of a heterogeneous environment on host feeding behaviour by Anopheles balabacensis (Diptera: Culicidae). Trop Biomed 1987, 4:67-70.

236. Hii JLK, Birley MH, Sang VY: Estimation of survival rate and oviposition interval of Anopheles balabacensis mosquitoes from mark-recapture experiments in Sabah, Malaysia. Med Vet Entomol 1990, 4:135-140.

237. Hii JLK, Chew M, Sang VY, Munstermann LE, Tan SG, Panyim S, Yasothornsrikul S: Population genetic analysis of host seeking and resting behaviors in the malaria vector, Anopheles balabacensis (Diptera: Culicidae). J Med Entomol 1991, 28:675-684

238. Rohani A, Lokman Hakim S, Hassan AR, Chan ST, Ong YF, Abdullah AG, Lee HL: Bionomics of Anopheles balabacensis Baisas, the principal malaria vector in Ranau, Sabah. Trop Biomed 1999, 2:31-38.

239. Chiang GL, Cheong WH, Samarawickrema WA, Mak JW, Kan SK: Filariasis in Bengkoka Peninsula, Sabah, Malaysia: vector studies in relation to the transmission of filariasis. Southeast Asian J Trop Med Public Health 1984, 15:179-189.

240. Subbarao SK, Adak T, Sharma VP: Anopheles culicifacies: sibling species distribution and vector incrimination studies. J Commun Dis 1980, 12:102-104

241. Subbarao SK: The Anopheles culicifacies complex and control of malaria. Parasitol Today 1988, 4:72-75.

242. Goswami G, Raghavendra K, Nanda N, Gakhar SK, Subbarao SK: PCR-RFLP of mitochondrial cytochrome oxidase subunit II and ITS2 of ribosomal DNA: markers for the identification of members of the Anopheles culicifacies complex (Diptera: Culicidae). Acta Trop 2005, 95:92-99.

243. Manonmani AM, Sadanandane C, Sahu SS, Mathivanan A, Jambulingam P: rDNA-ITS2-PCR assay for grouping the cryptic species of Anopheles culicifacies complex (Diptera: Culicidae). Acta Trop 2007, 104:72-77.

244. Goswami G, Singh OP, Nanda N, Raghavendra K, Gakhar SK, Subbarao SK: Identification of all members of the Anopheles culicifacies complex using allele-specific polymerase chain reaction assays. Am J Trop Med Hyg 2006, 75:454-460.

245. Singh OP, Goswami G, Nanda N, Raghavendra K, Chandra D, Subbarao SK: An allele-specific polymerase chain reaction assay for the differentiation of members of the Anopheles culicifacies complex. J Biosci 2004, 29:275-280.

246. Raghavendra K, Cornel AJ, Reddy BP, Collins FH, Nanda N, Chandra D, Verma $V$, Dash AP, Subbarao SK: Multiplex PCR assay and phylogenetic analysis of sequences derived from D2 domain of 28S rDNA distinguished Anopheles culicifacies sibling species complex into two groups, A/D and B/C/E. Infect Genet Evol 2009, 9:271-277.

247. Kobayashi J, Nambanya S, Miyagi I, Vanachone B, Manivong K, Koubouchan $T$, Amano $H$, Nozaki H, Inthakone $S$, Sato $Y$ : Collection of anopheline mosquitoes in three villages endemic for malaria in Khammouane, Lao PDR. Southeast Asian J Trop Med Public Health 1997, 28:20.

248. Van Bortel W, Sochanta T, Harbach RE, Socheat D, Roelants P, Backeljau T, Coosemans M: Presence of Anopheles culicifacies B in Cambodia established by the PCR-RFLP assay developed for the identification of Anopheles minimus species $\mathrm{A}$ and $\mathrm{C}$ and four related species. Med Vet Entomol 2002, 16:329-334.
249. Vatandoost $H$, Shahi H, Abai MR, Hanafi-Bojd AA, Oshaghi MA, Zamani G: Larval habitats of main malaria vectors in Hormozgan Province and their susceptibility to different larvicides. Southeast Asian J Trop Med Public Health 2004, 35(Suppl 2):22-25.

250. Zhang Z, Yang C: Application of deltamethrin-impregnated bednets for mosquito and malaria control in Yunnan, China. Southeast Asian J Trop Med Public Health 1996, 27:367-371.

251. Subbarao SK, Sharma VP: Anopheline species complexes and malaria control. Indian J Med Res 1997, 106:164-173.

252. Jude PJ, Dharshini S, Vinobaba M, Surendran SN, Ramasamy R: Anopheles culicifacies breeding in brackish waters in Sri Lanka and implications for malaria control. Malar J 2010, 9:106.

253. Surendran SN, Abhayawardana TA, De Silva BG, Ramasamy R, Ramasamy MS: Anopheles culicifacies Y-chromosome dimorphism indicates sibling species ( $B$ and $E$ ) with different malaria vector potential in Sri Lanka. Med Vet Entomol 2000, 14:437-440.

254. Sharma VP: Fighting malaria in India. Curr Sci 1998, 75:1127-1140.

255. Subbarao SK, Vasantha K, Raghavendra K, Sharma VP, Sharma GK: Anopheles culicifacies: siblings species composition and its relationship to malaria incidence. J Am Mosa Control Assoc 1988, 4:29-33.

256. Surendran SN, De Silva BG, Srikrishnaraj KA, Ramasamy MS, Ramasamy R: Establishment of species $E$, not $B$ as the major vector of malaria in the Anopheles culicifacies complex in the country. Proc Sri Lanka Assoc Advmt Sci 2003, 59:18.

257. Sharma SK, Nanda N, Dutta VK: Studies on the bionomics of Anopheles fluviatilis s.l. and the sibling species composition in the foothills of Shiwalik Range, India. Southeast Asian J Trop Med Public Health 1995, 26:566-572.

258. Nanda N, Yadav RS, Subbarao SK, Joshi H, Sharma VP: Studies on Anopheles fluviatilis and Anopheles culicifacies sibling species in relation to malaria in forested hilly and deforested riverine ecosystems in northern Orissa, India. J Am Mosq Control Assoc 2000, 16:199-205.

259. Subbarao SK, Vasantha K, Joshi H, Raghavendra K, Usha Devi C, Sathyanarayan TS, Cochrane AH, Nussenzweig RS, Sharma VP: Role of Anopheles culicifacies sibling species in malaria transmission in Madhya Pradesh State, India. Trans R Soc Trop Med Hyg 1992, 86:613-614.

260. Harrison BA, Rattanarithikul R, Peyton EL, Mongkolpanya K: Taxonomic changes, revised occurrence records and notes on the Culicidae of Thailand and neighboring countries. Mosq Syst 1990, 22:196-227.

261. lyengar MO: Vector of malaria in Kabul, Afghanistan. Trans $R$ Soc Trop Med Hyg 1954, 48:319-324.

262. Amerasinghe FP, Ariyasena TG: Larval survey of surface water-breeding mosquitoes during irrigation development in the Mahaweli Project, Sri Lanka. J Med Entomol 1990, 27:789-802.

263. Sabesan S, Krishnamoorthy K, Jambulingam P, Rajendran G, Kumar NP, Rajagopalan PK: Breeding habitats of Anopheles culicifacies in Rameswaram Island. Indian J Med Res 1986, 84:44-52.

264. Surendran SN, Ramasamy R: Some characteristics of the larval breeding sites of Anopheles culicifacies species B and E in Sri Lanka. J Vector Borne Dis 2005, 42:39-44.

265. Roberts D: Mosquitoes (Diptera: Culicidae) breeding in brackish water: female ovipositional preferences or larval survival? J Med Entomol 1996, 33:525-530.

266. Reisen WK, Aslamkhan M: Biting rhythms of some Pakistan mosquitoes (Diptera: Culicidae). Bull Entomol Res 1978, 68:313-330.

267. Senior White R, Ghosh AR, Venkat Rao JV: On the adult bionomics of some Indian anophelines; with special reference to malaria control by pyrethrum-spraying. J Malar Inst India 1945, 6:129-215.

268. Bhatt RM, Sharma RC, Yadav RS, Sharma VP: Resting of mosquitoes in outdoor pit shelters in Kheda District, Gujarat. Indian J Malariol 1989, 26:75-81.

269. Chand SK, Yadav RS, Sharma VP: Seasonality of indoor resting mosquitoes in a broken-forest ecosystem of north-western Orissa. Indian J Malariol 1993, 30:145-154.

270. Baimai V, Andre RG, Harrison BA, Kijchalao U, Panthusiri L: Crossing and chromosomal evidence for two additional sibling species within the taxon Anopheles dirus Peyton and Harrison (Diptera: Culicidae) in Thailand. Proc Entomol Soc Wash 1987, 89:157-166.

271. Baimai V: Population cytogenetics of the malaria vector Anopheles leucosphyrus group. Southeast Asian J Trop Med Public Health 1988, 19:667-680. 
272. Green CA, Munstermann LE, Tan SG, Panyim S, Baimai V: Population genetic evidences for species A, B, C, and D of the Anopheles dirus complex in Thailand and enzyme electromorphs for their identification. Med Vet Entomol 1992, 6:29-36.

273. Hii JLK: Involvement of the X-chromosome in hybrid male sterility from crosses between species A and species B of the taxon Anopheles dirus. Mosa News 1984, 44:192-196.

274. Sallum MA, Peyton EL, Wilkerson RC: Six new species of the Anopheles leucosphyrus group, reinterpretation of An. elegans and vector implications. Med Vet Entomol 2005, 19:158-199.

275. Rosenberg R, Andre RG, Somchit L: Highly efficient dry season transmission of malaria in Thailand. Trans R Soc Trop Med Hyg 1990, 84:22-28.

276. Peyton EL, Harrison BA: Anopheles (Cellia) takasagoensis Morishita 1946, an additional species in the Balabacensis Complex of Southeast Asia (Diptera: Culicidae). Mosq Syst 1980, 12:335-347.

277. Peyton EL, Ramalingam S: Anopheles (Cellia) nemophilous, a new species of the Leucosphyrus Group from peninsular Malaysia and Thailand (Diptera: Culicidae). Mosq Syst 1988, 20:272-299.

278. Dutta P, Bhattacharyya DR, Khan SA, Sharma CK, Mahanta J: Feeding patterns of Anopheles dirus, the major vector of forest malaria in north east India. Southeast Asian J Trop Med Public Health 1996, 27:378-381.

279. Manguin S, Bangs MJ, Pothikasikorn J, Chareonviriyaphap T: Review on global co-transmission of human Plasmodium species and Wuchereria bancrofti by Anopheles mosquitoes. Infect Genet Evol 2010, 10:159-177.

280. Prakash A, Bhattacharyya DR, Mohapatra PK, Mahanta J: Malaria transmission risk by the mosquito Anopheles baimaii (formerly known as An. dirus species D) at different hours of the night in North-east India. Med Vet Entomol 2005, 19:423-427.

281. Rattanarithikul R, Konishi E, Linthicum KJ: Detection of Plasmodium vivax and Plasmodium falciparum circumsporozoite antigen in anopheline mosquitoes collected in southern Thailand. Am J Trop Med Hyg 1996, 54:114-121.

282. Misra SP, Nandi J, Narasimham MV, Rajagopal R: Malaria transmission in Nagaland, India. Part I. Anophelines and their seasonality. J Commun Dis 1993, 25:62-66.

283. Nandi J, Kaul SM, Sharma SN, Lal S: Anthropophily of anophelines in Duars of West Bengal and other regions of India. J Commun Dis 2000, 32:95-99.

284. Vythilingam I, Phetsouvanh $R$, Keokenchanh $K$, Yengmala V, Vanisaveth $V$, Phompida S, Hakim SL: The prevalence of Anopheles (Diptera: Culicidae) mosquitoes in Sekong Province, Lao PDR in relation to malaria transmission. Trop Med Int Health 2003, 8:525-535.

285. Baimai V, Kijchalao U, Sawadwongporn P, Green CA: Geographic distribution and biting behaviour of four species of the Anopheles dirus complex (Diptera: Culicidae) in Thailand. Southeast Asian J Trop Med Public Health 1988, 19:151-161.

286. Baimai V: Speciation and species complexes of the Anopheles malaria vector in Thailand. Proceeding of the 3 rd conference on malaria research; Thailand, 18-20 October 1989

287. Manguin S, Kengne P, Sonnier L, Harbach RE, Baimai V, Trung HD, Coosemans M: SCAR markers and multiplex PCR-based identification of isomorphic species in the Anopheles dirus complex in Southeast Asia. Med Vet Entomol 2002, 16:46-54.

288. Walton C, Handley JM, Kuvangkadilok C, Collins FH, Harbach RE, Baimai V, Butlin RK: Identification of five species of the Anopheles dirus complex from Thailand, using allele-specific polymerase chain reaction. Med Vet Entomol 1999, 13:24-32.

289. Htay A, Minn S, Thaung S, Mya MM, Than SM, Hlaing T, Soe S, Druilhe $P$, Queuche F: Well-breeding Anopheles dirus and their role in malaria transmission in Myanmar. Southeast Asian J Trop Med Public Health 1999, 30:447-453.

290. Oo TT, Storch V, Becker N: Studies on the bionomics of Anopheles dirus (Culicidae: Diptera) in Mudon, Mon State, Myanmar. J Vector Ecol 2002, 27:44-54.

291. Prakash A, Bhattacharyya DR, Mohapatra PK, Mahanta J: Physico-chemical characteristics of breeding habitats of Anopheles dirus (Diptera: Culicidae) in Assam, India. J Environ Biol 2002, 23:95-100.

292. Prakash A, Bhattacharyya DR, Mohapatra PK, Mahanta J: Breeding and day resting habitats of Anopheles dirus in Assam, India. Southeast Asian J Trop Med Public Health 1997, 28:610-614.
293. Dutta P, Khan SA, Bhattarcharyya DR, Khan AM, Sharma CK, Mahanta J: Studies on the breeding habitats of the vector mosquito Anopheles baimaii and its relationship to malaria incidence in northeastern region of India: breeding habitats of Anopheles baimaii and its role in incidence of malaria in northeastern region of India. EcoHealth 2010.

294. Nandi J, Rao JS, Dasgupta RK, Sharma RS: Ecological observations on the anopheline mosquitoes of Jalpaiguri Duars, West Bengal. J Commun Dis 1996, 28:279-286.

295. Chen B, Butlin RK, Harbach RE: Molecular phylogenetics of the Oriental members of the Myzomyia Series of Anopheles subgenus Cellia (Diptera: Culicidae) inferred from nuclear and mitochondrial DNA sequences. Syst Entomol 2003, 28:57-69.

296. Somboon P, Tuno N, Tsuda Y, Takagi M: Evidence of the specific status of Anopheles flavirostris (Diptera: Culicidae). J Med Entomol 2000, 37:476-479.

297. Sharpe RG, Harbach RE, Butlin RK: Molecular variation and phylogeny of members of the Minimus Group of Anopheles subgenus Cellia (Diptera: Culicidae). Syst Entomol 2000, 25:263-272.

298. Sawabe K, Takagi M, Tsuda Y, Tuno N: Molecular variation and phylogeny of the Anopheles minimus complex (Diptera: Culicidae) inhabiting Southeast Asian countries, based on ribosomal DNA internal transcribed spacers, ITS1 and 2, and the 28S D3 sequences. Southeast Asian J Trop Med Public Health 2003, 34:771-780.

299. Lee VH, Nalim S, Olson JG, Gubler DJ, Ksiazek TG, Aep S: A survey of adult mosquitoes on Lombok Island, Republic of Indonesia. Mosq News 1984, 44:184-191.

300. Catangui FP, Valera CV, Cabrera BD: Vectors of malaria in the Philippines. Southeast Asian J Trop Med Public Health 1985, 16:139-140.

301. Schultz GW: Animal influence on man-biting rates at a malarious site in Palawan, Philippines. Southeast Asian J Trop Med Public Health 1989, 20:49-53.

302. Salazar NP: The malaria situation in the Philippines: A critique. RITM, Dept of Health 1989, Tech Rep Ser 7, 49.

303. Foley DH, Torres EP, Mueller I: Stream-bank shade and larval distribution of the Philippine malaria vector Anopheles flavirostris. Med Vet Entomol 2002, 16:347-355.

304. Wooster MT, Rivera D: Breeding point and larval association of anopheline mosquitoes of northwest Mindoro, Philippines. Southeast Asian J Trop Med Public Health 1985, 16:59-65.

305. Torres EP, Salazar NP, Belizario WY, Saul A: Vector abundance and behaviour in an area of low malaria endemicity in Bataan, the Philippines. Acta Trop 1997, 63:209-220.

306. Foley DH, Torres EP, Mueller I, Bryan JH, Bell D: Host-dependent Anopheles flavirostris larval distribution reinforces the risk of malaria near water. Trans R Soc Trop Med Hyg 2003, 97:283-287.

307. Schultz GW: A survey of the mosquitos [sic] (Diptera: Culicidae) of Napsan, Palawan, Republic of the Philippines. Southeast Asian J Trop Med Public Health 1993, 24:376-383.

308. Hii JLK, Kan S, Vun YS, Chin KF, Lye MS, Mak JW, Cheong WH: Anopheles flavirostris incriminated as a vector of malaria and Bancroftian filariasis in Banggi Island, Sabah, Malaysia. Trans R Soc Trop Med Hyg 1985, 79:677-680.

309. Asinas CY, Hugo CT, Boase CJ, Evans RG: Evaluation of selective spraying of bendiocarb (Ficam VC) for the control of Anopheles flavirostris in the Philippines. J Am Mosa Control Assoc 1994, 10:496-500.

310. Subbarao SK, Nanda N, Vasantha K, Dua VK, Malhotra MS, Yadav RS, Sharma VP: Cytogenetic evidence for three sibling species in Anopheles fluviatilis. Ann Entomol Soc Am 1994, 87:116-121.

311. Chen B, Butlin RK, Pedro PM, Wang XZ, Harbach RE: Molecular variation, systematics and distribution of the Anopheles fluviatilis complex in southern Asia. Med Vet Entomol 2006, 20:33-43.

312. Manonmani $A$, Townson $H$, Adeniran $T$, Jambulingam $P$, Sahu $S$, Vijayakumar T: rDNA-ITS2 polymerase chain reaction assay for the sibling species of Anopheles fluviatilis. Acta Trop 2001, 78:3-9.

313. Manonmani A, Nanda N, Jambulingam P, Sahu S, Vijayakumar T, Ramya Vani J, Subbarao SK: Comparison of polymerase chain reaction assay and cytotaxonomy for identification of sibling species of Anopheles fluviatilis (Diptera: Culicidae). Bull Entomol Res 2003, 93:169-171.

314. Singh OP, Chandra D, Nanda N, Raghavendra K, Sunil S, Sharma SK, Dua VK, Subbarao SK: Differentiation of members of the Anopheles fluviatilis species complex by an allele-specific polymerase chain reaction based on $28 \mathrm{~S}$ ribosomal DNA sequences. Am J Trop Med Hyg 2004, 70:27-32. 
315. Raeisi A, Vatandoost H, Mousakazemi SH: Understanding bionomics of main malaria vectors in irrigated areas in southern Baluchistan, for implementation of impregnated bednets in Iran. International Conference on Malaria; 4-6 November; New Delhi, India 2005.

316. Nanda N, Joshi H, Subbarao SK, Yadav RS, Shukla RP, Dua VK, Sharma VP: Anopheles fluviatilis complex: host feeding patterns of species $\mathrm{S}, \mathrm{T}$, and U. J Am Mosa Control Assoc 1996, 12:147-149.

317. Eshghi N, Motabar M, Javadian E, Manoutcheri AV: Biological features of Anopheles fluviatilis and its role in the transmission of malaria in Iran. Trop Geogr Med 1976, 28:41-44.

318. Naddaf SR, Oshaghi MA, Vatandoost H, Assmar M: Molecular characterization of Anopheles fluviatilis species complex in the Islamic Republic of Iran. East Mediterr Health J 2003, 9:257-265.

319. Reisen WK, Pradhan SP, Shrestha JP, Shrestha SL, Vaidya RG, Shrestha JD: Anopheline mosquito (Diptera: Culicidae) ecology in relation to malaria transmission in the inner and outer terai of Nepal, 1987-1989. J Med Entomol 1993, 30:664-682.

320. Hanafi-Bojd AA, Vatandoost $H$, Jafari R: Susceptibility status of Anopheles $d$ thali and An. fluviatilis to commonly used larvicides in an endemic focus of malaria, southern Iran. J Vector Borne Dis 2006, 43:34-38.

321. Gunasekaran K: Age composition, natural survival and population growth of Anopheles fluviatilis James, 1902, the major malaria vector in the endemic belt of Koraput District, Orissa, India. Southeast Asian J Trop Med Public Health 1994, 25:196-200.

322. Bhatt RM, Srivastava HC, Pujara PK: Biology of malaria vectors in central Gujarat. Indian J Malariol 1994, 31:65-76.

323. Shukla RP, Nanda N, Pandey AC, Kohli VK, Joshi H, Subbarao SK: Studies on bionomics of Anopheles fluviatilis and its sibling species in Nainital District, U.P. Indian J Malariol 1998, 35:41-47.

324. Shukla RP, Pandey AC, Kohli VK, Ojha VP, Sharma VP: Bionomics of vector anophelines in District Naini Tal, Uttar Pradesh. Indian J Malariol 1995, 32:153-163.

325. Sallum MAM, Foster PG, Li C, Sithiprasasna R, Wilkerson RC: Phylogeny of the Leucosphyrus Group of Anopheles (Cellia) (Diptera: Culicidae) based on mitochondrial gene sequences. Ann Entomol Soc Am 2007, 100:27-35

326. Baimai V, Harbach RE, Sukowati S: Cytogenetic evidence for two species within the current concept of the malaria vector Anopheles leucosphyrus in Southeast Asia. J Am Mosa Control Assoc 1988, 4:44-50.

327. Colless DH: The Anopheles leucosphyrus group. Trans R Entomol Soc Lond 1956, 108:37-116.

328. de Zulueta J: Malaria in Sarawak and Brunei. Bull WId HIth Org 1956, 15:651-671.

329. Chang MS, Doraisingam P, Hardin S, Nagum N: Malaria and filariasis transmission in a village/forest setting in Baram District, Sarawak, Malaysia. J Trop Med Hyg 1995, 98:192-198.

330. Chang MS, Matusop A, Fam KS: Differences in Anopheles composition and malaria transmission in the village settlements and cultivated farming zone in Sarawak, Malaysia. Southeast Asian J Trop Med Public Health 1999, 30:454-459.

331. Macdonald WW, Traub R: Malaysian parasites XXXVII. An introduction to the ecology of the mosquitoes of the lowland dipterocarp forest of Selangor, Malaya. In Studies from the Institute for Medical Research. Volume 29. Kuala Lumpur: Malaya Government Press; 1960:79-109.

332. Wharton $\mathrm{RH}$, Eyles DE, Warren M, Cheong WH: Studies to determine the vectors of monkey malaria in Malaya. Ann Trop Med Parasitol 1964, 58:56-77.

333. Vythilingam I, Tan CH, Asmad M, Chan ST, Lee KS, Singh B: Natural transmission of Plasmodium knowlesi to humans by Anopheles latens in Sarawak, Malaysia. Trans R Soc Trop Med Hyg 2006, 100:1087-1088.

334. Tan CH, Vythilingam I, Matusop A, Chan ST, Singh B: Bionomics of Anopheles latens in Kapit, Sarawak, Malaysian Borneo in relation to the transmission of zoonotic simian malaria parasite Plasmodium knowlesi. Malar J 2008, 7:52.

335. Wharton RH: The biology of Mansonia mosquitoes in relation to the transmission of filariasis in Malaya. Bull Inst Med Res Kuala Lumpur 1962, 11:1-114.

336. Somboon P, Thongwat D, Harbach RE: Anopheles (Cellia) rampae n. sp., alias chromosomal form $\mathrm{K}$ of the Oriental Maculatus Group (Diptera: Culicidae) in Southeast Asia. Zootaxa 2011, 2810:47-55.

337. Ma Y, Li S, Xu J: Molecular identification and phylogeny of the Maculatus Group of Anopheles mosquitoes (Diptera: Culicidae) based on nuclear and mitochondrial DNA sequences. Acta Trop 2006, 99:272-280.
338. Rattanarithikul R, Harbach RE: Anopheles maculatus (Diptera: Culicidae) from the type locality of Hong Kong and two new species of the Maculatus Complex from the Philippines. Mosq Syst 1990, 22:160-183.

339. Torres EP, Foley DH, Saul A: Ribosomal DNA sequence markers differentiate two species of the Anopheles maculatus (Diptera: Culicidae) complex in the Philippines. J Med Entomol 2000, 37:933-937.

340. Walton C, Somboon P, O'Loughlin SM, Zhang S, Harbach RE, Linton YM, Chen B, Nolan K, Duong S, Fong MY, Vythilingum I, Mohammed ZD, Trung HD, Butlin RK: Genetic diversity and molecular identification of mosquito species in the Anopheles maculatus group using the ITS2 region of rDNA. Infect Genet Evol 2007, 7:93-102.

341. Rahman WA, Abu Hassan A, Adanan CR, Rashid MR: The prevalence of Plasmodium falciparum and $P$. vivax in relation to Anopheles maculatus densities in a Malaysian village. Acta Trop 1993, 55:231-235.

342. Rongnoparut $P$, Yaicharoen S, Sirichotpakorn N, Rattanarithikul R, Lanzaro GC, Linthicum KJ: Microsatellite polymorphism in Anopheles maculatus, a malaria vector in Thailand. Am J Trop Med Hyg 1996, 55:589-594.

343. Upatham ES, Prasittisuk C, Ratanatham S, Green CA, Rojanasunan W, Setakana P, Theerasilp N, Tremongkol A, Viyanant V, Pantuwatana S, Andre RG: Bionomics of Anopheles maculatus complex and their role in malaria transmission in Thailand. Southeast Asian J Trop Med Public Health 1988, 19:259-269.

344. Hodgkin EP: The transmission of malaria in Malaya. Studies Inst Med Res Malaya 1956, 27:1-98.

345. Rattanarithikul R, Linthicum KJ, Konishi E: Seasonal abundance and parity rates of Anopheles species in southern Thailand. J Am Mosq Control Assoc 1996, 12:75-83.

346. Somboon P, Aramrattana A, Lines J, Webber R: Entomological and epidemiological investigations of malaria transmission in relation to population movements in forest areas of north-west Thailand. Southeast Asian J Trop Med Public Health 1998, 29:3-9.

347. Pradhan SP, Shrestha SL, Vaidya RG: Malaria transmission in high mountain valleys of west Nepal including the first record of Anopheles willmori (James) as a third vector of malaria. J Nepal Med Assoc 1970, 8:89-97.

348. Kankaew P, Krasaesub S, Sithiprasasna R: Soil analysis around anopheline breeding habitats in north-western Thailand. Southeast Asian J Trop Med Public Health 2005, 36:1153-1161.

349. Kengluecha A, Singhasivanon $P$, Tiensuwan $M$, Jones JW, Sithiprasasna R: Water quality and breeding habitats of anopheline mosquito in northwestern Thailand. Southeast Asian J Trop Med Public Health 2005, 36:46-53.

350. Rattanarithikul R, Mongkolpanya K, Noigamol C, Chanaimongkol S, Mahapibul P, Nakngen S: Dry season distribution of mosquito larvae in the bed of the Mekong River, northeastern Thailand. J Am Mosq Control Assoc 1994, 10:197-201.

351. Rattanarithikul R, Green CA, Panyim S, Noigamol C, Chanaimongkol S, Mahapibul P: Larval habitats of malaria vectors and other Anopheles mosquitoes around a transmission focus in northwestern Thailand. J Am Mosq Control Assoc 1995, 11:428-433.

352. Rohani A, Wan Najdah WM, Zamree I, Azahari AH, Mohd Noor I, Rahimi H, Lee HL: Habitat characterization and mapping of Anopheles maculatus (Theobald) mosquito larvae in malaria endemic areas in Kuala Lipis, Pahang, Malaysia. Southeast Asian J Trop Med Public Health 2010, 41:821-830.

353. Harbach RE, Garros C, Manh ND, Manguin S: Formal taxonomy of species $\mathrm{C}$ of the Anopheles minimus sibling species complex (Diptera: Culicidae). Zootaxa 2007, 1654:41-54.

354. Harbach RE, Parkin E, Chen B, Butlin RK: Anopheles (Cellia) minimus Theobald (Diptera: Culicidae): neotype designation, characterization, and systematics. Proc Entomol Soc Wash 2006, 108:198-209.

355. Somboon P, Rory A, Tsuda Y, Takagi M, Harbach RE: Systematics of Anopheles (Cellia) yaeyamaensis sp. n., alias species E of the An. minimus complex of southeastern Asia (Diptera: Culicidae). Zootaxa 2010, 2651:43-51.

356. Farid MA, Chen CT, Hsu TC, Liu SY: Report of WHO evaluation team on malaria eradication in the Ryukyu Islands, 1965. Geneva; 1966, 1-53.

357. Miyagi I, Toma T, Malenganisho WL, Uza M: Historical review of mosquito control as a component of malaria eradication program in the Ryukyu Archipelago. Southeast Asian J Trop Med Public Health 1996, 27:498-511. 
358. Chen B, Harbach RE, Butlin RK: Molecular and morphological studies on the Anopheles minimus group of mosquitoes in southern China: Taxonomic review, distribution and malaria vector status. Med Vet Entomol 2002, 16:253-265.

359. Pothikasikorn J, Bangs MJ, Boonplueang R, Chareonviriyaphap T: Susceptibility of various mosquitoes of Thailand to nocturnal subperiodic Wuchereria bancrofti. J Vector Ecol 2008, 33:313-320.

360. Dev V: Anopheles minimus: its bionomics and role in the transmission of malaria in Assam, India. Bull World Health Organ 1996, 74:61-66.

361. Van Bortel W, Trung HD, Roelants P, Backeljau T, Coosemans M: Population genetic structure of the malaria vector Anopheles minimus A in Vietnam. Heredity 2003, 91:487-493.

362. Duc NH, Huu HV: Distribution of Anopheles minimus in Northern Vietnam. Ann Scientific Works 1973, 134-140.

363. Singh OP, Nanda N, Dev V, Bali P, Sohail M, Mehrunnisa A, Adak T, Dash AP: Molecular evidence of misidentification of Anopheles minimus as Anopheles fluviatilis in Assam (India). Acta Trop 2010, 113:241-244.

364. Chareonviriyaphap T, Prabaripai A, Bangs MJ, Aum-Aung B: Seasonal abundance and blood feeding activity of Anopheles minimus Theobald (Diptera: Culicidae) in Thailand. J Med Entomol 2003, 40:876-881.

365. Dev V, Bhattacharyya PC, Rupjyoti Talukdar: Transmission of malaria and its control in the northeastern region of India. J Assoc Physicians India 2003, 51:1073-1076.

366. Suthas N, Phorn S, Udom C, Cullen JE: The behaviour of Anopheles minimus Theobald (Diptera: Culicidae) subjected to different levels of DDT selection pressure in northern Thailand. Bull Entomol Res 1986, 76:303-312.

367. Ismail IA, Notananda V, Schepens J: Studies on malaria and responses of Anopheles balabacensis balabacensis and Anopheles minimus to DDT residual spraying in Thailand. I. Pre-spraying observations. Acta Trop 1974, 31:129-164.

368. Garros C, Marchand RP, Quang NT, Hai NS, Manguin S: First record of Anopheles minimus $C$ and significant decrease of An. minimus $A$ in central Vietnam. J Am Mosa Control Assoc 2005, 21:139-143.

369. Sungvornyothin S, Muenvorn V, Garros C, Manguin S, Prabaripai A, Bangs MJ, Chareonvirlyaphap T: Trophic behavior and biting activity of the two sibling species of the Anopheles minimus complex in western Thailand. J Vector Ecol 2006, 31:252-261.

370. Van Bortel W, Trung HD, Sochantha T, Keokenchan K, Roelants P, Backeljau T, Coosemans M: Eco-ethological heterogeneity of the members of the Anopheles minimus complex (Diptera: Culicidae) in Southeast Asia and its consequences for vector control. J Med Entomol 2004, 41:366-374.

371. Beebe NW, Bakote'e B, Ellis JT, Cooper RD: Differential ecology of Anopheles punctulatus and three members of the Anopheles farauti complex of mosquitoes on Guadalcanal, Solomon Islands, identified by PCR-RFLP analysis. Med Vet Entomol 2000, 14:308-312.

372. Cattani J, Taufa T, Anderson W, Lourie J: Malaria and filariasis in the Ok Tedi region of the Star Mountains, Papua New Guinea. P N G Med J 1983, 26:122-126

373. Cattani JA, Tulloch JL, Vrbova H, Jolley D, Gibson FD, Moir JS, Heywood PF, Alpers MP, Stevenson A, Clancy R: The epidemiology of malaria in a population surrounding Madang, Papua New Guinea. Am J Trop Med Hyg 1986, 35:3-15.

374. Bryan JH: Vectors of Wuchereria bancrofti in the Sepik Provinces of Papua New Guinea. Trans R Soc Trop Med Hyg 1986, 80:123-131.

375. Desowitz RS, Spark RA: Malaria in the Maprik area of the Sepik Region, Papua New Guinea: 1957-1984. Trans R Soc Trop Med Hyg 1987, 81:175-176.

376. Charlwood JD, Bryan JH: A mark-recapture experiment with the filariasis vector Anopheles punctulatus in Papua New Guinea. Ann Trop Med Parasitol 1987, 81:429-436.

377. Burkot TR, Graves PM, Paru R, Wirtz RA, Heywood PF: Human malaria transmission studies in the Anopheles punctulatus complex in Papua New Guinea: sporozoite rates, inoculation rates, and sporozoite densities. Am J Trop Med Hyg 1988, 39:135-144.

378. Burkot TR, Molineaux L, Graves PM, Paru R, Battistutta D, Dagoro H, Barnes A, Wirtz RA, Garner P: The prevalence of naturally acquired multiple infections of Wuchereria bancrofti and human malarias in anophelines. Parasitology 1990, 100:369-375.
379. Anthony RL, Bangs MJ, Hamzah N, Basri H, Purnomo, Subianto B: Heightened transmission of stable malaria in an isolated population in the highlands of Irian Jaya, Indonesia. Am J Trop Med Hyg 1992, 47:346-356.

380. Bockarie MJ, Tavul L, Kastens W, Michael E, Kazura JW: Impact of untreated bednets on prevalence of Wuchereria bancrofti transmitted by Anopheles farauti in Papua New Guinea. Med Vet Entomol 2002, 16:116-119.

381. Bell D, Cameron A, Fernando M, Pholsyna K, Foley D, Bakote'e B, Bryan JH: Malaria in Honiara, Solomon Islands: vector studies. Southeast Asian J Trop Med Public Health 1996, 27:372-377.

382. Attenborough RD, Burkot TR, Gardner DS: Altitude and the risk of bites from mosquitoes infected with malaria and filariasis among the Mianmin people of Papua New Guinea. Trans R Soc Trop Med Hyg 1997, 91:8-10.

383. Pribadi W, Sutanto I, Atmosoedjono S, Rasidi R, Surya LK, Susanto L: Malaria situation in several villages around Timika, south central Irian Jaya, Indonesia. Southeast Asian J Trop Med Public Health 1998, 29:228-235.

384. Burkot TR, Dye C, Graves PM: An analysis of some factors determining the sporozoite rates, human blood indexes, and biting rates of members of the Anopheles punctulatus complex in Papua New Guinea. Am J Trop Med Hyg 1989, 40:229-234.

385. Burkot TR, Narara A, Paru R, Graves PM, Garner P: Human host selection by anophelines: no evidence for preferential selection of malaria or microfilariae-infected individuals in a hyperendemic area. Parasitology 1989, 98:337-342.

386. Bockarie M, Kazura J, Alexander N, Dagoro H, Bockarie F, Perry R, Alpers M: Transmission dynamics of Wuchereria bancrofti in East Sepik Province, Papua New Guinea. Am J Trop Med Hyg 1996, 54:577-581.

387. Kazura JW, Bockarie M, Alexander N, Perry R, Bockarie F, Dagoro $H$, Dimber Z, Hyun P, Alpers MP: Transmission intensity and its relationship to infection and disease due to Wuchereria bancrofti in Papua New Guinea. J Infect Dis 1997, 176:242-246.

388. Hii JLK, Kanai L, Foligela A, Kan SK, Burkot TR, Wirtz RA: Impact of permethrin-impregnated mosquito nets compared with DDT housespraying against malaria transmission by Anopheles farauti and An. punctulatus in the Solomon Islands. Med Vet Entomol 1993, 7:333-338.

389. Foley DH, Meek SR, Bryan JH: The Anopheles punctulatus group of mosquitoes in the Solomon Islands and Vanuatu surveyed by allozyme electrophoresis. Med Vet Entomol 1994, 8:340-350.

390. Cooper RD, Frances SP: Malaria vectors on Buka and Bougainville Islands, Papua New Guinea. J Am Mosq Control Assoc 2002, 18:100-106.

391. Benet A, Mai A, Bockarie F, Lagog M, Zimmerman P, Alpers MP, Reeder JC, Bockarie MJ: Polymerase chain reaction diagnosis and the changing pattern of vector ecology and malaria transmission dynamics in Papua New Guinea. Am J Trop Med Hyg 2004, 71:277-284.

392. Cooper RD, Waterson DG, Frances SP, Beebe NW, Pluess B, Sweeney AW: Malaria vectors of Papua New Guinea. Int J Parasitol 2009, 39:1495-1501.

393. Beebe NW, Cooper RD, Morrison DA, Ellis JT: A phylogenetic study of the Anopheles punctulatus group of malaria vectors comparing rDNA sequence alignments derived from the mitochondrial and nuclear small ribosomal subunits. Mol Phylogenet Evol 2000, 17:430-436.

394. Beebe NW, Saul A: Discrimination of all members of the Anopheles punctulatus complex by polymerase chain reaction-restriction fragment length polymorphism analysis. Am J Trop Med Hyg 1995, 53:478-481.

395. Beebe NW, Cooper RD, Morrison DA, Ellis JT: Subset partitioning of the ribosomal DNA small subunit and its effects on the phylogeny of the Anopheles punctulatus group. Insect Mol Biol 2000, 9:515-520.

396. Beebe NW, Ellis JT, Cooper RD, Saul A: DNA sequence analysis of the ribosomal DNA ITS2 region for the Anopheles punctulatus group of mosquitoes. Insect Mol Biol 1999, 8:381-390.

397. Foley $\mathrm{DH}$, Bryan JH: Shared salinity tolerance invalidates a test for the malaria vector Anopheles farauti s.s. on Guadalcanal, Solomon Islands. Med Vet Entomol 2000, 14:450-452.

398. Sweeney AW: Larval salinity tolerances of the sibling species of Anopheles farauti. J Am Mosq Control Assoc 1987, 3:589-592.

399. Lee DJ, Hicks MM, Griffiths M, Debenham ML, Bryan JH, Russell RC, Geary M, Marks EN: The Culicidae of the Australasian Region. Volume 5. Nomenclature, synonymy, literature, distribution, biology and relation to disease. Genus Anopheles. Subgenera Anopheles, Cellia Canberra: Australian Government Publishing Service; 1987. 
400. Birley MH, Charlwood JD: The effect of moonlight and other factors on the oviposition cycle of malaria vectors in Madang, Papua New Guinea. Ann Trop Med Parasitol 1989, 83:415-422.

401. Bockarie MJ, Alexander N, Bockarie F, Ibam E, Barnish G, Alpers M: The late biting habit of parous Anopheles mosquitoes and pre-bedtime exposure of humans to infective female mosquitoes. Trans $R$ Soc Trop Med Hyg 1996, 90:23-25.

402. Hii JLK, Smith T, Mai A, Ibam E, Alpers MP: Comparison between anopheline mosquitoes (Diptera: Culicidae) caught using different methods in a malaria endemic area of Papua New Guinea. Bull Entomol Res 2000, 90:211-219.

403. Koella JC, Packer MJ: Malaria parasites enhance blood-feeding of their naturally infected vector Anopheles punctulatus. Parasitology 1996, 113(Pt 2):105-109.

404. Afifi SE, Spencer M, Hudson PB, Tavil NW: Biting prevalence and malaria transmission patterns in the Anopheles punctulatus complex (Diptera: Culicidae) in Papua New Guinea. Aust J Exp Biol Med Sci 1980, 58:1-17.

405. Foley DH, Bryan JH: Electrophoretic keys to identify members of the Anopheles punctulatus complex of vector mosquitoes in Papua New Guinea. Med Vet Entomol 1993, 7:49-53.

406. Foley DH, Paru R, Dagoro H, Bryan JH: Allozyme analysis reveals six species within the Anopheles punctulatus complex of mosquitoes in Papua New Guinea. Med Vet Entomol 1993, 7:37-48.

407. Henry-Halldin CN, Reimer L, Thomsen E, Koimbu G, Zimmerman A, Keven JB, Dagoro H, Hetzel MW, Mueller I, Siba P, Zimmerman PA: High throughput multiplex assay for species identification of Papua New Guinea malaria vectors: members of the Anopheles punctulatus (Diptera: Culicidae) species group. Am J Trop Med Hyg 2011, 84:166-173.

408. Hii JL, Smith T, Mai A, Mellor S, Lewis D, Alexander N, Alpers MP: Spatial and temporal variation in abundance of Anopheles (Diptera: Culicidae) in a malaria endemic area in Papua New Guinea. J Med Entomol 1997, 34:193-205.

409. Hasan AU, Suguri S, Fujimoto C, Itaki RL, Harada M, Kawabata M, Bugoro H, Albino B: Genetic diversity in two sibling species of the Anopheles punctulatus group of mosquitoes on Guadalcanal in the Solomon Islands. BMC Evol Biol 2008, 8:318.

410. Suzuki H: Malaria vector mosquitoes in the Solomon Islands. In Malaria research in the Solomon Islands. Edited by: Ishii A, Nihei N, Sasa M. Toyko: Inter Group Corp; 1998:104-113.

411. Ebsworth P, Bryan JH, Foley DH: Ecological distribution of mosquito larvae of the Anopheles punctulatus group on Niolam (Lihir) Island, Papua New Guinea. J Am Mosa Control Assoc 2001, 17:181-185.

412. Bangs MJ, Rusmiarto S, Anthony RL, Wirtz RA, Subianto DB: Malaria transmission by Anopheles punctulatus in the highlands of Irian Jaya, Indonesia. Ann Trop Med Parasitol 1996, 90:29-38.

413. Cooper RD, Waterson DG, Kupo M, Foley DH, Beebe NW, Sweeney AW: Anopheline mosquitoes of the western province of Papua New Guinea. J Am Mosa Control Assoc 1997, 13:5-12.

414. Spencer T, Spencer M, Venters D: Malaria vectors of Papua New Guinea. PNG Med J 1974, 17:22-30.

415. Bangs MJ, Subianto DB: El Nińo and associated outbreaks of severe malaria in highland populations in Irian Jaya, Indonesia: a review and epidemiological perspective. Southeast Asian J Trop Med Public Health 1999, 30:608-619.

416. Charlwood JD: A differential response to mosquito nets by Anopheles and Culex mosquitoes from Papua New Guinea. Trans $R$ Soc Trop Med Hyg 1986, 80:958-960.

417. Charlwood JD: The influence of larval habitat on the ecology and behavior of females of the Punctulatus Group of Anopheles mosquitoes from Papua New Guinea. In Ecology of mosquitoes: Proceedings of a workshop. Edited by: Lounibos LP, Rey JR, Frank JH. Vero Beach: Florida Medical Entomology Laboratory; 1985:399-406.

418. Schmidt ER, Foley DH, Hartel GF, Williams GM, Bryan JH: Descriptions of the Anopheles (Cellia) farauti complex of sibling species (Diptera: Culicidae) in Australia. Bull Entomol Res 2001, 91:389-411.

419. Bower JE, Dowton M, Cooper RD, Beebe NW: Intraspecific concerted evolution of the rDNA ITS1 in Anopheles farauti sensu stricto (Diptera: Culicidae) reveals recent patterns of population structure. $J \mathrm{Mol}$ Evol 2008, 67:397-411.

420. Sweeney AW, Cooper RD, Frances SP: Distribution of the sibling species of Anopheles farauti in the Cape York Peninsula, northern Queensland, Australia. J Am Mosq Control Assoc 1990, 6:425-429.
421. Charlwood JD, Dagoro H, Paru R: Blood-feeding and resting behaviour in the Anopheles punctulatus Dönitz complex (Diptera: Culicidae) from coastal Papua New Guinea. Bull Entomol Res 1985, 75:463-475.

422. Charlwood JD, Graves PM, Alpers MP: The ecology of the Anopheles punctulatus group of mosquitoes from Papua New Guinea: a review of recent work. P N G Med J 1986, 29:19-26.

423. Cooper RD, Frances SP: Biting sites of Anopheles koliensis on human collectors in Papua New Guinea. J Am Mosa Control Assoc 2000, 16:266-267.

424. Frances SP, Cooper RD, Popat S, Beebe NW: Field evaluation of repellents containing deet and Al3-37220 against Anopheles koliensis in Papua New Guinea. J Am Mosq Control Assoc 2001, 17:42-44

425. Samarawickrema WA, Parkinson AD, Kere N, Galo O: Seasonal abundance and biting behaviour of Anopheles punctulatus and An. koliensis in Malaita Province, Solomon Islands, and a trial of permethrin impregnated bednets against malaria transmission. Med Vet Entomol 1992, 6:371-378.

426. Krishnan KS: A. stephensi Liston, 1901. Vectors of Malaria in India. 2 edition. Delhi: National Society of India for Malaria and Other Mosquito-born Disease; 1961, 39-58.

427. Manouchehri AV, Javadian E, Eshighy N, Motabar M: Ecology of Anopheles stephensi Liston in southern Iran. Trop Geogr Med 1976, 28:228-232.

428. Vatandoost H, Oshaghi MA, Abaie MR, Shahi M, Yaaghoobi F, Baghaii M, Hanafi-Bojd AA, Zamani G, Townson H: Bionomics of Anopheles stephensi Liston in the malarious area of Hormozgan Province, southern Iran, 2002. Acta Trop 2006, 97:196-203.

429. Pervez SD, Shah $\mathrm{H}$ : Role of Anopheles stephensi as malaria vector in rural areas of Pakistan. Pak J Health 1989, 26:73-84.

430. Singh OP: Bionomics of malaria vectors in India. Malaria Research Centre; 2002, 19-31.

431. Davidson G: Studies on insecticide resistance in anopheline mosquitos. Bull World Health Organ 1958, 18:579-621.

432. Rao BA, Sweet WC, Subba Rao AM: Ova measurements of $A$. stephensi type and A. stephensi var. mysorensis. J Malar Inst India 1938, 1:261-266.

433. Subbarao SK, Vasantha K, Adak T, Sharma VP, Curtis CF: Egg-float ridge number in Anopheles stephensi: Ecological variation and genetic analysis. Med Vet Entomol 1987, 1:265-271.

434. Subbarao SK: Anopheline species complexes in Southeast Asia. New Delhi: WHO, SEARO; Technical Publication No. 18; 1998, 81.

435. Eshghy N, Janbakhsh B: Insecticide resistance of Anopheles stephensi mysorensis in the province of Fars, southern Iran, 1975. Mosq News 1976, 36:336-339.

436. Motabar M, Tabibzadeh I, Manouchehri AV: Malaria and its control in Iran. Trop Geogr Med 1975, 27:71-78.

437. Basseri HR, Moosakazemi SH, Yosafi S, Mohebali M, Hajaran H, Jedari M: Anthropophily of malaria vectors in Kahnouj District, south of Kerman, Iran. Iranian J Publ Health 2005, 34:27-35.

438. Batra CP, Mittal PK, Adak T, Subbarao SK: Efficacy of Agnique MMF monomolecular surface film against Anopheles stephensi breeding in urban habitats in India. J Am Mosq Control Assoc 2006, 22:426-432.

439. Batra CP, Reuben R: Breeding of Anopheles stephensi (Liston) in wells and cisterns in Salem, Tamil Nadu. Indian J Med Res 1979, 70(Suppl):114-122.

440. Biswas D, Dutta RN, Ghosh SK, Chatterjee KK, Hati AK: Breeding habits of Anopheles stephensi Liston in an area of Calcutta. Indian J Malariol 1992, 29:195-198.

441. Chakraborty S, Ray S, Tandon N: Seasonal prevalence of Anopheles stephensi larvae and existence of two forms of the species in an urban garden in Calcutta City. Indian J Malariol 1998, 35:8-14.

442. Reisen WK: Population dynamics of some Pakistan mosquitoes: the impact of residual organophosphate insecticide spray on anopheline relative abundance. Ann Trop Med Parasitol 1986, 80:69-75.

443. Zaim M, Ershadi MR, Manouchehri AV, Hamdi MR: The use of CDC light traps and other procedures for sampling malaria vectors in southern Iran. J Am Mosa Control Assoc 1986, 2:511-515.

444. Chatterjee KK, Biswas D, Choudhuri DK, Mukherjee H, Hati AK: Resting sites of Anopheles stephensi Liston in Calcutta. Indian J Malariol 1993, 30:109-112.

445. Reisen WK, Aslamkhan M: A release-recapture experiment with the malaria vector, Anopheles stephensi Liston, with observations on dispersal, survivorship, population size, gonotrophic rhythm and mating behaviour. Ann Trop Med Parasitol 1979, 73:251-269. 
446. Sweet WC, Rao B: Races of Anopheles stephensi Liston, 1901. Ind Med Gaz 1937, 72:665-674.

447. Bruce-Chwatt LJ, Garrett-Jones C, Weitz B: Ten years' study (1955-64) of host selection by anopheline mosquitos [sic]. Bull World Health Organ 1966, 35:405-439.

448. Reid JA: A note on Anopheles subpictus Grassi and A. indefinitus Ludlow (Diptera: Culicidae). J Med Entomol 1966, 3:327-331.

449. Suguna SG: Cytological and morphological evidence for sibling species in Anopheles subpictus Grassi. J Commun Dis 1982, 14:1-8.

450. Reuben R, Suguna SG: Morphological differences between sibling species of the taxon Anopheles subpictus Grassi in India, with notes on relationships with known forms. Mosq Syst 1983, 15:117-126.

451. Suguna SG, Rathinam KG, Rajavel AR, Dhanda V: Morphological and chromosomal descriptions of new species in the Anopheles subpictus complex. Med Vet Entomol 1994, 8:88-94.

452. Abhayawardana TA, Wijesuriya SR, Dilrukshi RK: Anopheles subpictus complex: distribution of sibling species in Sri Lanka. Indian J Malariol 1996, 33:53-60.

453. Reuben R, Kalyanasundaram M, Suguna SG: Salinity tolerance of sibling species in the taxon Anopheles subpictus Grassi, 1899. Indian J Med Res 1984, 80:67-70.

454. Surendran SN, Singh OP, Jude PJ, Ramasamy R: Genetic evidence for malaria vectors of the Anopheles sundaicus complex in Sri Lanka with morphological characteristics attributed to Anopheles subpictus species B. Malar J 2010, 9:343.

455. Kohn M: A survey on indoor resting mosquito species in Phnom Penh, Kampuchea. Folia Parasitol (Praha) 1990, 37:165-174.

456. Das LK, Mohapatra SS, Jambulingam P, Gunasekaran K, Pani SP, Das PK: Malaria and other common ailments among upper Bonda tribals in Koraput District, Orissa. Indian J Med Res 1989, 89:334-339.

457. Srivastava HC, Yadav RS: Malaria outbreak in a tribal area of Gujarat State, India. Southeast Asian J Trop Med Public Health 2000, 31:219-224.

458. Banerjee PK, Ghosh KN, Chatterjee RN: Gel diffusion analysis of host preference pattern of Anopheles subpictus in West Bengal, India. Indian J Malariol 1991, 28:157-159.

459. Bhuyan M, Das NG, Chakraborty BC, Talukdar PK, Sarkar PK, Das SC, Santhanam K: Role of Anopheles culicifacies during an outbreak of malaria in Gorubandha P.H.C., Assam. J Commun Dis 1997, 29:243-246.

460. Sundararaj R, Rao DR: Field evaluation of a microgel droplet formulation of Bacillus sphaericus 1593M (Biocide-S) against Anopheles culicifacies and Anopheles subpictus in south India. Southeast Asian I Trop Med Public Health 1993, 24:363-368.

461. Krishnamoorthy K, Jambulingam P, Natarajan R, Shriram AN, Das PK, Sehgal S: Altered environment and risk of malaria outbreak in South Andaman, Andaman \& Nicobar Islands, India affected by tsunami disaster. Malar J 2005, 4:30.

462. Singh N, Mishra AK, Chand SK, Sharma VP: Population dynamics of Anopheles culicifacies and malaria in the tribal area of central India. J Am Mosa Control Assoc 1999, 15:283-290.

463. Batra CP, Raghavendra K, Adak T, Singh OP, Singh SP, Mittal PK, Malhotra MS, Sharma RS, Subbarao SK: Evaluation of bifenthrin treated mosquito nets against anopheline and culicine mosquitoes. Indian J Med Res 2005, 121:55-62.

464. Sumodan PK, Kumar A, Yadav RS: Resting behavior and malaria vector incrimination of Anopheles stephensi in Goa, India. J Am Mosa Control Assoc 2004, 20:317-318.

465. Sharma VP, Sharma GK, Ansari MA, Mittal PK, Razdan RK, Batra CP: Impact of malathion thermal fogging on mosquito populations in Delhi and its place in malaria control. Indian J Malariol 1986, 23:65-67.

466. Nagao Y, Dachlan YP, Soedarto, Hidajati S, Yotopranoto S, Kusmartisnawati, Subekti S, Ideham B, Tsuda Y, Kawabata M, Takagi M, Looareesuwan S: Distribution of two species of malaria, Plasmodium falciparum and Plasmodium vivax, on Lombok Island, Indonesia. Southeast Asian J Trop Med Public Health 2003, 34:495-500.

467. Jaal Z, Macdonald WW: The ecology of anopheline mosquitos [sic] in northwest coastal Malaysia: Larval habitats and adult seasonal abundance. Southeast Asian J Trop Med Public Health 1993, 24:522-529.

468. Rowland M, Mahmood P, lqbal J, Carneiro I, Chavasse D: Indoor residual spraying with alphacypermethrin controls malaria in Pakistan: a community-randomized trial. Trop Med Int Health 2000, 5:472-481.
469. Hewitt S, Kamal M, Muhammad N, Rowland M: An entomological investigation of the likely impact of cattle ownership on malaria in an Afghan refugee camp in the North West Frontier Province of Pakistan. Med Vet Entomol 1994, 8:160-164.

470. Cooper RD, Waterson DG, Frances SP, Beebe NW, Sweeney AW: The anopheline fauna of Papua New Guinea. J Am Mosa Control Assoc 2006, 22:213-221.

471. Baimai V, Kijchalao U, Rattanarithikul R: Metaphase karyotypes of Anopheles of Thailand and Southeast Asia. VI. The Pyretophorus and the Neomyzomyia series, subgenus Cellia (Diptera: Culicidae). J Am Mosa Control Assoc 1996, 12:669-675.

472. Kusumawathie PH, Wickremasinghe AR, Karunaweera ND, Wijeyaratne MJ, Yapabandara AM: Anopheline breeding in river bed pools below major dams in Sri Lanka. Acta Trop 2006, 99:30-33.

473. Merlin: Merlin/WHO emergency control of malaria and other vector borne diseases in East Timor. London: Merlin; 2001.

474. Kannathasan S, Antonyrajan A, Srikrishnaraj KA, Karunaratne SH, Karunaweera ND, Surendran SN: Studies on prevalence of anopheline species and community perception of malaria in Jaffna District, Sri Lanka. J Vector Borne Dis 2008, 45:231-239.

475. Singh SP, Raghavendra K, Kumar R, Nanda N, Subbarao SK: Morphotaxonomic studies to identify the members of the Anopheles subpictus Grassi (Diptera: Culicidae) species complex in riverine villages of District Sonepat, Haryana State, India. J Commun Dis 2004, 36:35-40.

476. Mukhtar M, Ensink J, Van der Hoek W, Amerasinghe FP, Konradsen F: Importance of waste stabilization ponds and wastewater irrigation in the generation of vector mosquitoes in Pakistan. J Med Entomol 2006 43:996-1003.

477. Herrel N, Amerasinghe FP, Ensink J, Mukhtar M, van der Hoek W, Konradsen F: Breeding of Anopheles mosquitoes in irrigated areas of South Punjab, Pakistan. Med Vet Entomol 2001, 15:236-248.

478. Kant R, Pandey SD, Sharma SK: Mosquito breeding in relation to aquatic vegetation and some physico-chemical parameters in rice fields of central Gujarat. Indian J Malariol 1996, 33:30-40.

479. Yadav RS, Sharma RC, Bhatt RM, Sharma VP: Studies on the anopheline fauna of Kheda District and species specific breeding habitats. Indian J Malariol 1989, 26:65-74.

480. Kulkarni SM, Naik PS: Breeding habitats of mosquitoes in Goa. Indian J Malariol 1989, 26:41-44.

481. Kant R, Pandey SD, Sharma RC: Seasonal prevalence and succession of rice field breeding mosquitoes of central Gujarat. J Commun Dis 1992, 24:164-172.

482. Sharma SN, Prasad RN: Observations on the breeding of anophelines in rice fields of Shahjahanpur District, Uttar Pradesh. Indian J Malariol 1991 28:83-89.

483. Yapabandara AM, Curtis CF: Vectors and malaria transmission in a gem mining area in Sri Lanka. J Vector Ecol 2004, 29:264-276.

484. Amerasinghe PH, Amerasinghe FP, Wirtz RA, Indrajith NG, Somapala W, Pereira $L R$, Rathnayake AM: Malaria transmission by Anopheles subpictus (Diptera: Culicidae) in a new irrigation project in Sri Lanka. J Med Entomol 1992, 29:577-581.

485. Jaal Z, Macdonald WW: The ecology of anopheline mosquitos [sic] in northwest coastal Malaysia: Host preferences and biting-cycles. Southeast Asian J Trop Med Public Health 1993, 24:530-535.

486. Kawada H, Maekawa Y, Tsuda Y, Takagi M: Trial of spatial repellency of metofluthrin-impregnated paper strip against Anopheles and Culex in shelters without walls in Lombok, Indonesia. J Am Mosa Control Assoc 2004, 20:434-437.

487. Bansal SK, Singh KV: Prevalence and seasonal distribution of anopheline fauna in District Bikaner (Rajasthan). Indian J Malariol 1993, 30:119-125.

488. Bhatt RM, Sharma RC, Gautam AS, Gupta DK, Srivastava HC: A quantitative survey of anophelines in six villages of Kheda District, Gujarat. J Commun Dis 1991, 23:109-117.

489. Herrel N, Amerasinghe FP, Ensink J, Mukhtar M, van der Hoek W, Konradsen F: Adult anopheline ecology and malaria transmission in irrigated areas of South Punjab, Pakistan. Med Vet Entomol 2004, 18:141-152.

490. Reisen WK, Milby MM: Population dynamics of some Pakistan mosquitoes: changes in adult relative abundance over time and space. Ann Trop Med Parasitol 1986, 80:53-68. 
491. Surendran SN, Ramasamy R: The Anopheles culicifacies and An. subpictus species complexes in Sri Lanka and their implications for malaria control in the country. Trop Med Health 2010, 38:1-11.

492. Lien JC, Atmosoedjono S, Usfinit AU, Gundelfinger BF: Observations on natural plasmodial infections in mosquitoes and a brief survey of mosquito fauna in Belu Regency, Indonesian Timor. J Med Entomol 1975, 12:333-337.

493. Lee VH, Atmosoedjono S, Dennis DT, Suhaepi A, Suwarta A: The anopheline (Diptera: Culicidae) vectors of malaria and bancroftian filariasis in Flores Island, Indonesia. J Med Entomol 1983, 20:577-578.

494. Panicker KN, Geetha Bai M, Bheema Rao US, Viswam K, Suryanarayana Murthy U: Anopheles subpictus, vector of malaria in coastal villages of south-east India. Curr Sci 1981, 50:694-695.

495. Kumari S, Parida SK, Marai N, Tripathy A, Hazra RK, Kar SK, Mahapatra N: Vectorial role of Anopheles subpictus Grassi and Anopheles culicifacies Giles in Angul District, Orissa, India. Southeast Asian J Trop Med Public Health 2009, 40:713-719.

496. Chang MS, Linton YM, Harbach RE: The Anopheles sundaicus species complex - a preliminary study of larval ecology from two sites in Sarawak, Malaysia. Mekong Malaria Forum 2001, 8:91-95.

497. Das MK, Nagpal BN, Sharma VP: Mosquito fauna and breeding habitats of anophelines in Car Nicobar Island, India. Indian J Malariol 1998, 35:197-205.

498. Nagpal BN, Kalra NL: Malaria vectors of India. J Parasit Dis 1997, 21:105-112.

499. Sukowati S, Baimai V, Harun S, Dasuki Y, Andris H, Efriwati M: Isozyme evidence for three sibling species in the Anopheles sundaicus complex from Indonesia. Med Vet Entomol 1999, 13:408-414.

500. Reid JA: Systematics of malaria vectors - anopheline systematics and malaria control, with special reference to Southeast Asia. Misc Pub Entomol Soc Am 1970, 7:52-62.

501. Sukowati S, Baimai V, Andris H: Sex chromosome variation in natural populations of the Anopheles sundaicus complex from Thailand and Indonesia. Mosa Borne Dis Bull 1996, 13:8-13.

502. Alam MT, Das MK, Ansari MA, Sharma YD: Molecular identification of Anopheles (Cellia) sundaicus from the Andaman and Nicobar islands of India. Acta Trop 2006, 97:10-18.

503. Dusfour I, Michaux JR, Harbach RE, Manguin S: Speciation and phylogeography of the Southeast Asian Anopheles sundaicus complex. Infect Genet Evol 2007, 7:484-493.

504. Linton YM, Dusfour I, Howard TM, Ruiz LF, Duc Manh N, Ho Dinh T, Sochanta T, Coosemans M, Harbach RE: Anopheles (Cellia) epiroticus (Diptera: Culicidae), a new malaria vector species in the Southeast Asian Sundaicus Complex. Bull Entomol Res 2005, 95:329-339.

505. Nanda N, Das MK, Wattal S, Adak T, Subbarao SK: Cytogenetic characterization of Anopheles sundaicus (Diptera: Culicidae) population from Car Nicobar island, India. Ann Entomol Soc Am 2004, 97:171-176.

506. Dusfour I, Blondeau J, Harbach RE, Vythilingham I, Baimai V, Trung HD, Sochanta T, Bangs MJ, Manguin S: Polymerase chain reaction identification of three members of the Anopheles sundaicus (Diptera: Culicidae) complex, malaria vectors in Southeast Asia. J Med Entomol 2007, 44:723-731.

507. Harinasuta C, Guptavanij P, Vasuvat C: Studies on the medical ecological epidemiology in mangrove areas in Thailand. Southeast Asian J Trop Med Public Health 1974, 5:105-127.

508. Ikemoto T, Sumitro S, Panjaitan W, Shibuya T: Laboratory and small-scale field tests of larvicides and larvivorous fishes against Anopheles sundaicus larvae at Perupuk village, North Sumatra, Indonesia. Jpn J Sanit Zool 1986, 37:105-112.

509. Kalra NL: National malaria eradication programme, India - its problems, management and research needs. J Commun Dis 1978, 10:1-20.

510. Nguyen TA, Le QR, Vu TH, Ngyuen BL: Entomo-epidemiological studies of malaria in the coastal zone of Ho Chi Minh City, 1990-1992. Santé 1993, 3:464-473

511. Trung HD, Van Bortel W, Sochantha T, Keokenchanh K, Quang NT, Cong LD, Coosemans M: Malaria transmission and major malaria vectors in different geographical areas of Southeast Asia. Trop Med Int Health 2004, 9:230-237.

512. Christophers SR: The fauna of British India, including Ceylon and Burma, Vol N., Diptera, Family Culicidae, Tribe Anophelini London: Taylor and Francis; 1933.
513. Nagpal BN, Sharma VP: Indian anophelines Lebanon, New Hampshire, USA: Science Publishers, Inc; 1995.

514. Phan VT: Epidémiologie du paludisme et lutte antipaludique au Vietnam Hanoi: Editions Médicales Vietnam; 1998.

515. Kirnowardoya S, Yoga GP: Entomological investigations of an outbreak of malaria in Chilacap on south coast of central Java, Indonesia during 1985. J Commun Dis 1987, 19:121-127.

516. Sen P: Anopheles sundaicus (Ludlow) and malaria in Calcutta. J Malar Inst India 1938, 1:83-107.

517. Huehne WH: Experience with an insecticide-drug combination and observations on suppressive chloroquine-pyrimethamine treatment. $J$ Trop Med Hyg 1971, 74:110-116

518. Kumari R, Joshi H, Giri A, Sharma VP: Feeding preferences of Anopheles sundaicus in Car Nicobar Island. Indian J Malariol 1993, 30:201-206.

519. Coosemans M, Cong D, Socheat D, Inthakone S, Baimai V, Manguin S, Harbach RE: Identification and characterization of malaria vectors in Southeast Asia: a prerequisite for appropriate vector control. INCO-DEC report; 1998, ERBIC18. CT. 970211110.

520. MAP. [http://www.map.ox.ac.uk/].

521. Macdonald G: Local features of malaria. The epidemiology and control of malaria London: Oxford University Press; 1957, 63-99.

522. Service MW: The Anopheles vector. In Bruce-Chwatt's Essential Malariology. Third edition. Edited by: Gilles HM, Warrell DA. London: Edward Arnold; 1993:96-123.

523. Service MW: Appendix II. Characteristics of some major Anopheles vectors of human malaria. In Bruce-Chwatt's Essential Malariology.. Third edition. Edited by: Gilles HM, Warrell DA. London: Edward Arnold; 1993:305-310.

524. Kiszewski A, Mellinger A, Spielman A, Malaney P, Sachs SE, Sachs J: A global index representing the stability of malaria transmission. Am J Trop Med Hyg 2004, 70:486-498.

525. Mouchet J, Carnevale P, Coosemans M, Julvez J, Manguin S, RichardLenoble D, Sircoulon J: Biodiversité du paludisme dans le monde Montrouge, France: John Libbey Eurotext; 2004.

526. Kant R, Pandey SD, Sharma SK, Sharma VP: Species diversity and interspecific associations among mosquitoes in rice agro-ecosystem of Kheda District, Gujarat. Indian J Malariol 1998, 35:22-30.

527. Kumar K, Katyal R, Gill KS: Feeding pattern of anopheline and culicine mosquitoes in relation to biotopes and seasons in Delhi and environs. J Commun Dis 2002, 34:59-64.

528. Prakash A, Bhattacharyya DR, Mohapatra PK, Mahanta J: Investigation on malaria vectors and mosquito fauna in south Tripura District, Tripura State. Indian J Malariol 1998, 35:151-159.

529. Das MK, Nagpal BN, Ansari MA: Mosquito fauna and breeding habitats of anophelines in Little Andaman Island, Andaman and Nicobar Islands, India. Indian J Malariol 2002, 39:83-95.

530. Amerasinghe FP, Konradsen F, Fonseka KT, Amerasinghe PH: Anopheline (Diptera: Culicidae) breeding in a traditional tank-based village ecosystem in north central Sri Lanka. J Med Entomol 1997, 34:290-297.

531. van der Hoek W, Amerasinghe FP, Konradsen F, Amerasinghe PH: Characteristics of malaria vector breeding habitats in Sri Lanka: relevance for environmental management. Southeast Asian J Trop Med Public Health 1998, 29:168-172.

532. Yadav RS, Sampath RR, Sharma VP: Deltamethrin treated bednets for control of malaria transmitted by Anopheles culicifacies (Diptera: Culicidae) in India. J Med Entomol 2001, 38:613-622.

533. Tun-Lin W, Thu MM, Than SM, Mya MM: Hyperendemic malaria in a forested, hilly Myanmar village. J Am Mosq Control Assoc 1995, 11:401-407.

534. Singh S, Singh RP, Jauhari RK: Biting activity of the malaria vector, Anopheles culicifacies, on man and cattle in Doon Valley, India. Appl Parasitol 1995, 36:185-191.

535. Sampath TR, Yadav RS, Sharma VP, Adak T: Evaluation of lambdacyhalothrin-impregnated bednets in a malaria endemic area of India. Part 2. Impact on malaria vectors. J Am Mosq Control Assoc 1998, 14:437-443.

536. Ramasamy MS, Kulasekera R, Srikrishnaraj KA, Ramasamy R: Population dynamics of anthropophilic mosquitoes during the northeast monsoon season in the malaria epidemic zone of Sri Lanka. Med Vet Entomol 1994, 8:265-274.

537. Gunasekaran K, Sadanandane C, Parida SK, Sahu SS, Patra KP, Jambulingam P: Observations on nocturnal activity and man biting habits of malaria vectors, Anopheles fluviatilis, An. annularis and An. 
culicifacies in the hill tracts of Koraput District, Orissa, India. Southeast Asian J Trop Med Public Health 1994, 25:187-195.

538. Dewit I, Coosemans M, Srikrishnaraj K, Wery M: Population dynamics of anophelines in a malathion treated village in the intermediate zone of Sri Lanka. Ann Soc Belg Med Trop 1994, 74:93-103.

539. Bhatt RM, Sharma RC, Kohli VK, Gautam AS, Gupta DK: Biting rhythms of malaria vector Anopheles culicifacies in Kheda District, Gujarat. Indian J Malariol 1991, 28:91-97.

540. Ansari MA, Sharma VP, Razdan RK: Esbiothrin-impregnated ropes as mosquito repellent. Indian J Malariol 1992, 29:203-210.

541. Joshi H, Vasantha K, Subbarao SK, Sharma VP: Host feeding patterns of Anopheles culicifacies species A and B. J Am Mosq Control Assoc 1988, 4:248-251.

542. Batra CP, Adak T, Sharma VP, Mittal PK: Impact of urbanization on bionomics of An. culicifacies and An. stephensi in Delhi. Indian J Malariol 2001, 38:61-75.

543. Tun-Lin W, Htay A, Moe M, Sebastian A, Myo P, Myat Myat T: Some environmental factors influencing the breeding of Anopheles balabacensis complex (dirus) in domestic wells in Burma. J Commun Dis 1987, 19:291-299.

544. Toma T, Miyagi I, Okazawa T, Kobayashi J, Saita S, Tuzuki A, Keomanila H, Nambanya S, Phompida S, Uza M, Takakura M: Entomological surveys of malaria in Khammouane Province, Lao PDR, in 1999 and 2000. Southeast Asian J Trop Med Public Health 2002, 33:532-546.

545. Suwonkerd W, Overgaard HJ, Tsuda Y, Prajakwong S, Takagi M: Malaria vector densities in transmission and non-transmission areas during 23 years and land use in Chiang Mai Province, Northern Thailand. Basic Appl Ecol 2002, 3:197-207.

546. Rattanarithikul R, Konishi E, Linthicum KJ: Observations on nocturnal biting activity and host preference of anophelines collected in southern Thailand. J Am Mosa Control Assoc 1996, 12:52-57.

547. Nandi J, Misra SP, Rajagopal R, Narasimham MV: Present perspectives of malaria transmission in Boko area of Assam. J Commun Dis 1993, 25:18-26.

548. Mya MM, Saxena RK, Soe P: Study of malaria in a village of lower Myanmar. Indian J Malariol 2002, 39:96-102.

549. Kobayashi J, Phompida S, Toma T, Looareensuwan S, Toma H, Miyagi I: The effectiveness of impregnated bed net in malaria control in Laos. Acta Trop 2004, 89:299-308.

550. Kitthawee S, Edman JD, Upatham ES: Mosquito larvae and associated macroorganisms occurring in gem pits in southern Tha Mai District, Chanthaburi Province, Thailand. Southeast Asian I Trop Med Public Health 1993, 24:143-151.

551. Kitthawee S, Edman JD, Upatham ES: Relationship between female Anopheles dirus (Diptera: Culicidae) body size and parity in a biting population. J Med Entomol 1992, 29:921-926.

552. Gingrich JB, Weatherhead A, Sattabongkot J, Pilakasiri C, Wirtz RA: Hyperendemic malaria in a Thai village: dependence of year-round transmission on focal and seasonally circumscribed mosquito (Diptera: Culicidae) habitats. J Med Entomol 1990, 27:1016-1026.

553. Dutta P, Dev V, Bhattacharrya DR: Anopheline fauna and malaria incidence in Changlang District (Arunachal Pradesh). Indian J Malariol 1993, 30:135-143.

554. Reiff DM, Kaneko A, Taleo G, Amos M, Lum JK: Population structure and gene flow of Anopheles farauti s.s. (Diptera: Culicidae) among ten sites on five islands of Vanuatu: implications for malaria control. J Med Entomol 2007, 44:601-607.

555. Kere NK, Arabola A, Bakote'e B, Qalo O, Burkot TR, Webber RH, Southgate BA: Permethrin-impregnated bednets are more effective than DDT house-spraying to control malaria in Solomon Islands. Med Vet Entomol 1996, 10:145-148.

556. Kay BH: Man-mosquito contact at Kowanyama, northern Queensland, Australia. J Am Mosa Control Assoc 1985, 1:191-194.

557. Hii JLK, Birley MH, Kanai L, Foligeli A, Wagner J: Comparative effects of permethrin-impregnated bednets and DDT house spraying on survival rates and oviposition interval of Anopheles farauti No. 1 (Diptera: Culicidae) in Solomon Islands. Ann Trop Med Parasitol 1995, 89:521-529.

558. Hanna JN, Ritchie SA, Eisen DP, Cooper RD, Brookes DL, Montgomery BL: An outbreak of Plasmodium vivax malaria in Far North Queensland, 2002. Med J Aust 2004, 180:24-28.
559. Cooper RD, Frances SP, Sweeney AW: Distribution of members of the Anopheles farauti complex in the northern territory of Australia. J Am Mosa Control Assoc 1995, 11:66-71.

560. Charlwood JD, Paru R, Dagoro H, Lagog M: Influence of moonlight and gonotrophic age on biting activity of Anopheles farauti (Diptera: Culicidae) from Papua New Guinea. J Med Entomol 1986, 23:132-135.

561. Charlwood JD, Graves PM: The effect of permethrin-impregnated bednets on a population of Anopheles farauti in coastal Papua New Guinea. Med Vet Entomol 1987, 1:319-327.

562. Bell D, Bryan J, Cameron A, Foley D, Pholsyna K: Salinity tolerance of Anopheles farauti Laveran sensu stricto. P N G Med J 1999, 42:5-9.

563. Abe M, Yaviong J, Taleo G, Ichimori K: Microfilarial periodicity of Wuchereria bancrofti in Vanuatu. Trans R Soc Trop Med Hyg 2003, 97:498-500.

564. Sadanandane C, Jambulingam P, Subramanian S: Role of modified CDC miniature light-traps as an alternative method for sampling adult anophelines (Diptera: Culicidae) in the National Mosquito Surveillance Programme in India. Bull Entomol Res 2004, 94:55-63.

565. Joshi RD, Sharma SN, Dhingra N, Thapar BR, Yadava RL, Lal S: Some aspects of changing behaviour of malaria vectors in tribal areas of India. J Commun Dis 1998, 30:267-278.

566. Dominic Amalraj D, Sahu SS, Jambulingam P, Boopathi Doss PS, Kalyanasundaram M, Das PK: Efficacy of aqueous suspension and granular formulations of Bacillus thuringiensis (Vectobac) against mosquito vectors. Acta Trop 2000, 75:243-246.

567. Charlwood JD, Graves PM: Capture-recapture studies with mosquitoes of the group of Anopheles punctulatus Dönitz (Diptera: Culicidae) from Papua New Guinea. Bull Entomol Res 1986, 76:211-227.

568. Bryan JH, Dagoro H, Southgate BA: Filarial vector studies in a diethylcarbamazine-treated and in untreated villages in Papua New Guinea. J Trop Med Hyg 1995, 98:445-451.

569. Wang SH, Zheng HJ: Blood meals of mosquito vectors of filariasis in Guizhou Province, China. Southeast Asian J Trop Med Public Health 1989, 20:175-177.

570. Song J, Peng Y: Field trials of combined use of two species of mermithid nematodes to control Anopheles and Culex breeding in China. Indian J Malariol 1996, 33:161-165.

571. Liu JY, Liu XJ, Chen Z, Tu ZP, Zheng GB, Chen YN, Zhang YZ, Weng SP, Huang XH, Yang FZ: Filariasis and its control in Fujian, China. Southeast Asian J Trop Med Public Health 1991, 22:147-154.

572. Huang GQ, Li HF, Zhang HX, Liu JY, Zhang JB, Chen GY, Yu PH, Ming GZ: Environmental investigation in areas where Anopheles anthropophagus distributed in Hubei Province [in Chinese]. Zhongguo Ji Sheng Chong Xue Yu Ji Sheng Chong Bing Za Zhi 2001, 19:340-343.

573. Claborn DM, Hshieh PB, Roberts DR, Klein TA, Zeichner BC, Andre RG: Environmental factors associated with larval habitats of malaria vectors in northern Kyunggi Province, Republic of Korea. J Am Mosq Control Assoc 2002, 18:178-185

574. Ooi PL, Goh KT, Lee KM: Local transmission of Plasmodium vivax malaria in Singapore. Ann Acad Med Singapore 1997, 26:588-592.

575. Devi NP, Jauhari RK: Altitudinal distribution of mosquitoes in mountainous area of Garhwal region: Part I. J Vector Borne Dis 2004, 41:17-26.

576. Chiang GL, Loong KP, Chan ST, Eng KL, Yap HH: Capture-recapture studies with Anopheles maculatus Theobald (Diptera: Culicidae) the vector of malaria in peninsular Malaysia. Southeast Asian J Trop Med Public Health 1991, 22:643-647.

577. Rwegoshora RT, Sharpe RG, Baisley K, Kittayapong P: Biting behavior and seasonal variation in the abundance of Anopheles minimus species A and C in Thailand. Southeast Asian J Trop Med Public Health 2002, 33:694-701.

578. Ratanatham S, Upatham ES, Prasittisuk C, Rojanasunan W, Theerasilp N, Tremongkol A, Viyanant V: Bionomics of Anopheles minimus and its role in malaria transmission in Thailand. Southeast Asian J Trop Med Public Health 1988, 19:283-289.

579. Overgaard HJ, Tsuda Y, Suwonkerd W, Takagi M: Characteristics of Anopheles minimus (Diptera: Culicidae) larval habitats in northern Thailand. Environ Entomol 2002, 31:134-141.

580. Myo-Paing, Tun Lin W, Sebastian AA: Behaviour of Anopheles minimus (Theobald) in relation to its role as vector of malaria in a forested foothill area of Burma. Trop Biomed 1988, 5:161-166. 
581. Okazawa T, Bakote'e B, Suzuki H, Kawada H, Kere N: Field evaluation of an insect growth regulator, pyriproxyfen, against Anopheles punctulatus on north Guadalcanal, Solomon Islands. J Am Mosq Control Assoc 1991, 7:604-607.

582. Kere NK, Parkinson AD, Samrawickerema WA: The effect of permethrin impregnated bednets on the incidence of Plasmodium falciparum, in children of north Guadalcanal, Solomon Islands. Southeast Asian J Trop Med Public Health 1993, 24:130-137.

583. Zhang SQ, Zhang QJ, Cheng F, Wang LL, Pen GP: Threshold of transmission of Brugia malayi by Anopheles sinensis. J Trop Med Hyg 1991, 94:245-250.

584. Sunahara T, Ishizaka K, Mogi M: Habitat size: a factor determining the opportunity for encounters between mosquito larvae and aquatic predators. J Vector Ecol 2002, 27:8-20.

585. Shin EH, Lee WJ, Lee HI, Lee DK, Klein TA: Seasonal population density and daily survival of anopheline mosquitoes (Diptera: Culicidae) in a malaria endemic area, Republic of Korea. J Vector Ecol 2005, 30:33-40.

586. Joo CY, Kang GT: Epidemio-entomological survey on malarial vector mosquitoes in Kyongbuk, Korea. Kisaengchunghak Chapchi 1992, 30:329-340.

587. Easton ER: Urbanization and its effects on the ecology of mosquitoes in Macau, Southeast Asia. J Am Mosa Control Assoc 1994, 10:540-544.

588. Thapar BR, Sharma SN, Dasgupta RK, Kaul SM, Bali A, Chhabra K, Lal S: Blood meal identification by using Microdot ELISA in vector mosquitoes. J Commun Dis 1998, 30:283-287.

589. Sharma SN, Subbarao SK, Choudhury DS, Pandey KC: Role of An. culicifacies and An. stephensi in malaria transmission in urban Delhi. Indian J Malariol 1993, 30:155-168.

590. Sharma RS: Urban malaria and its vectors Anopheles stephensi and Anopheles culicifacies (Diptera: Culicidae) in Gurgaon, India. Southeast Asian J Trop Med Public Health 1995, 26:172-176.

591. Kumar A, Thavaselvam D: Breeding habitats and their contribution to Anopheles stephensi in Panaji. Indian J Malariol 1992, 29:35-40.

592. Kar I, Eapen A, Ravindran KJ: Domestic breeding sources and their contribution in Anopheles stephensi breeding in Dindigul, Tamil Nadu. Indian J Malariol 1996, 33:191-199.

593. Hati AK, Chatterjee KK, Biswas D: Daytime resting habits of Anopheles stephensi in an area of Calcutta. Indian J Malariol 1987, 24:85-87.

594. Haq S, Bhatt RM, Vaishnav KG, Yadav RS: Field evaluation of biolarvicides in Surat city, India. J Vector Borne Dis 2004, 41:61-66.

595. Devi NP, Jauhari RK: Mosquito species associated within some western Himalayas phytogeographic zones in the Garhwal region of India. J Insect Sci 2007, 7:1-10.

596. Chandra G, Chatterjee KK, Hati AK: Feeding behaviour of Anopheles stephensi in Calcutta. Indian J Malariol 1996, 33:103-105.

597. Ansari MA, Sharma VP, Mittal PK, Razdan RK: Evaluation of juvenile hormone analogue JHM/S-31183 against immature stages of mosquitoes in natural habitats. Indian J Malariol 1991, 28:39-43.

598. Rajavel AR, Natarajan R, Vaidyanathan K, Soniya VP: Mosquitoes of the mangrove forests of India: Part 5 - Chorao, Goa, and Vikhroli, Maharashtra. J Am Mosq Control Assoc 2007, 23:91-94.

599. Takagi M, Pohan W, Hasibuan H, Panjaitan W, Suzuki T: Evaluation of shading of fish farming ponds as a larval control measure against Anopheles sundaicus Rodenwaldt (Diptera: Culicidae). Southeast Asian J Trop Med Public Health 1995, 26:748-753.

600. Linton YM, Harbach RE, Seng CM, Anthony TG, Matusop A: Morphological and molecular identity of Anopheles (Cellia) sundaicus (Diptera: Culicidae), the nominotypical member of a malaria vector species complex in Southeast Asia. Syst Entomol 2001, 26:357-366.

601. Kumari R, Sharma VP: Resting and biting habits of Anopheles sundaicus in Car Nicobar Island. Indian J Malariol 1994, 31:103-114.

602. Dusfour I, Linton YM, Cohuet A, Harbach RE, Baimai V, Trung HD, Seng CM, Matusop A, Manguin S: Molecular evidence of speciation between island and continental populations of Anopheles (Cellia) sundaicus (Diptera: Culicidae), a principal malaria vector taxon in Southeast Asia. J Med Entomol 2004, 41:287-295.

603. Das SC, Nath DR, Bhuyan M, Das NG, Baruah I, Talukdar PK: Studies on malaria and filariasis vectors in Kamorta and Great Nicobar Islands. Indian J Malariol 1989, 26:153-157. doi:10.1186/1756-3305-4-89

Cite this article as: Sinka et al:: The dominant Anopheles vectors of human malaria in the Asia-Pacific region: occurrence data, distribution maps and bionomic précis. Parasites \& Vectors 2011 4:89.

\section{Submit your next manuscript to BioMed Central and take full advantage of:}

- Convenient online submission

- Thorough peer review

- No space constraints or color figure charges

- Immediate publication on acceptance

- Inclusion in PubMed, CAS, Scopus and Google Scholar

- Research which is freely available for redistribution

Submit your manuscript at www.biomedcentral.com/submit 